Universidade de São Paulo

Faculdade de Saúde Pública

\title{
Comparação de índices de avaliação da assistência pré- natal em base de dados nacional: uma análise com modelagem de equações estruturais
}

\author{
Matheus Souza Ferreira \\ Dissertação apresentada ao Programa de \\ Pós-Graduação em Saúde Pública para \\ obtenção do título de Mestre. \\ Área de concentração: Epidemiologia \\ Orientador: Prof. Dr. Gizelton Pereira \\ Alencar
}

São Paulo 


\title{
Comparação de índices de avaliação da assistência pré- natal em base de dados nacional: uma análise com modelagem de equações estruturais
}

\author{
Matheus Souza Ferreira \\ Dissertação apresentada ao Programa de \\ Pós-Graduação em Saúde Pública para \\ obtenção do título de Mestre. \\ Área de concentração: Epidemiologia \\ Orientador: Prof. Dr. Gizelton Pereira \\ Alencar \\ (versão revisada)
}

São Paulo

2018 
É expressamente proibida a comercialização deste documento tanto na sua forma impressa como eletrônica. Sua reprodução total ou parcial é permitida exclusivamente para fins acadêmicos e científicos, desde que na sua reprodução figure a identificação do autor, título, instituição e ano da dissertação. 


\section{Agradecimentos}

À minha mãe Ednilda e ao meu pai Ivan, por terem priorizado minha educação e proporcionado estrutura e apoio durante minha trajetória acadêmica, incentivando a continuidade de meus estudos e projetos; esse apoio e suporte são inestimáveis para mim.

Ao Professor Gizelton Pereira Alencar, que tem me orientado desde minha iniciação científica, pelo acompanhamento cuidadoso e criterioso, paciência e amizade ao longo desses anos, em que tive a feliz oportunidade de ter tantos conhecimentos compartilhados e competências desenvolvidas.

À Professora Zilda Pereira da Silva, com quem tenho aprendido desde a graduação, à Professora Valéria Troncoso Baltar, à Professora Hillegonda Maria Dutilh Novaes e ao Professor Hugo Cogo Moreira, pela disponibilidade e pelas preciosas contribuições oferecidas durante o exame de qualificação e pré-banca para a elaboração e qualidade deste trabalho.

À Professora Marcia Furquim de Almeida e a todos os integrantes do grupo de pesquisa, pelas estimulantes discussões que tanto contribuíram para minha formação e pelas importantes sugestões para esse trabalho.

Aos colegas e aos Professores da Faculdade de Saúde Pública, por todas as contribuições, ensinamentos e inspirações; e aos funcionários, em especial das secretarias de pós-graduação e de epidemiologia, que tanto me auxiliaram durante esse período.

À minha irmã Gabriela, pela companhia, amizade, aconselhamentos e por todo suporte, inclusive ortográfico e gramatical, durante a escrita desta dissertação.

Ao meu padrasto Carlos, à minha madrasta Rosana e aos meus irmãos "postiços" Gustavo, Bruno e Victor, pelo apoio e por sempre me motivarem.

Ao CNPq, pela bolsa que foi fundamental para minha permanência e dedicação exclusiva ao curso de Mestrado e atividades envolvidas, assim como a viabilização deste trabalho. 


\section{Resumo}

Introdução: A assistência pré-natal adequada é importante para redução da morbimortalidade materna e perinatal, identificando fatores que possam colocar a gestante e o feto frente a maior risco de resultados adversos. A avaliação da adequação da assistência pré-natal se faz por meio de diferentes medidas que envolvem o acompanhamento, acesso e qualidade da assistência. Objetivo: Comparar resultados de diferentes índices de inadequação da assistência pré-natal, como desfechos, em modelos de equações estruturais a partir de um modelo teórico de fatores de risco. Métodos: O estudo empregou dados da Pesquisa Nacional de Saúde (PNS) 2013, que contou com 1.851 mães que fizeram o último parto entre 2011 e 2013, representando 3.818 .936 mulheres, a partir de amostragem complexa. Foram utilizados modelos de equações estruturais para a parte de mensuração das variáveis latentes envolvidas no modelo teórico e modelagem de fatores de risco para a inadequação da assistência. Medidas de ajuste foram empregadas para avaliar os modelos. Resultados: Quatro índices foram considerados para estimar a variável de inadequação da assistência pré-natal. A Vulnerabilidade Socioeconômica esteve fortemente associada ao desfecho inadequação do pré-natal e outras covariáveis das dimensões psicossociais e biológicas. Efeitos de hipertensão foram identificados para alguns desfechos. A presença de doenças crônicas influenciou a autoavaliação de saúde, porém esse não apresentou efeito sobre o desfecho. Modelos com e sem peso amostral apresentaram resultados distintos. Conclusão: O aspecto socioeconômico deve ser considerado quando se avalia a inadequação da assistência pré-natal. Os resultados obtidos sugerem que diferentes caminhos causais podem estar associados a diversos aspectos da assistência.

Palavras-chave: Cuidado pré-natal; Fatores de risco; Modelos de Equações Estruturais; Qualidade, acesso e avaliação da assistência à saúde. 


\begin{abstract}
Introduction: The adequate prenatal care is important to reduce maternal and perinatal morbidity and mortality, identifying factors that may put the pregnant woman and the fetus at greater risk of adverse outcomes. The assessment of the adequacy of prenatal care is done through different measures that involve the monitoring, access and quality of care. Objective: Compare results of different indices of inadequacy of prenatal care, as outcomes, in structural equation models from a theoretical model for risk factors. Methods: The study used data from the Brazilian 2013 National Health Survey (PNS), with a sample of 1,851 mothers who had their last births between 2011 and 2013, representing 3,818,936 women, applying the complex sampling weight. Structural equation models were employed for the measurement of the latent variables involved in the theoretical model and for the modeling of risk factors for the inadequacy of the assistance. Fit indices were used to evaluate the models. Results: Four indices were considered to estimate the variable of inadequacy of prenatal care. Socioeconomic Vulnerability was strongly associated with the inadequate outcome of prenatal care and other covariates of the psychosocial and biological dimensions. Effects of hypertension were identified for some outcomes. The presence of chronic diseases influenced the health self-assessment, but had no effect on the outcome. Models with and without sample weight presented different results. Conclusion: The socioeconomic aspects should be considered when assessing the inadequacy of prenatal care. The results suggest that different causal pathways may be associated with different aspects of care.
\end{abstract}

Keywords: Prenatal Care; Risk Factors; Structural Equation Modeling; Health Care Quality, Access, and Evaluation. 


\section{Lista de figuras}

Figura 1. Exemplo de Modelo de Equações Estruturais e representação de seus componentes. Adaptado de modelo apresentado nos tutoriais da biblioteca "lavaan", R (“HolzingerSwineford1939"). Disponível em: <http://lavaan.ugent.be/tutorial/cfa.html> (acesso em maio de 2017).

Figura 2. Proposta de modelo de fatores de risco e associados para desfecho Assistência pré-natal. 19

Figura 3. Mapas temáticos - (1) Distribuição percentual de mães brasileiras com último parto entre 2011 e 2013 segundo Unidade da Federação de Residência. Calculado com peso amostral. PNS, 2013. (2) Distribuição percentual de nascimentos vivos segundo Unidade da Federação de Residência. Brasil, 2011-2013.

Figura 4. Mapas temáticos - (1) Percentual de mães brasileiras com último parto entre 2011 e 2013 que realizaram 7 ou mais consultas de pré-natal (cobertura) por Unidade da Federação de Residência. Calculado com peso amostral. PNS, 2013. (2) Percentual de mães brasileiras com último parto entre 2011 e 2013 que receberam uma assistência pré-natal adequada segundo método "PHPN simples" (qualidade) por Unidade da Federação de Residência. Calculado com peso amostral. PNS, 2013.

Figura 5. Diagrama representando o componente estrutural da modelagem com equações estruturais realizada para o desfecho "Inadequação da Assistência Pré-Natal PHPN Simples (sem peso amostral). Modelo proposto por OLIVEIRA (2014).

Estimador WLSMV 36

Figura 6. Diagrama representando o componente estrutural da modelagem com equações estruturais realizada para o desfecho "Inadequação da Assistência Pré-Natal índice proposto por Silva” como variável latente. Calculado sem peso amostral. Estimador WLSMV.

Figura 7. Diagrama representando o componente estrutural da modelagem com equações estruturais realizada para o desfecho "Inadequação da Assistência Pré-Natal índice proposto por Silva" como variável latente. Calculado com peso amostral. Estimador WLSMV.

Figura 8. Diagramas de Venn - Delimitação das sub-amostras de mães brasileiras com último parto entre 2011 e 2013 segundo uso do SUS durante as consultas da assistência pré-natal. Calculado com peso amostral. PNS, 2013. 
Figura 9. Mapa temático - Percentual de mães brasileiras da amostra com último parto entre 2011 e 2013 com uso predominante da saúde suplementar durante as consultas de pré-natal por Unidade da Federação de Residência. Calculado com peso amostral. PNS, 2013. 


\section{Lista de quadros}

Quadro 1. Módulos da PNS 2013 separados por componentes e informante. 17

Quadro 2. Variáveis criadas e variáveis originais da PNS 2013.

Quadro 3. Variáveis usadas para construção do índice "PHPN - Simples", aplicado no estudo de SUCCI et al. (2008).

Quadro 4. Variáveis usadas para construção do índice de Takeda de adequação da utilização da assistência pré-natal, aplicada no estudo de TAKEDA (1993).

Quadro 5. Variáveis usadas para construção do índice de Silva de qualidade do prénatal, aplicado no estudo de SILVA (2008).

Quadro 6. Variáveis adicionadas posteriormente aos modelos.

Quadro 7. Variáveis selecionadas e tipo de variável assumido para a modelagem com equações estruturais. 


\section{Lista de tabelas}

Tabela 1. Frequências relativas de nascimentos pré-termo. SINASC e variáveis derivadas - PNS 2013 (calculadas com peso amostral) e amostra de mães com último parto entre 2011 e 2013 e população representada pela amostragem complexa. Brasil, 2012-2013.

Tabela 2. Classificação dos estudos nacionais selecionados no levantamento realizado segundo método quantitativo empregado para avaliação da assistência pré-natal......... 28 Tabela 3. Distribuição de mães brasileiras da amostra com último parto entre $2011 \mathrm{e}$ 2013 segundo qualidade da assistência pré-natal (método PHPN simples). Calculado com peso amostral. PNS, 2013.

Tabela 4. Distribuições percentuais de mães brasileiras de 2011 a 2013 segundo adequação da assistência pré-natal e índice de avaliação. Calculado com peso amostral. PNS, 2013.

Tabela 5. Distribuição percentual de mulheres brasileiras segundo história reprodutiva, faixa etária e autoavaliação da saúde. Calculado com peso amostral. PNS, 2013. 35

Tabela 6. Percentuais de mães brasileiras da amostra com último parto entre $2011 \mathrm{e}$ 2013 segundo variáveis do modelo teórico proposto e qualidade da assistência pré-natal (método PHPN simples). Calculado com peso amostral. PNS, 2013.

Tabela 7. Resumo dos modelos de regressão logística simples considerando todas as variáveis consideradas na análise como regressoras e inadequação do pré-natal método PHPN simples como variável resposta. Modelos com e sem peso amostral..... 38 Tabela 8. Resumo das análises fatoriais confirmatórias para foramação das variáveis latentes do modelo teórico com adição das novas variáveis (componente de mensuração dos modelos com equações estruturais) com e sem peso amostral. Estimador WLSMV.

Tabela 9. Resumo dos modelos com e sem peso amostral para o desfecho "Inadequação da Assistência Pré-Natal - PHPN Simples". Estimador WLSMV. 44

Tabela 10. Resumo dos modelos com e sem peso amostral para o desfecho “Inadequação da Assistência Pré-Natal - Índice de Takeda”. Estimador WLSMV. 46

Tabela 11. Resumo dos modelos com e sem peso amostral para o desfecho “Inadequação da Assistência Pré-Natal - Índice proposto por Silva". Estimador WLSMV. 
Tabela 12. Resumo dos modelos com e sem peso amostral para o desfecho "Realização de menos de sete consultas de pré-natal”. Estimador WLSMV.

Tabela 13. Resumo dos modelos com e sem peso amostral para o desfecho “Inadequação da Assistência Pré-Natal - PHPN Simples". Estimador MLR

Tabela 14. Resumo dos modelos com e sem peso amostral para o desfecho

“Inadequação da Assistência Pré-Natal - Índice de Takeda”. Estimador MLR.

Tabela 15. Resumo dos modelos com e sem peso amostral para o desfecho

“Inadequação da Assistência Pré-Natal - Índice proposto por Silva”. Estimador MLR.

Tabela 16. Resumo dos modelos com e sem peso amostral para o desfecho "Realização de menos de sete consultas de pré-natal". Estimador MLR.

Tabela 17. Distribuição das mães brasileiras da amostra com último parto entre $2011 \mathrm{e}$ 2013 segundo aferição da pressão arterial durante a assistência pré-natal. Calculado com peso amostral. PNS, 2013.

Tabela 18. Resumo dos modelos com e sem peso amostral para o desfecho

“Inadequação da Assistência Pré-Natal - Índice proposto por Silva como variável latente". Estimador WLSMV.

Tabela 19. Resumo dos modelos com e sem peso amostral para o desfecho

“Inadequação da Assistência Pré-Natal - PHPN Simples". População usuária SUS

(exclusivamente). Estimador WLSMV.

Tabela 20. Resumo dos modelos com e sem peso amostral para o desfecho

“Inadequação da Assistência Pré-Natal - PHPN Simples”. População usuária

(exclusivamente ou não) da Saúde Suplementar. Estimador WLSMV. 


\section{Lista de siglas}

Análise Fatorial Confirmatória

AFC

Adequacy of Prenatal Care Utilization

APNCU

Índice de Ajuste Comparativo

CFI

Comissão Nacional de Ética em Pesquisa

CONEP

Instituto Brasileiro de Geografia e Estatística

IBGE

Índice de Massa Corporal

IMC

Last Visit Adequacy of Prenatal Care

LV-APNC

Modelagem com Equações Estruturais

MEE

Robust Maximum Likelihood

MLR

Não Aceitação da Gestação

NAG

Odds-Ratio

OR

Programa de Humanização do Parto e Nascimento

PHPN

Pesquisa Nacional por Amostra de Domicílios

PNAD

Pesquisa Nacional de Saúde

PNS

Raiz do Erro Quadrático Médio de Aproximação

RMSEA

Sistema de Informações sobre Nascidos Vivos

SINASC

Índice de Ajuste de Tucker-Lewis

TLI

Vulnerabilidade Familiar

VF

Vulnerabilidade Socioeconômica

VSE

Mean and Variance Adjusted Weighted Least Squares

WLSMV

Raiz do Resíduo Quadrático Médio Ponderado

WRMR 


\section{ÍNDICE}

1. INTRODUÇÃO ................................................................................................. 1

1.1 Assistência pré-natal e sua importância para redução dos nascimentos pré-termo 1

1.2 Métodos para avaliação da assistência pré-natal ................................................. 2

1.3 Fatores que influenciam a adequação da assistência pré-natal .............................. 5

1.3.1 Acesso e utilização de serviços de saúde........................................................... 5

1.3.2 Cobertura da assistência pré-natal e adequação da assistência pré-natal ............ 6

1.3.3 Vulnerabilidade familiar e condições socioeconômicas..................................... 7

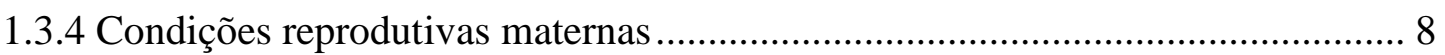

1.3.5 Intercorrências e gestações de risco................................................................. 9

1.3.6 Autoavaliação do estado da saúde em gestantes e puérperas ............................. 9

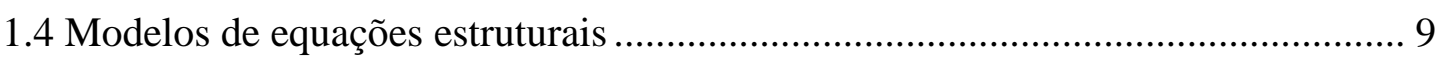

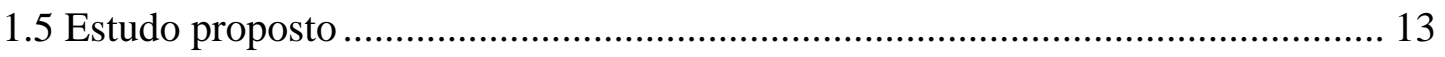

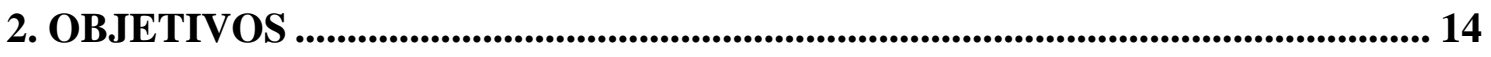

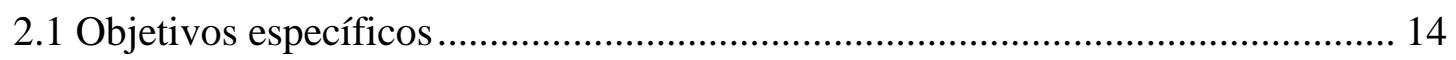

3. MÉTODOS............................................................................................................. 15

3.1 Fontes de dados e população do estudo - PNS 2013 .......................................... 15

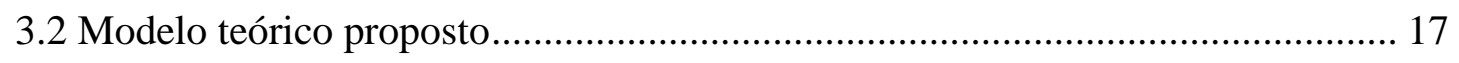

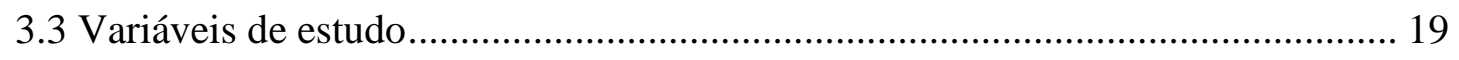

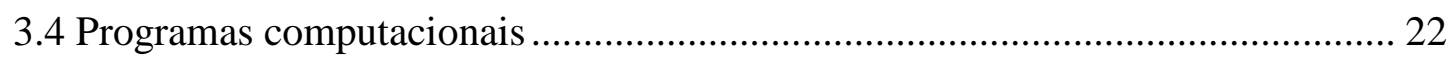

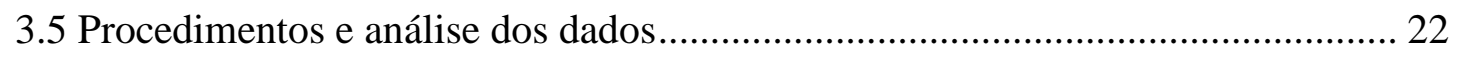

3.6 Modelos de Equações Estruturais ..................................................................... 23

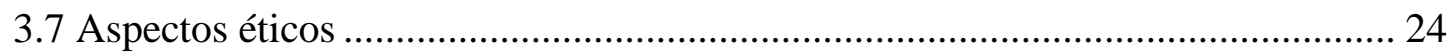

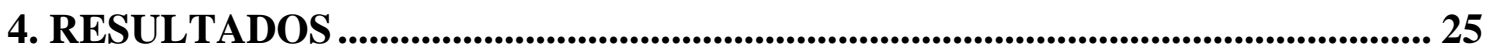

4.1 Representatividade da amostra do módulo S da PNS 2013 .............................. 25

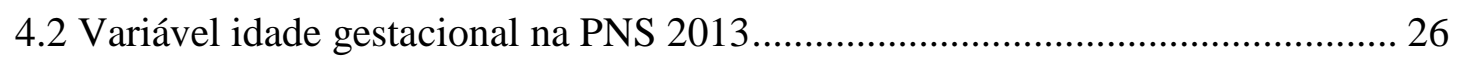

4.3 Principais índices usados em estudos brasileiros ................................................ 27

4.3.1 Descrição dos índices de adequação da assistência pré-natal........................... 29

4.3.1.1 Índice de adequação/qualidade da assistência pré-natal PHPN Simples........ 29

4.3.2 Outros índices de adequação da assistência pré-natal ...................................... 30 
4.4 Autoavaliação da saúde e maternidade.

4.5 Distribuições percentuais da amostra segundo variáveis do modelo ................... 35

4.5 Seleção das variáveis dos modelos de equações estruturais ................................. 36

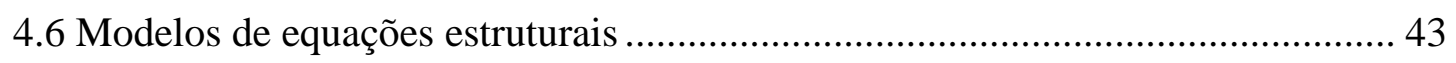

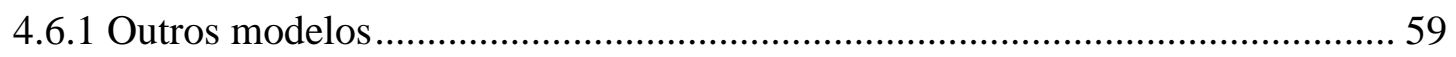

4.6.1.1 Assistência pré-natal como variável latente .................................................... 59

4.6.1.2 Proposta de Modelos separados - sub-amostras SUS e não-SUS .................. 63

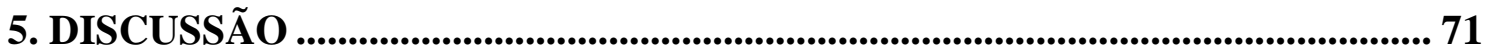

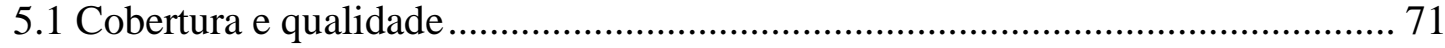

5.2 Autoavaliação da saúde e presença de história reprodutiva ................................ 71

5.3 Comparação de diferentes índices para avaliação do pré-natal ............................ 72

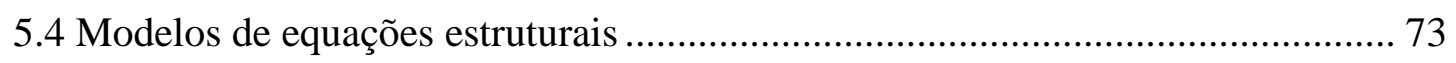

5.4.1 Considerações sobre a modelagem.............................................................. 73

5.4.2 Orientação dos efeitos ........................................................................... 74

5.4.3 Modelos sem e com aplicação de peso amostral com estimador MLR ............. 75

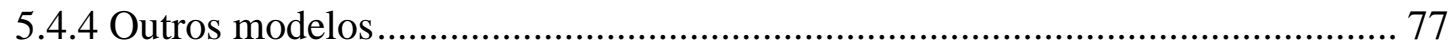

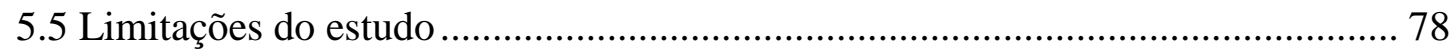

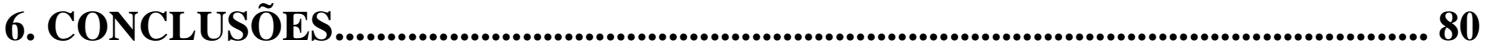

7. REFERÊNCIAS BIBLIOGRÁFICAS ........................................................................ 81

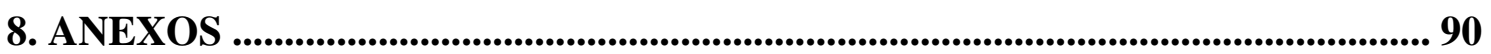

8.1 Parecer Consubstanciado do Comitê de Ética em Pesquisa - Anexo A............... 90

8.2 Detalhamento do levantamento realizado - Anexo B ........................................ 92

8.3 Módulos R e S da PNS 2013 - Anexo C............................................................. 99 


\section{Introdução}

1.1 Assistência pré-natal e sua importância para redução dos nascimentos pré-termo

A assistência pré-natal adequada propicia a redução da morbimortalidade materna e perinatal, identificando fatores que possam colocar a gestante e o feto em risco de resultados adversos, em tempo hábil de intervenção e tratamento para evitar ou reduzir desfechos negativos, como os nascimentos pré-termo (recém-nascidos com menos de 37 semanas de gestação).

Os nascimentos pré-termo apresentam risco de mortalidade significativamente maior do que os não pré-termo e risco mais elevado de apresentar deficiências de desenvolvimento e agravos de saúde ao longo da vida, levando a importantes custos para os serviços públicos de saúde, de educação, além de custos financeiros e emocionais para suas famílias (KATZ et al., 2013; IOM, 2007).

Diversos fatores de risco para a prematuridade são descritos na literatura, incluindo: fatores ambientais; socioeconômicos; características biológicas da mãe ao engravidar; história reprodutiva materna; condições da gestação abrangendo questões psicossociais; o uso do fumo, álcool e drogas; condição de trabalho; atividade física; intercorrências da gestação; características fetais; entre outros, sendo que a não realização ou o início tardio da assistência pré-natal são considerados importantes fatores de risco (ALMEIDA et al., 2011; MUGLIA e KATZ, 2010; GOLDENBERG et al., 2008; TUCKER e MCGUIRE, 2005).

Considerando que uma adequada assistência pré-natal é fator de proteção para a prematuridade e outros desfechos negativos da gestação, a avaliação da assistência 
em termos de acompanhamento e acesso é importante e de interesse à Saúde Pública (AAP, 2002).

\subsection{Métodos para avaliação da assistência pré-natal}

Os métodos de avaliação da assistência pré-natal são classificados como os que medem acesso, definido como a entrada dos usuários aos serviços de saúde e a continuidade do cuidado (ANDERSEN, 1995), e os que avaliam adequação do processo de cuidado, definido como as atividades envolvendo profissionais de saúde e pacientes de acordo com padrões técnicos, científicos e/ou administrativos (HANDLER, et al. 2001). Os métodos de avaliação são inseridos na lógica do modelo de avaliação estrutura-processo-resultado (SILVEIRA e SANTOS, 2001; DONABEDIAN, 1988).

A avaliação da assistência pré-natal envolve componentes de diversas dimensões, abrangendo dados de serviços e dados individuais: desde a estrutura do local de realização das consultas (planta física, recursos humanos e materiais, normas, atividades, procedimentos, entre outros) ao acesso e utilização de serviços pelas gestantes; número de consultas e início do pré-natal; realização de exames físicos e laboratoriais; presença de morbidade materna; frequência de realização de exames de sangue, urina, sorologia para sífilis, anti-HIV, hepatite $\mathrm{B}$, toxoplasmose $\mathrm{e}$ ultrassonografia (crescimento fetal); identificação de hipertensão arterial sistêmica, diabetes mellitus, depressão, anemia, ameaça de aborto, trabalho de parto prematuro, corrimento vaginal, infecção do trato urinário e sangramento vaginal; recebimento de orientações sobre sinais de alerta na gestação, de como identificar o início do trabalho de parto e sobre aleitamento materno, indicação de serviço de saúde a ser realizado o 
parto; percepção e satisfação da gestante em relação à assistência, entre outros (SAAVEDRA e CESAR, 2015; DE FREITAS ORTIGARA et al., 2015; SILVA, 2008; COIMBRA et al., 2003; SILVEIRA e SANTOS, 2001).

Em geral, os índices que avaliam adequação da assistência pré-natal são direcionados principalmente ao grupo de gestantes de baixo risco, e estimar a adequação para gestações de alto risco enfrenta dificuldades, sendo sugerido o uso de índices que envolvem também a qualidade das consultas da assistência pré-natal, incluindo procedimentos e orientações (HEAMAN et al., 2014; ASSUNÇÃO et al., 2012; SILVEIRA e SANTOS, 2014; STRINGER, 1998).

No cenário internacional, índices e suas variações foram propostos, difundidos e aprimorados com ênfase naqueles que mensuram a adequação da utilização da assistência pré-natal, como o Índice de Kessner, GINDEX, R-GINDEX, e, especialmente, o Índice de Kotelchuck (e modificações deste, como o Last Visit Adequacy of Prenatal Care LV-APNC Index) (DEBESSAI et al., 2016; KAMBOUROVA e GEORGIEVA, 2015; HEAMAN et al., 2014; KURTZMAN et al., 2014; TAYEBI et al., 2014; ALEXANDER e KOTELCHUCK, 1996).

O índice de utilização APNCU (Adequacy of Prenatal Care Utilization Index), ou índice de Kotelchuck, considera o número de consultas ajustado pela idade gestacional ao início da assistência pré-natal, que deveria ser até o $4^{\circ}$ mês, e com a idade gestacional à ocasião do parto. Esse índice considera a relação entre o número de consultas realizadas e o número de consultas esperadas. A assistência pré-natal é considerada adequada quando a proporção de consultas realizadas é maior ou igual a 80\% das consultas esperadas. O índice não é ajustável para as condições de risco das gestantes, mas propõe uma categoria adicional, a de "cuidado intensivo" ou "muito adequado" (adequate plus), quando a razão entre o número de consultas realizadas 
pelo número de consultas esperadas é superior a $110 \%$, sendo que essa categoria pode sugerir um grupo de gestantes de alto risco que precisam de um cuidado mais intensivo, apesar de ser difícil separar esse grupo do grupo de gestantes que realizaram mais consultas de rotina, por exemplo (KOTELCHUCK, 1994).

No cenário nacional, o Programa de Humanização do Pré-Natal e Nascimento - PHPN do Ministério da Saúde (2000) adota o conceito de que uma assistência prénatal adequada deve começar até o $4^{\circ}$ mês, com um total de seis visitas: uma no primeiro trimestre, duas no segundo trimestre e três no terceiro trimestre, além de indicações para realização de procedimentos.

Por outro lado, o Ministério da Saúde utiliza um indicador a nível agregado para avaliar a cobertura da assistência pré-natal, que tem como referência a proporção de gestantes que realizaram 7 ou mais consultas (BRASIL, 2004; SERRUYA et al., 2004).

São encontradas na literatura modificações de índices estabelecidos para avaliação da assistência pré-natal considerando a realidade brasileira e o desenvolvimento de novos índices, muitos baseados nas orientações do PHPN de 2000, resultando em uma vasta gama de medidas (LEAL et al., 2015; MARTINELLI et al., 2014; SANTOS NETO et al., 2013).

Não é consenso qual índice é mais adequado para ser utilizado na avaliação da assistência pré-natal a fim de propor intervenções visando a proteção à saúde da população em diferentes contextos, uma vez que são tantos os fatores envolvidos, a nível individual e a nível agregado, como acesso à tecnologia no pré-natal, situação socioeconômica das mães, aspectos culturais, entre outros. Assim, se faz necessária a análise do leque de índices disponíveis e a comparação entre eles. 


\subsection{Fatores que influenciam a adequação da assistência pré-natal}

A assistência pré-natal inadequada pode evidenciar diversas condições que afetam a gestante, como dificuldade de acesso aos serviços de saúde, gravidez não planejada e gravidez indesejada e outros indicadores de vulnerabilidade socioeconômica e familiar. A utilização da assistência pré-natal exercida pela gestante ainda pode ser afetada pela presença de intercorrências na gestação e condições reprodutivas maternas. Assim, a assistência poderia ser inserida no caminho causal para prematuridade e outros desfechos negativos como mediadora entre fatores distais e proximais (IOM, 2007).

\subsubsection{Acesso e utilização de serviços de saúde}

A utilização dos serviços de saúde representa o contato entre a população e a rede assistencial existente, propiciando os processos de cuidados preventivos, curativos e de reabilitação nos quais se estruturam os sistemas de saúde. Dentre os determinantes da utilização dos serviços de saúde estão dispostos desde fatores individuais relacionados aos usuários até fatores mais abrangentes, como a nível da gestão pública e organização da oferta de serviços e a nível territorial (social e espacialmente) (TRAVASSOS e CASTRO, 2008).

Neste contexto, o acesso ou acessibilidade aos serviços de saúde são conceitos complexos definidos de diferentes formas, geralmente abrangendo também, para além do contato entre os pacientes e serviços, os resultados dessa interação, considerando a adequação do cuidado recebido (adequação dos serviços, profissionais e recursos 
tecnológicos), que será determinante para a continuidade do processo de cuidado após o primeiro contato do usuário com o serviço (TRAVASSOS e MARTINS, 2004).

São propostos diferentes modelos teóricos de acessibilidade, acesso e utilização, como os de DONABEDIAN (1973), ANDERSEN e NEWMAN (1973) e ANDERSEN (1995), entre outros, que consideram a influência de fatores de diferentes ordens, e, também, os obstáculos e barreiras de acesso existentes, como recursos financeiros, geográficos e territoriais, tempo de espera, organizacionais, entre outros.

A complexidade das inter-relações envolvidas nos conceitos de acesso e utilização dos serviços de saúde deve estar contemplada nos modelos e análises de estudos que se propõem a trabalhar com essas variáveis.

\subsubsection{Cobertura da assistência pré-natal e adequação da assistência pré-natal}

No Brasil, políticas públicas e programas nacionais como o Bolsa Família e Estratégia Saúde da Família desde a sua implementação contribuíram para aumento da cobertura da assistência pré-natal, medida por meio do percentual de mulheres que realizaram 7 ou mais consultas de pré-natal (BRASIL, 2004), interferindo em fatores inversamente associados à mortalidade infantil e perinatal, ao atuar sobre a redução da pobreza e aumento de acesso aos serviços de saúde (RASELLA et al., 2013).

Entretanto, o aumento da cobertura da assistência pré-natal, a nível individual, poderia representar um aumento do número de consultas de pré-natal realizadas sem que houvesse necessariamente aumento da adequação da assistência recebida pelas gestantes, sendo que estudos constataram desigualdades aos cuidados da assistência pré-natal oferecidos (COIMBRA et al., 2003; VICTORA et al., 1988; MCCORNIK et al., 1985). 
A revisão da adequação da assistência pré-natal (calculada através dos índices de adequação da utilização como o de Kotelchuck e derivados) no Brasil publicada em 2016 evidenciou aumento da cobertura da assistência no país, no período entre 2005 e 2015, e, em contrapartida, baixos índices de adequação da assistência no país (NUNES et al., 2016).

\subsubsection{Vulnerabilidade familiar e condições socioeconômicas}

A vulnerabilidade representa a falta de acesso pelas famílias a bens e serviços considerados essenciais, exercendo a renda papel determinante, assim como o acesso à educação representado pela escolaridade, intimamente ligada à qualificação profissional (IPEA, 2006). A vulnerabilidade pode ser dividida em dois componentes: a vulnerabilidade familiar e a socioeconômica, descritas a seguir.

A vulnerabilidade familiar é referente à composição da estrutura familiar refletindo necessidades de acordo com o perfil dos membros da família: crianças, adolescentes, adultos e idosos. Dependendo da composição familiar e das relações interpessoais vivenciadas entre os membros, a vulnerabilidade familiar pode variar de acordo com a necessidade de recursos para a satisfação de suas necessidades básicas (BRAY, 1995). Estudos apontam como fator de risco para uma situação de vulnerabilidade ou estresse o estado civil da mãe, caracterizado como "mãe solteira", "separada" ou "ausência de união estável", sendo que a presença de família "estruturada" poderia funcionar como um fator de proteção para as situações causadoras de estresse, depressão ou ansiedade na gestante (GOLDENBERG et al., 2008; BEHRMAN e BUTLER, 2007). 
A vulnerabilidade socioeconômica é referente a condições socioeconômicas mais desfavoráveis, sendo que mulheres com vulnerabilidade apresentam maior risco de carência nutricional, baixa escolaridade, trabalhos mais pesados, uso de drogas ilícitas, tabagismo, e assistência pré-natal inadequada (GOLDENBERG et al., 2008; CNATTINGIUS, 2004; KRAMER et al., 2000). Mulheres em situação de maior vulnerabilidade também são mais afetadas por condições desfavoráveis ao planejamento da gravidez (MUÑOS et al., 2013).

\subsubsection{Condições reprodutivas maternas}

Uma série de condições anteriores à gravidez que são características da mulher pode influenciar a utilização da assistência pré-natal e o desfecho da gestação, como idade da mãe, estado nutricional e história reprodutiva da mulher.

Gestantes com idade inferior a 19 anos (gravidez precoce) e superior a 34 anos (gravidez tardia) apresentam maior risco para nascimento pré-termo, sendo que gestantes adolescentes apresentam com maior frequência condições socioeconômicas mais desfavoráveis e maior vulnerabilidade (CERQUEIRA-SANTOS et al., 2010; SABROZA et al., 2004; GAMA et al., 2002).

Estudos indicaram que mulheres com obesidade pré-gestacional apresentaram maior risco para síndromes hipertensivas da gravidez; e nascidos vivos de mulheres com baixo peso pré-gestacional apresentaram maior risco de baixo peso ao nascer (peso menor que 2.500g) (MARANO et al., 2014; SAUNDERS et al., 2011; PADILHA et al., 2007).

Gestantes com história reprodutiva apresentando ocorrência de nascimento pré-termo anterior, ocorrência de aborto, e intervalo intergestacional curto ou longo em relação a gestações anteriores, podem apresentar maior risco. Gestações múltiplas apresentam risco de nascimento pré-termo maior a gestações únicas, sendo mais frequentes em gestantes que realizam tratamentos para fertilidade; estas gestações também podem apresentar mais complicações, como a diabetes gestacional, préeclâmpsia e anemia (MUGLIA e KATZ, 2010; GOLDENBERG et al., 2008). 


\subsubsection{Intercorrências e gestações de risco}

A ocorrência durante a gestação de intercorrências, como sangramento vaginal, hipertensão, complicações placentárias, ruptura de membranas e internações pode caracterizar a gestante como sendo de maior risco, podendo ter uma utilização da assistência pré-natal mais elevada por conta da necessidade de maior número de consultas (GOLDENBERG et al., 2008; ALEXANDER e KOTELCHUCK, 1996).

\subsubsection{Autoavaliação do estado da saúde em gestantes e puérperas}

A autoavaliação da saúde é considerada uma medida válida para predizer mortalidade, morbidade e o uso de serviços de saúde. Estudos encontraram que a condição socioeconômica e renda familiar foram preditores importantes para a variável (OSTROVE et al., 2000) e que a autoavaliação da saúde pode sofrer alterações durante o período gestacional e primeiro ano de maternidade, com aumento do grupo de gestantes que avaliam sua saúde negativamente (SCHYTT e INGEGERD, 2011; SCHYTT et al., 2005).

\subsection{Modelos de equações estruturais}

A modelagem com equações estruturais (MEE) é um método quantitativo para testar e validar modelos teóricos, que envolve diversas técnicas estatísticas, como análise fatorial, geralmente confirmatória, e análise de caminhos, abordagem que é 
uma extensão de regressões múltiplas. É formado por duas partes: a) o modelo de mensuração, resultante da análise fatorial, para inclusão de variáveis latentes não observadas - constructos que podem representar conceitos abstratos ou não mensurados diretamente, criados a partir de um conjunto de variáveis observadas (variáveis indicadoras) -, permitindo estimar os erros de mensuração; b) o modelo estrutural, análise de caminhos, com inclusão e mensuração das relações e efeitos simultâneos entre as variáveis, latentes ou observadas, em relação ao(s) desfecho(s) estudado(s), conforme proposto pelo modelo teórico.

Ao construir modelos epidemiológicos causais podem ocorrer situações em que é desejado analisar relações entre um grupo de variáveis simultaneamente, incluindo no modelo efeitos de mediação e outros que seriam excluídos com o emprego de outros métodos, como o modelo de regressão múltipla, e, ainda, incluir no modelo variáveis latentes não diretamente observadas além da explicitação de erros de mensuração ou erros residuais, sendo o emprego da MEE uma possível alternativa para tanto. Há também outras abordagens da MEE que podem ser empregadas, dependendo dos objetivos do estudo e dados disponíveis, como a MEE exploratória, envolvendo análise fatorial exploratória em contraposição à análise confirmatória que pressupõe um modelo teórico inicial a ser validado (como empregada na MEE confirmatória), assim como a MEE multinível, quando os dados de um estudo constam com variáveis mensuradas em diferentes agrupamentos hierárquicos, possibilitando verificar efeitos de variáveis de determinado nível hierárquico sob variáveis pertencentes a outros níveis (LEI e WU, 2007; LOEHLEN, 1998; SKRONDAL e RABE-HESKETH, 2004).

Na MEE, os modelos apresentam simbologia definida para representar os tipos de variáveis, tipos de erros e direcionalidades causais ou não de efeitos. A MEE é dividida em dois componentes: o de mensuração e o estrutural, conforme definido a 
seguir:

Componente de mensuração - análise fatorial: formas retangulares representam variáveis observadas; formas elípticas representam variáveis latentes; setas unidirecionais partindo de variável latente representa quais as variáveis observadas indicadoras que a formaram; seta apontando para variável observada indicadora que não parte de variável cercada por nenhuma forma representa erro de mensuração da variável.

Componente estrutural - diagrama de caminhos: formas retangulares representam variáveis observadas; formas elípticas representam variáveis latentes; seta unidirecional representa direção causal; seta bidirecional representa covariância ou correlação (dependendo se a unidade de medida das variáveis foi ou não padronizada); setas bidirecionais curvadas representam que variáveis independentes podem estar correlacionadas; seta apontando para variável dependente que não parte de variável cercada por nenhuma forma representa o erro residual da variável (representando a existência de outras causas para a variável externas ao modelo proposto). 
Figura 1. Exemplo de Modelo de Equações Estruturais e representação de seus componentes. Adaptado de modelo apresentado nos tutoriais da biblioteca "lavaan", R ("HolzingerSwineford1939"). Disponível em: <http://lavaan.ugent.be/tutorial/cfa.html> (acesso em maio de 2017).

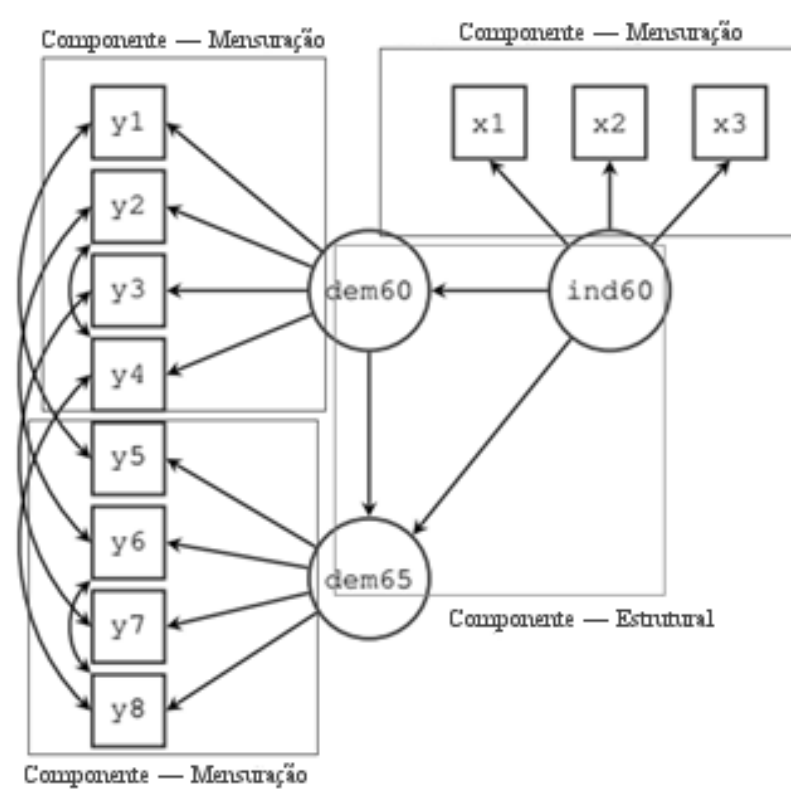

Fommas elíticas: varióveis latentes não observadas

Foumas retangulares: variáveis observadas

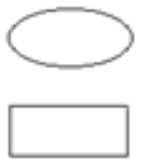

Componente de Menstração: Análise Fatorial

Componente Estrutural: Análise de caminhos (setas representam direção causal)

Os parâmetros são estimados através de matrizes de correlação, determinadas a partir das variáveis observadas, sendo que a MEE pode ser expressada em notação matricial (JÖRESKOG e SÖRBOM, 1996; BOLLEN, 1989):

$$
\begin{aligned}
& Y=\Lambda_{y} \eta+\varepsilon, \text { componente de mensuração (variável latente } \eta \text { “eta") } \\
& X=\Lambda_{x} \xi+\delta, \text { componente de mensuração (variável latente } \xi \text { “csi”) }
\end{aligned}
$$

em que "Y" e "X" são vetores de variáveis observadas; $\Lambda_{y}$ (lambda "y") e $\Lambda_{x}$ (lambda “x") são matrizes de coeficientes cujos elementos representam os efeitos das variáveis latentes $\eta$ (eta) e $\xi$ (csi) sobre as variáveis observadas "Y" e "X"; $\varepsilon$ (epsilon) é o vetor que representa os erros de mensuração das variáveis observadas "Y", que 
compõem a variável latente $\eta$ (eta); e $\delta$ (delta) é o vetor que representa os erros de mensuração das variáveis observadas “ $X$ ”, que compõem a variável latente $\xi$ (csi);

$$
\begin{gathered}
\eta=B \eta+\Gamma \xi+\zeta, \text { componente estrutural do modelo (para a variável } \\
\text { dependente } \eta \text { “eta") }
\end{gathered}
$$

Sendo $\eta$ (eta) o vetor de variáveis latentes dependentes, $\xi$ (csi) o vetor de variáveis latentes independentes, $\beta$ (beta) a matriz de coeficientes cujos elementos representam efeitos causais de variáveis $\eta$ (eta) sobre outras variáveis dependentes $\eta$ (eta), $\Gamma$ (gama) a matriz de coeficientes cujos elementos representam efeitos causais de variáveis $\xi$ (csi) sobre variáveis dependentes $\eta$ (eta) e $\zeta$ (zeta) o vetor que representa erros residuais das variáveis dependentes.

\subsection{Estudo proposto}

Considerou-se que a assistência pré-natal realizada pelas gestantes sofre efeito de dificuldades de acesso aos serviços de saúde, vulnerabilidade familiar, não aceitação da gravidez e, ainda, que sua utilização pode ser afetada pela presença de intercorrências na gestação e condições reprodutivas maternas. Assim, verificando a importância de se estudar melhor esses caminhos causais e os diferentes índices existentes para estimação do desfecho, o estudo visa explorar como esses e outros fatores se relacionam em modelo de equações estruturais de fatores de risco para a inadequação da assistência pré-natal a partir dos dados da Pesquisa Nacional de Saúde (PNS) 2013. 


\section{Objetivos}

Comparar resultados de diferentes índices que medem adequação da assistência pré-natal como desfecho, em modelos de equações estruturais e verificar sua relação com fatores de risco, empregando-se dados do estudo brasileiro de abrangência nacional Pesquisa Nacional de Saúde (PNS) 2013.

\subsection{Objetivos específicos}

- Identificar os índices que medem a adequação da assistência pré-natal utilizados em estudos populacionais brasileiros.

- Descrever os índices de avaliação da adequação da atenção pré-natal e comparar suas distribuições para os dados da PNS 2013.

- Testar modelos de equações estruturais com o desfecho inadequação da assistência pré-natal obtido de diferentes formas para os dados do estudo PNS 2013 com variáveis das dimensões: demográfica; socioeconômica; ambiental; estrutura familiar; reprodutivas da gestante; intercorrências na gestação; comparando os resultados dos modelos. 


\section{Métodos}

3.1 Fontes de dados e população do estudo - PNS 2013

A PNS 2013 foi um estudo brasileiro de base nacional com delineamento do tipo transversal realizado entre 2013 e 2014 pelo Instituto Brasileiro de Geografia e Estatística (IBGE), em parceria com o Ministério da Saúde e a Fundação Oswaldo Cruz, e teve seus dados divulgados publicamente (IBGE, 2014). A população-alvo do estudo foi constituída de pessoas que residem em domicílios particulares permanentes de todo País. Seu desenho contou com um plano de amostragem complexa considerando as cinco macrorregiões do país.

O objetivo da PNS foi caracterizar a situação de saúde e os estilos de vida da população brasileira (lacunas de informação no âmbito do SUS); atenção à saúde acesso e uso aos serviços, às ações preventivas, a continuidade dos cuidados e ao financiamento (SZWARCWALD et al.,2014). A pesquisa foi desenvolvida por meio de questionários direcionados a informações sobre o domicílio, informações gerais de todos os moradores e informações específicas respondidas por morador adulto selecionado, sendo que também foram realizadas mensurações físicas e coleta de materiais biológicos do morador adulto selecionado (dados ainda não divulgados) (DAMACENA et al., 2015). O questionário foi dividido em 21 módulos, nomeados com letras do alfabeto entre "A" e "W", distribuídos em três partes: sendo a primeira parte "Questões sobre informações do domicílio e visitas domiciliares realizadas pela equipe de Saúde da Família e agentes de endemias" e a segunda parte "Moradores do domicílio" respondidas por um residente do domicílio que detinha, no momento da entrevista, informações sobre o domicílio e sobre a situação socioeconômica e de 
saúde de todos os moradores. A terceira parte "Individual" foi respondida por um morador com 18 anos ou mais de idade selecionado aleatoriamente.

O módulo S - Atendimento Pré-Natal que contempla a população considerada nesse estudo contou com uma amostra de 1.851 mães, que fazem parte da amostra de morador de 18 anos ou mais selecionado, com menos de 50 anos de idade e que tiveram último parto no período de 28/07/2011 a 27/07/2013 (parte do grupo de mulheres do módulo R - Saúde da Mulher, contemplando mulheres de 18 anos e mais de idade moradoras selecionadas). Aplicando o peso da amostra (SOUZA-JÚNIOR et al., 2015), observa-se representar cerca de 3.818.936 mulheres.

Uma das vantagens de se empregar dados da PNS 2013 é que esta apresenta informações representativas de toda população de usuários SUS e não SUS, sendo que através de outras fontes de dados mais comumente empregadas muitas das informações são restritas à população de usuários SUS apenas, e para o desfecho adequação da assistência pré-natal existem diferenças de cobertura e adequação da assistência pré-natal em relação ao âmbito público e privado (PARIS et al., 2013; CESAR et al., 2011).

Os dados da PNS 2013 são divulgados sem valores faltantes para todas variáveis que foram utilizadas. Assim, todas as 1.851 observações do módulo S foram consideradas para as análises.

O Quadro 1, a seguir, traz detalhamento dos módulos da pesquisa com identificação dos que contiveram variáveis que foram empregadas nas análises do presente trabalho: 
Quadro 1. Módulos da PNS 2013 separados por componentes e informante.

\begin{tabular}{|c|c|c|}
\hline MÓDULOS* & COMPONENTE & INFORMANTE \\
\hline A & Informações do Domicílio & \multirow{11}{*}{ Morador do domicílio } \\
\hline $\mathrm{B}$ & Visitas domiciliares de Equipe de Saúde da Família e Agentes de Endemias & \\
\hline $\mathbf{C}$ & Características Gerais dos moradores & \\
\hline $\mathrm{D}$ & Características de educação das pessoas com 5 anos ou mais & \\
\hline $\mathbf{E}$ & Trabalho dos moradores do domicílio de 14 anos ou mais de idade & \\
\hline $\mathbf{F}$ & Rendimentos domiciliares & \\
\hline $\mathrm{G}$ & Pessoas com deficiências & \\
\hline I & Cobertura de Plano de Saúde & \\
\hline $\mathrm{J}$ & Utilização de Serviços de Saúde & \\
\hline $\mathrm{K}$ & Saúde dos indivíduos com 60 anos ou mais & \\
\hline $\mathrm{L}$ & Crianças com Menos de 2 Anos & \\
\hline $\mathrm{M}$ & Outras características de trabalho e apoio social & \multirow{10}{*}{ Morador de 18 anos ou mais selecionado } \\
\hline $\mathbf{N}$ & Percepção do estado de saúde & \\
\hline $\mathrm{O}$ & Acidentes e violências & \\
\hline $\mathrm{P}$ & Estilo de vida & \\
\hline $\mathrm{Q}$ & Doenças crônicas & \\
\hline $\mathbf{R}$ & Saúde da Mulher & \\
\hline $\mathbf{S}$ & Atendimento Pré-natal & \\
\hline $\mathrm{U}$ & Saúde Bucal & \\
\hline $\mathrm{X}$ & Atendimento médico & \\
\hline $\mathrm{W}$ & Informações laboratoriais & \\
\hline
\end{tabular}

*Os módulos destacados apresentaram variáveis consideradas nas análises.

\subsection{Modelo teórico proposto}

O modelo teórico apresentado (Figura 2) é baseado no modelo de fatores de risco para o desfecho nascimento pré-termo proposto por OLIVEIRA (2014), que considera as relações das variáveis latentes independentes (fatores da análise fatorial), vulnerabilidade socioeconômica (VSE) e vulnerabilidade familiar (VF) oriundas de características socioeconômicas, com as variáveis de não aceitação da gestação (NAG) (latente), que engloba em sua composição o planejamento da gravidez e aceitações da mãe, do pai e da família e variáveis de intercorrências e condições reprodutivas, compondo o modelo no qual a assistência pré-natal exerce papel de mediação entre tais variáveis e o desfecho nascimento pré-termo (Idade Gestacional).

Neste estudo foi considerado como desfecho a inadequação da assistência prénatal, com a proposta de se utilizar diferentes formas para mensuração dessa variável, com emprego de dados de um estudo de base nacional, sendo que, originalmente, o 
modelo foi aplicado aos dados do estudo caso-controle "Fatores de Risco para nascimento pré-termo no município de Londrina - Paraná", com mães de nascidos vivos hospitalares residentes em Londrina (junho/2006 e março/2007) (SILVA, 2009), que contava com 328 casos (nascimentos pré-termo) e 369 controles, amostra representativa de recém-nascidos.

A "Inadequação da assistência pré-natal” apresenta diferentes formas de ser estimada, através de índices, que envolvem diferentes dimensões da assistência, como a da "qualidade". O Programa de Humanização do Parto e Nascimento do Ministério da Saúde (PHPN) (BRASIL, 2000) propõe uma medida para estimar a qualidade da assistência pré-natal, apesar de não propor uma metodologia padrão para seu cálculo, estabelecendo que é adequada a assistência pré-natal com início até o $4^{\circ}$ mês gestacional e mínimo de seis consultas, distribuídas da seguinte forma: 1 consulta durante o primeiro trimestre, 2 durante o segundo e 3 no terceiro trimestre. Também é preconizada a realização de procedimentos essenciais na assistência. Além de trabalhar com o índice de avaliação da assistência pré-natal construído com base nessas orientações do PHPN, também foram empregados outros índices para estimar a inadequação, tendo sido, inclusive, considerada em forma de variável latente na MEE.

Para adaptação do modelo teórico no qual o modelo proposto foi baseado, foram incluídas outras variáveis disponíveis na PNS 2013 que não estavam presentes no estudo original, que apresentaram relação com a assistência pré-natal conforme levantamento bibliográfico realizado, como a autoavaliação do estado da saúde, com a vantagem de poderem ser analisadas com os dados da amostra de representatividade nacional do estudo.

A proposta de modelo teórico de fatores de risco e associados para desfecho assistência pré-natal (Figura 2) segue: 
Figura 2. Proposta de modelo de fatores de risco e associados para desfecho Assistência prénatal.

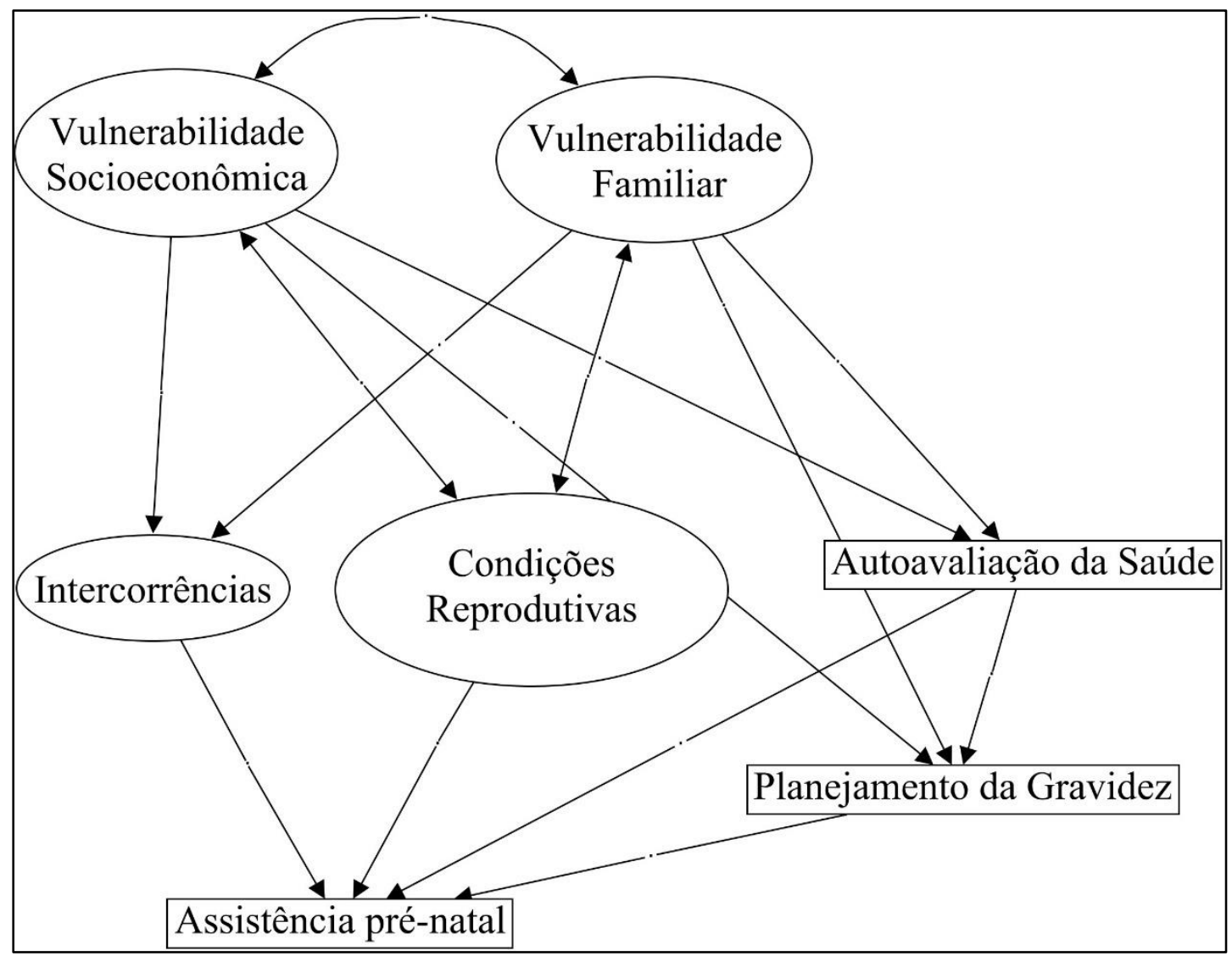

\subsection{Variáveis de estudo}

O modelo teórico (Figura 2) foi proposto contando com variáveis latentes e observadas. As variáveis latentes seguiram o formato reflexivo, conforme o modelo de referência (OLIVEIRA, 2014). A seguir, são descritas as variáveis:

Variáveis latentes: Vulnerabilidade Socioeconômica: número de pessoas por cômodo, renda média domiciliar per capita, escolaridade do responsável pelo sustento familiar no domicílio (Superior Completo; Superior incompleto ou equivalente; Médio completo ou equivalente; Médio incompleto ou equivalente; 
Fundamental completo ou equivalente; Fundamental incompleto ou equivalente; Sem instrução), escolaridade da mãe (Superior Completo; Superior incompleto ou equivalente; Médio completo ou equivalente; Médio incompleto ou equivalente; Fundamental completo ou equivalente; Fundamental incompleto ou equivalente; Sem instrução); Vulnerabilidade Familiar: tipo de família/família nuclear (sim/não), presença de morador com 60 anos ou mais no domicílio (sim/não), mãe do recém-nascido responsável pelo sustento familiar do domicílio (sim/não); Intercorrências: Hipertensão arterial (sim/não), diabetes (sim/não); Condições reprodutivas: idade da mãe igual ou superior a 35 anos ou igual ou inferior a 18 anos (sim/não), nascidos vivos pré-termo anteriores (sim/não), nascidos vivos com baixo peso ao nascer anteriores (sim/não), número de partos anteriores; Inadequação da assistência pré-natal, índice de Silva: formada por variáveis definidas a partir do trabalho de SILVA (2008): Mês de início do pré-natal, número de consultas de pré-natal, realizado exame de urina (sim/não), realizado exame de sangue (sim/não), realizado exame de ultra-sonografia (sim/não), mensuração da altura uterina (sim/não), ausculta dos batimentos cardio-fetais (sim/não), verificação do peso da gestante (sim/não), medida da pressão arterial da gestante ( $\operatorname{sim} /$ não), recebeu orientação sobre sinais de alerta na gestação (sim/não), recebeu orientação de como identificar início do trabalho de parto (sim/não). Variáveis observadas: autoavaliação da saúde (Muito bom; Bom; Regular; Ruim; Muito Ruim), planejamento da gravidez (sim/não), desfecho Inadequação da assistência pré-natal (sim/não) - medido através dos índices "PHPN simples" (SUCCI, 2008), “Takeda” (TAKEDA, 1993), "Silva” (SILVA, 2008) e "realização de menos de sete consultas de pré-natal”. 
As variáveis foram criadas a partir do questionário da PNS 2013, conforme explicitado no Quadro 2:

Quadro 2. Variáveis criadas e variáveis originais da PNS 2013.

\begin{tabular}{|c|c|}
\hline Variável criada & Variáveis da PNS de 2013 envolvidas em sua criação \\
\hline $\begin{array}{l}\text { Número de pessoas por cômodo servindo de } \\
\text { dormitório }\end{array}$ & v0022, a011 \\
\hline Renda média domiciliar per capita em reais & $\begin{array}{l}\text { e01602, e01604, e01802, e01804, f00102, f00702, } \\
\text { f00802, vdf00102, v0022 }\end{array}$ \\
\hline $\begin{array}{l}\text { Escolaridade do responsável pelo sustento } \\
\text { familiar no domicílio }\end{array}$ & vdd004, c004 \\
\hline Escolaridade da mãe & vdd004 \\
\hline Família/família nuclear (sim/não) & $\mathrm{c} 004, \mathrm{c} 006$ \\
\hline $\begin{array}{l}\text { Presença de morador com } 60 \text { anos ou mais no } \\
\text { domicílio (sim/não) }\end{array}$ & $\mathrm{c} 008$ \\
\hline $\begin{array}{l}\text { Mãe responsável pelo sustento familiar do } \\
\text { domicílio (sim/não) }\end{array}$ & $\mathrm{c} 004$ \\
\hline Hipertensão arterial (sim/não) & $\mathrm{s} 015$ \\
\hline Diabetes (sim/não) & $\mathrm{s} 021$ \\
\hline $\begin{array}{l}\text { Idade da mãe igual ou superior a } 35 \text { anos ou } \\
\text { igual ou inferior a } 18 \text { anos (sim/não) }\end{array}$ & $\mathrm{c} 008$ \\
\hline Filho pré-termo anterior (sim/não) & $\mathrm{r} 048$ \\
\hline $\begin{array}{l}\text { Filho com baixo peso ao nascer anterior } \\
(\operatorname{sim} / \text { não })\end{array}$ & r047 \\
\hline Multiparidade (sim/não) & $\mathrm{r} 043$ \\
\hline Autoavaliação da saúde & $\mathrm{n} 001$ \\
\hline $\begin{array}{l}\text { Adequação da assistência pré-natal } \\
\text { (diferentes métodos) }\end{array}$ & $\begin{array}{l}\text { s003, s004, s035, s020, s037, s01404, s01403, s01402, } \\
\text { s01401, s01102, s01101, s027, s033 }\end{array}$ \\
\hline Planejamento da da gravidez (sim/não) & $\mathrm{r} 035, \mathrm{r} 037, \mathrm{r} 042$ \\
\hline
\end{tabular}

Os módulos "R - Saúde da Mulher" e "S - Atendimento Pré-natal" da PNS 2013 completos contendo informações mais detalhadas sobre as variáveis utilizadas na análise estão no Anexo C. 
As análises estatísticas descritivas e analíticas foram realizadas com o software STATA 12 e a modelagem de equações estruturais foi realizada com o software Mplus versão 7.2.

\subsection{Procedimentos e análise dos dados}

A seguir, foram elencados os procedimentos realizados na análise:

1. Análise descritiva da distribuição da população de estudo na PNS 2013.

2. Avaliação do uso da variável idade gestacional coletado pela PNS 2013.

3. Levantamento de índices empregados em estudos brasileiros.

4. Descrição dos índices identificados com possibilidade de cálculo para os dados da pesquisa.

5. Elaboração de estatísticas descritivas para variáveis de interesse da PNS 2013.

6. Estimativa dos modelos de equações estruturais iniciais e seleção de variáveis para modelos finais.

7. Estimativa dos modelos finais:

- Para o desfecho inadequação do pré-natal obtido por diferentes índices, com e sem aplicação de peso amostral, e com os estimadores WLSMV e MLR;

- Estimativa do modelo com o desfecho como variável latente;

- Estimativa dos modelos separados segundo a assistência: SUS e não-SUS.

Foram comparados os índices por meio de tabelas cruzadas e testes estatísticos apropriados, como o teste de Qui-quadrado de Pearson, para verificar associações entre 
as variáveis; foi realizada análise bivariada para obter os efeitos, por meio do cálculo da odds-ratio (OR), das variáveis que estão possivelmente associadas ao desfecho adequação pré-natal (PEREIRA, 2010).

Há divergências na literatura sobre o emprego ou não dos pesos em estudos como a PNS 2013 para análises inferenciais (CIOL et al., 2006). Estudos realizados com a Pesquisa Nacional por Amostra de Domicílios (PNAD) (metodologia semelhante à da PNS) sugerem o emprego dos pesos amostrais em análises realizadas (DO NASCIMENTO SILVA et al., 2002). Entretanto, a não consideração no processo de amostragem dos totais da população alvo em análises específicas, poderia levar a problemas na estimação dos parâmetros de interesse (CIOL et al., 2006) ao se aplicar os pesos amostrais. Como a pesquisa não avaliou diretamente a população de mães, optou-se por apresentar as análises finais com modelos com e sem a aplicação de pesos amostrais.

\subsection{Modelos de Equações Estruturais}

Foi utilizada uma abordagem confirmatória, com emprego de análise fatorial confirmatória (AFC), a partir do modelo teórico proposto na construção de variáveis latentes, levando em consideração o número de dimensões e respectivos itens (MUTHÉN e MUTHÉN, 2010).

Foram construídos, depois de estabelecidas as variáveis latentes, modelos de equações estruturais (MEE) para o desfecho de inadequação da assistência pré-natal. O ajuste do modelo é verificado por meio de índices de ajuste: de Tucker-Lewis (TLI) (referência de bom ajuste TLI >0,95), índice de ajustamento comparativo (CFI) (referência >0,95), raiz do erro quadrático médio de aproximação (RMSEA) 
(referência $<0,05$ ), e raiz do resíduo quadrático médio ponderado (Weighted Root Mean Square Residual, WRMR) (referência <0,90; sendo que YU e MUTHÉN (2002) ressaltam que valores próximos de 1 são mais razoáveis para respostas binárias). É desejável também que não haja variância negativa dos resíduos, pois podem indicar uma má especificação do modelo (HU e BENTLER, 1999). Para se estabelecer um modelo melhor ajustado, foram utilizados índices de modificação que representam a variação da estatística Qui-quadrado quando se incluem novos parâmetros a serem estimados pelo modelo (SCHUMACKER e LOMAX, 2004). Maiores valores do índice de modificação indicam maior variação no valor do Qui-quadrado e, consequentemente, no seu ajuste. Todas as relações do modelo foram tratadas como estatisticamente significantes ao nível de 5\%. Foram considerados para as análises modelos separados com estimadores Mean and Variance Adjusted Weighted Least Squares (WLSMV) e Robust Maximum Likelihood (MLR), com intuito de verificar a consistência, a partir da verificação de diferenças e semelhanças com os estimadores, dos valores e efeitos obtidos (LI, 2014).

\subsection{Aspectos éticos}

A Pesquisa Nacional de Saúde 2013 foi aprovada pela Comissão Nacional de Ética em Pesquisa (CONEP) em junho de 2013, pelo parecer $n^{\circ} 328.159$, de 26 de junho de 2013, levando em conta todas as recomendações da Resolução 466/2012 do Conselho Nacional de Saúde. Os microdados da pesquisa são públicos e disponibilizados no site do IBGE.

Esse estudo foi aprovado pelo Comitê de Ética em Pesquisa da Faculdade de Saúde Pública sob o número 2.454.986 (Anexo A). 


\section{Resultados}

4.1 Representatividade da amostra do módulo S da PNS 2013

É constatada na Figura 3 a representatividade da amostra do módulo S da PNS 2013, composta de mães brasileiras com último parto entre 2011 e 2013, segundo Unidades da Federação de residência, quando comparada às distribuições dos Nascidos Vivos (segundo residência) de 2011 a 2013 obtidas pelo Sistema de Informações sobre Nascidos Vivos (SINASC/DATASUS), apresentando valores semelhantes:

Figura 3. Mapas temáticos - (1) Distribuição percentual de mães brasileiras com último parto entre 2011 e 2013 segundo Unidade da Federação de Residência. Calculado com peso amostral. PNS, 2013. (2) Distribuição percentual de nascimentos vivos segundo Unidade da Federação de Residência. Brasil, 2011-2013.
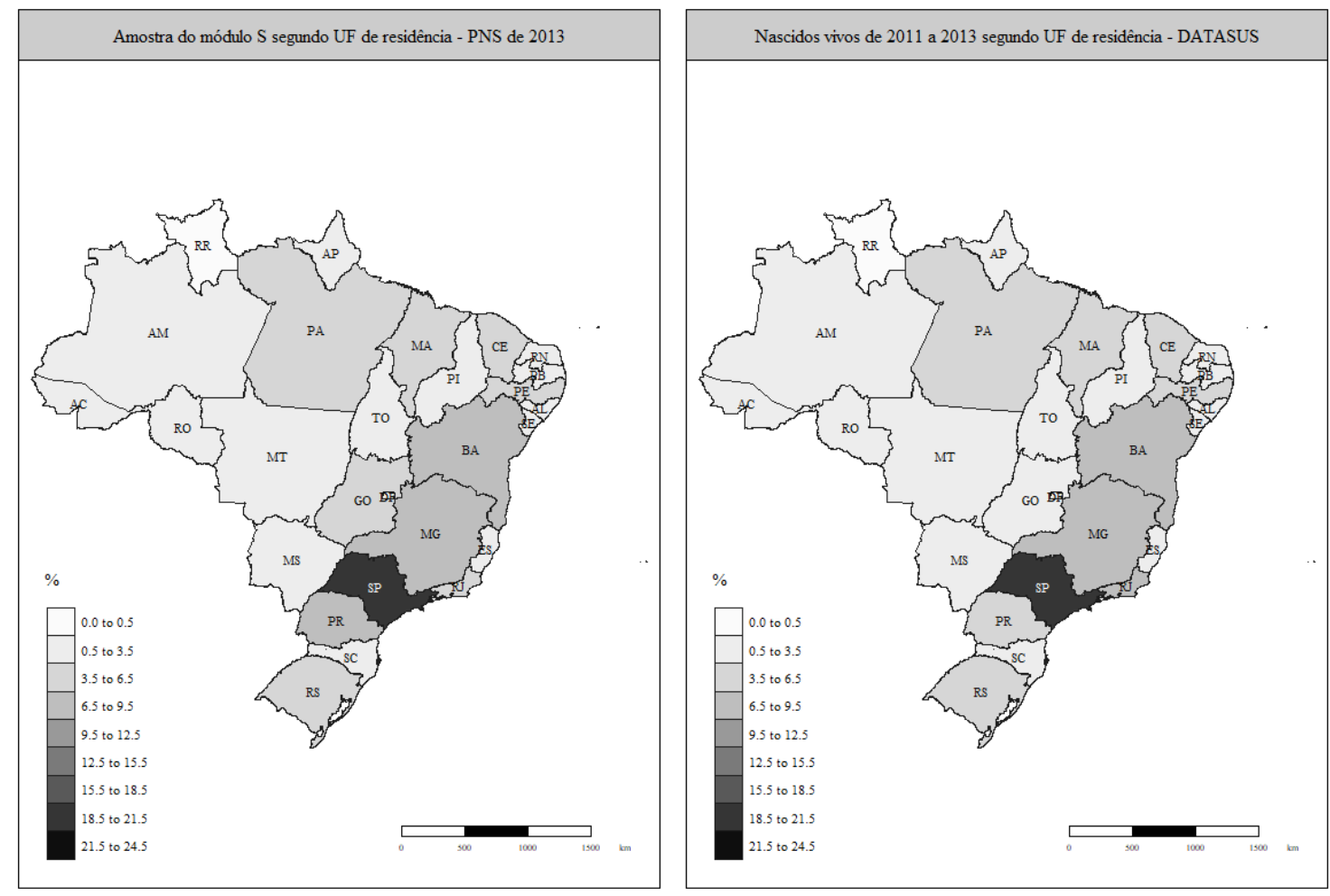

Fonte: PNS 2013/IBGE e DATASUS. 
Foi constatado que não seria possível criar importantes variáveis de avaliação da assistência pré-natal (como o índice de Kotelchuck) como pretendido inicialmente devido à não-divulgação (e confirmação posterior do IBGE de que a não-divulgação é definitiva) das variáveis "s059 - idade gestacional autorreferida" e "s060 - Peso do recém-nascido" do módulo "S - Atendimento Pré-natal" devido a problemas na etapa capitação/coleta, o que também impossibilita o cálculo da variável "nascimento prétermo" como variável de desfecho.

A Tabela 1 apresenta estimativas das distribuições de nascimentos pré-termos segundo variáveis disponíveis na PNS 2013 em comparação com as distribuições obtidas pelo SINASC, para os períodos 2012 e 2013, apenas 2012 e apenas 2013; para todas as mães e apenas as primíparas.

Foi considerado que, apesar de ser possível a obtenção da variável idade gestacional indiretamente através de outras variáveis da PNS 2013, não houve validade das estimativas para serem consideradas nas análises, considerando as elevadas variações percentuais entre as medidas. A prematuridade em 2012, por exemplo, estimada por variáveis da PNS 2013 foi de 27,50\% (IC95\% 23,0\%-32,6\%), valor $120,0 \%$ mais elevado em comparação à prematuridade obtida pelo SINASC $(12,50 \%)$. Também há, subsequentemente, importante perda de observações da amostra em decorrência da aplicação de restrições, sendo que a variável estimada para nascimentos pré-termos de primíparas em 2012 estaria disponível para apenas 12,43\% da amostra de mães brasileiras com último parto entre 2011 e 2013 sem aplicação de peso amostral (correspondentes a 13,89\% com peso amostral). 
Tabela 1. Frequências relativas de nascimentos pré-termo. SINASC e variáveis derivadas PNS 2013 (calculadas com peso amostral) e amostra de mães com último parto entre $2011 \mathrm{e}$ 2013 e população representada pela amostragem complexa. Brasil, 2012-2013.

\begin{tabular}{|c|c|c|c|c|c|c|c|}
\hline $\begin{array}{l}\text { Variáve is criadas* para es timar } \\
\text { prematuridade }\end{array}$ & $\begin{array}{l}\text { PNS } \\
2013 \\
(\%)\end{array}$ & $\begin{array}{l}\text { SINASC } \\
(\%)\end{array}$ & $\begin{array}{c}\text { Variação } \\
(\%)\end{array}$ & $\begin{array}{l}\text { N amostral } \\
\text { PNS 2013 }\end{array}$ & $\begin{array}{c}\% \text { da } \\
\text { amostra }\end{array}$ & $\begin{array}{c}\text { População } \\
\text { representada** }\end{array}$ & $\begin{array}{l}\% \text { da pop. } \\
\text { representada** }\end{array}$ \\
\hline 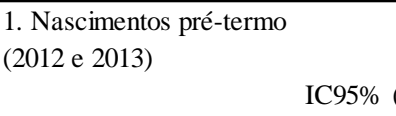 & $\begin{array}{r}24,30 \\
(20,9-28,1)\end{array}$ & 12,21 & 99,08 & 1337 & 72,23 & 2.874 .303 & 75,26 \\
\hline $\begin{array}{l}\text { 2. Nascimentos pré-termo } \\
\text { (2012) } \\
\text { IC } 95 \%\end{array}$ & $\begin{array}{r}27,50 \\
(23,0-32,6)\end{array}$ & 12,50 & 120,00 & 834 & 45,06 & 1.805 .596 & 47,28 \\
\hline $\begin{array}{l}\text { 3. Nascimentos pré-termo } \\
\text { (2013) } \\
\text { IC } 95 \%\end{array}$ & $\begin{array}{r}19,00 \\
(14,6-24,3)\end{array}$ & 11,95 & 59,00 & 503 & 27,17 & 1.068 .707 & 27,98 \\
\hline $\begin{array}{l}\text { 4. Nascimentos pré-termo em } \\
\text { primíparas (2012 e 2013) } \\
\text { IC } 95 \%\end{array}$ & $\begin{array}{r}17,70 \\
(13,1-23,4)\end{array}$ & 12,31 & 43,76 & 673 & 36,36 & 1.475 .310 & 38,63 \\
\hline $\begin{array}{l}\text { 5. Nascimentos pré-termo em } \\
\text { primíparas (2012) } \\
\text { IC } 95 \%\end{array}$ & $\begin{array}{r}23,20 \\
(14,4-35,1)\end{array}$ & 12,10 & 91,74 & 230 & 12,43 & 530.579 & 13,89 \\
\hline $\begin{array}{l}\text { 6. Nascimentos pré-termo em } \\
\text { primíparas (2013) } \\
\text { IC } 95 \%\end{array}$ & $\begin{array}{r}14,60 \\
(9,8-21,0)\end{array}$ & 12,56 & 16,21 & 443 & 23,93 & 944.732 & 24,74 \\
\hline Total & . & - & - & 1851 & 100,00 & 3.818 .936 & 100,00 \\
\hline
\end{tabular}

Fonte: DATASUS e PNS 2013/IBGE.

*As variáveis que possibilitaram tabular a frequência de "Nascimentos pré-termo" 2012 e 2013, 2012 e 2013 foram variáveis derivadas calculadas através das variáveis da PNS: "s042 - Intervalo de tempo entre o parto e a última consulta de pré-natal realizada", s043 Idade gestacional em semanas na última consulta de pré-natal", "r045 - número de nascidos vivos", "r043 - número de partos"; essas variáveis representam, na verdade, os nascimentos pré-termo de gestantes que realizaram ao menos uma consulta de pré-natal (durante a gestação mais recente) e cujos produtos de todas as gestações que vieram a parto foram nascidos vivos. Foi considerada "limpeza" de observações com valores para variável "Idade gestacional na última consulta" menores de 23 e maiores que 44 semanas, o que reduziu muito o número de gestantes da amostra e não foi aplicado.

As variáveis que possibilitaram tabular a frequência de "Nascimentos pré-termo de gestantes primíparas" foram variáveis derivadas calculadas através das variáveis da PNS: "r043 - número de partos", "r045 - número de nascidos vivos", "r048 - número de nascidos vivos que nasceram pré-termos" e "observação presente no módulo S (representado por 'observação com valor presente para variáveis do módulo S, como s042) - exprimindo que o último parto foi realizado de 28/07/2011 a 27/07/2013”.

**População representada pela amostra da PNS 2013 com aplicação do peso amostral da pesquisa.

\subsection{Principais índices usados em estudos brasileiros}

Para determinação dos principais métodos quantitativos para avaliação da assistência pré-natal empregados em estudos epidemiológicos brasileiros foi realizado um levantamento bibliográfico de estudos brasileiros que envolveram a avaliação da assistência pré-natal e foi realizada uma classificação desses artigos (anexo B) segundo 
ano, fonte dos dados, critério que o método empregado utilizou para classificar a adequação da assistência pré-natal, qual aspecto da assistência é abordada pelo método, a origem do método (se foi usada metodologia disponível, desenvolvido novo método, etc.), se seria possível calculá-lo a partir das variáveis da PNS, covariáveis da análise, tipo de análise empregada, tamanho da amostra e resultados. O levantamento foi realizado na base Lilacs em outubro de 2016 com os descritores "cuidado pré-natal" e "avaliação". Dos 109 estudos identificados no período de 2001 a 2015, 24 foram selecionados e foram considerados na classificação, sendo que, em primeiro momento, 10 foram classificados como tendo empregado métodos baseados nas recomendações do PHPN, 4 com modificações de índices de utilização da assistência, 4 com diferentes métodos empregados simultaneamente e 2 como tendo empregado apenas o número de consultas na avaliação (Tabela 2).

Em relação a viabilidade de cálculo do método empregado com os dados da PNS, 15 dos 24 estudos apresentaram métodos que seriam possíveis de serem calculados.

Tabela 2. Classificação dos estudos nacionais selecionados no levantamento realizado segundo método quantitativo empregado para avaliação da assistência pré-natal.

\begin{tabular}{lrr}
\hline Método utilizado para avaliar pré-natal & n & \% \\
\hline Baseado nas recomendações do PHPN (qualidade) & & \\
PHPN completo & 6 & 25,0 \\
PHPN incompleto & 4 & 16,7 \\
& & \\
Índices de Utilização (acesso) & 4 & 16,7 \\
Índices de Utilização sem modificações & 4 & 16,7 \\
Modificações de Índices de Utilização & & \\
& 2 & 8,3 \\
Realização de 7 ou mais consultas de pré-natal (cobertura) & 4 & 16,7 \\
Múltiplos métodos simultaneamente & $\mathbf{2 4}$ & $\mathbf{1 0 0 , 0}$ \\
\hline Total
\end{tabular}




\subsubsection{Descrição dos índices de adequação da assistência pré-natal}

\subsubsection{1 Índice de adequação/qualidade da assistência pré-natal PHPN Simples}

O Quadro 3 apresenta as variáveis que compõem o índice de qualidade da assistência pré-natal "PHPN - Simples", descrito no estuo de SUCCI et al. (2008). A Tabela 3 apresenta a distribuição relativa com uso de peso amostral das mães brasileiras da amostra com último parto entre 2011 e 2013 segundo a qualidade da assistência pré-natal medido pelo índice descrito:

Quadro 3. Variáveis usadas para construção do índice "PHPN - Simples", aplicado no estudo de SUCCI et al. (2008).

\begin{tabular}{l}
$\begin{array}{l}\text { Variáveis para construção do índice de "Qualidade do pré-natal", PHPN } \\
\text { simples*: }\end{array}$ \\
\hline Início do prénatal (adequado** - até o $3^{\circ}$ mês gestacional); \\
Número de consultas de pré-natal (adequado - 6 ou mais) \\
Realização de exames sorológicos para sífilis (VDRL) (adequado - 2 ou mais \\
exames); \\
Realização de exame sorológico para o vírus da imunodeficiência humana - \\
HIV (adequado - 1 ou mais); \\
*Método descrito por Succi et al. (2008). \\
**Foi considerado "Adequado" o pré-natal com respostas positivas para todas \\
as medidas.
\end{tabular}

Tabela 3. Distribuição de mães brasileiras da amostra com último parto entre 2011 e 2013 segundo qualidade da assistência pré-natal (método PHPN simples). Calculado com peso amostral. PNS, 2013.

\begin{tabular}{lcc}
\hline $\begin{array}{l}\text { Qualidade da assistência } \\
\text { pré-natal - PHPN simples }\end{array}$ & $\%$ & IC(95\%) \\
\hline Adequada & $59,25(55,5-62,9)$ \\
Inadequada & $40,75(37,1-44,6)$ \\
\hline Total & 100,00 \\
\hline
\end{tabular}

Ao comparar, na Figura 4, a qualidade da assistência medida pelo método "PHPN simples" à cobertura da assistência pré-natal (proporção de gestantes com 7 
ou mais consultas de pré-natal) no País, são verificados mais elevados percentuais de cobertura da assistência em relação aos de qualidade. Também são verificadas diferenças regionais, sendo que Estados das regiões Sul e Sudeste apresentam, em geral, percentuais mais elevados de cobertura e de qualidade da assistência.

Figura 4. Mapas temáticos - (1) Percentual de mães brasileiras com último parto entre 2011 e 2013 que realizaram 7 ou mais consultas de pré-natal (cobertura) por Unidade da Federação de Residência. Calculado com peso amostral. PNS, 2013. (2) Percentual de mães brasileiras com último parto entre 2011 e 2013 que receberam uma assistência pré-natal adequada segundo método "PHPN simples" (qualidade) por Unidade da Federação de Residência. Calculado com peso amostral. PNS, 2013.
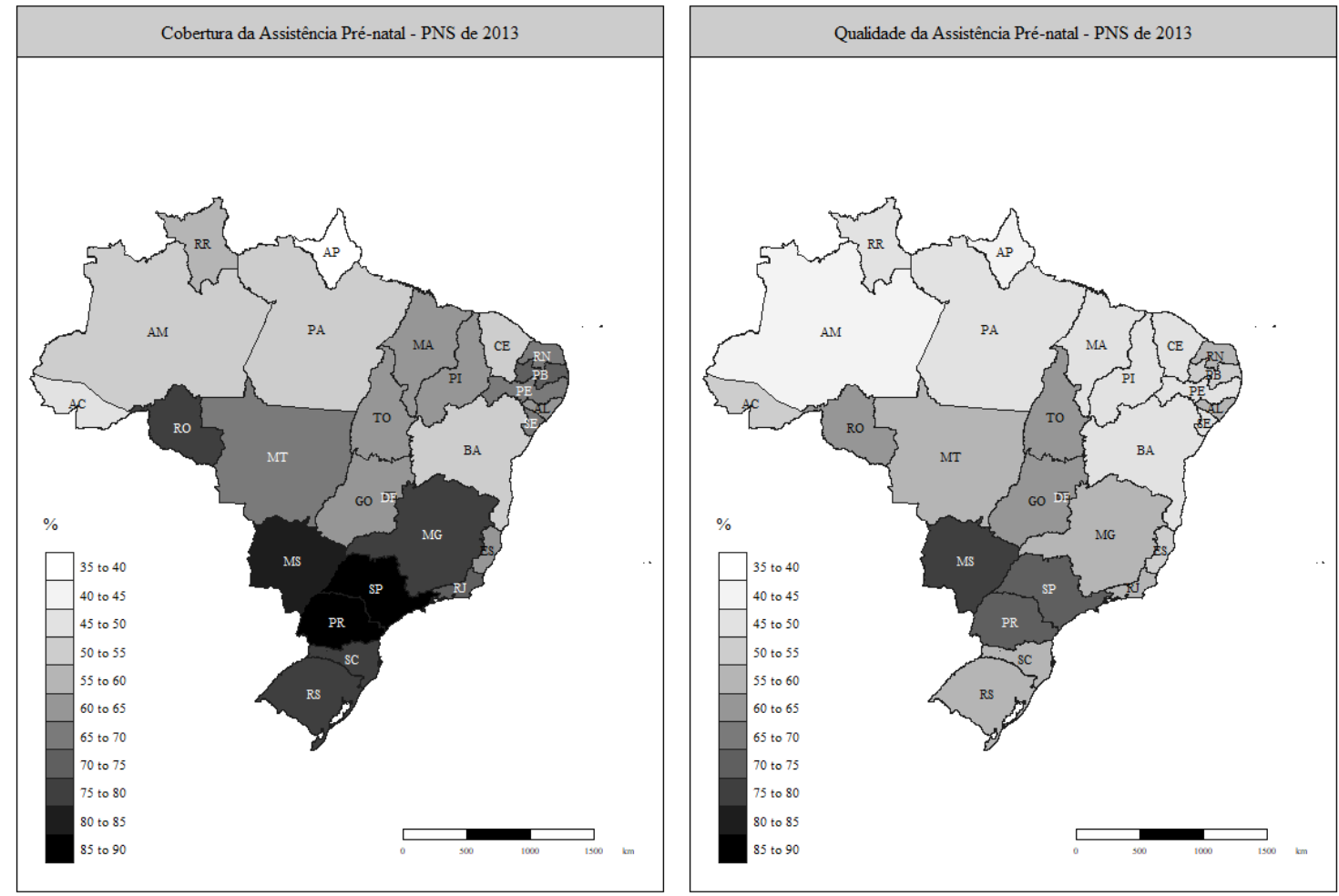

\subsubsection{Outros índices de adequação da assistência pré-natal}

Por conta da não divulgação da variável de idade gestacional do módulo S na PNS 2013 (por conta de falta de validade, como mencionado anteriormente), não foi possível calcular todos os métodos de avaliação da assistência pré-natal encontrados 
no levantamento de estudos realizado, em especial, os índices que mensuram a adequação da utilização do pré-natal que consideram, em sua maior parte, a relação entre as consultas realizadas e as que seriam esperadas para determinada idade gestacional.

Assim, com essa limitação, foram selecionados três índices para estimar adequação da assistência pré-natal além do "PHPN - simples" (Quadro 3), que puderam ser calculados com os dados disponíveis da PNS 2013: a) O índice de Takeda (1993) (Quadro 4), que considera o número de consultas de pré-natal realizadas e mês gestacional de início do pré-natal (o índice foi proposto como uma modificação do índice de Kessner); b) o índice de Silva (2008) (Quadro 5), que considera em sua composição 11 itens do conteúdo das consultas de pré-natal além do mês gestacional de início da assitência e número de consultas; c) a realização de menos de sete consultas de pré-natal (BRASIL, 2004).

Quadro 4. Variáveis usadas para construção do índice de Takeda de adequação da utilização da assistência pré-natal, aplicada no estudo de TAKEDA (1993).

Variáveis para construção do índice de Takeda* de adequação da utilização do pré-natal: Início do pré-natal (adequado** - até o $4^{\circ}$ mês gestacional);

Número de consultas de pré-natal (adequado - 6 ou mais);

*Método descrito por Takeda (1993).

**Foi considerado "Adequado" o pré-natal com respostas positivas para todas as medidas. 
Quadro 5. Variáveis usadas para construção do índice de Silva de qualidade do pré-natal, aplicado no estudo de SILVA (2008).

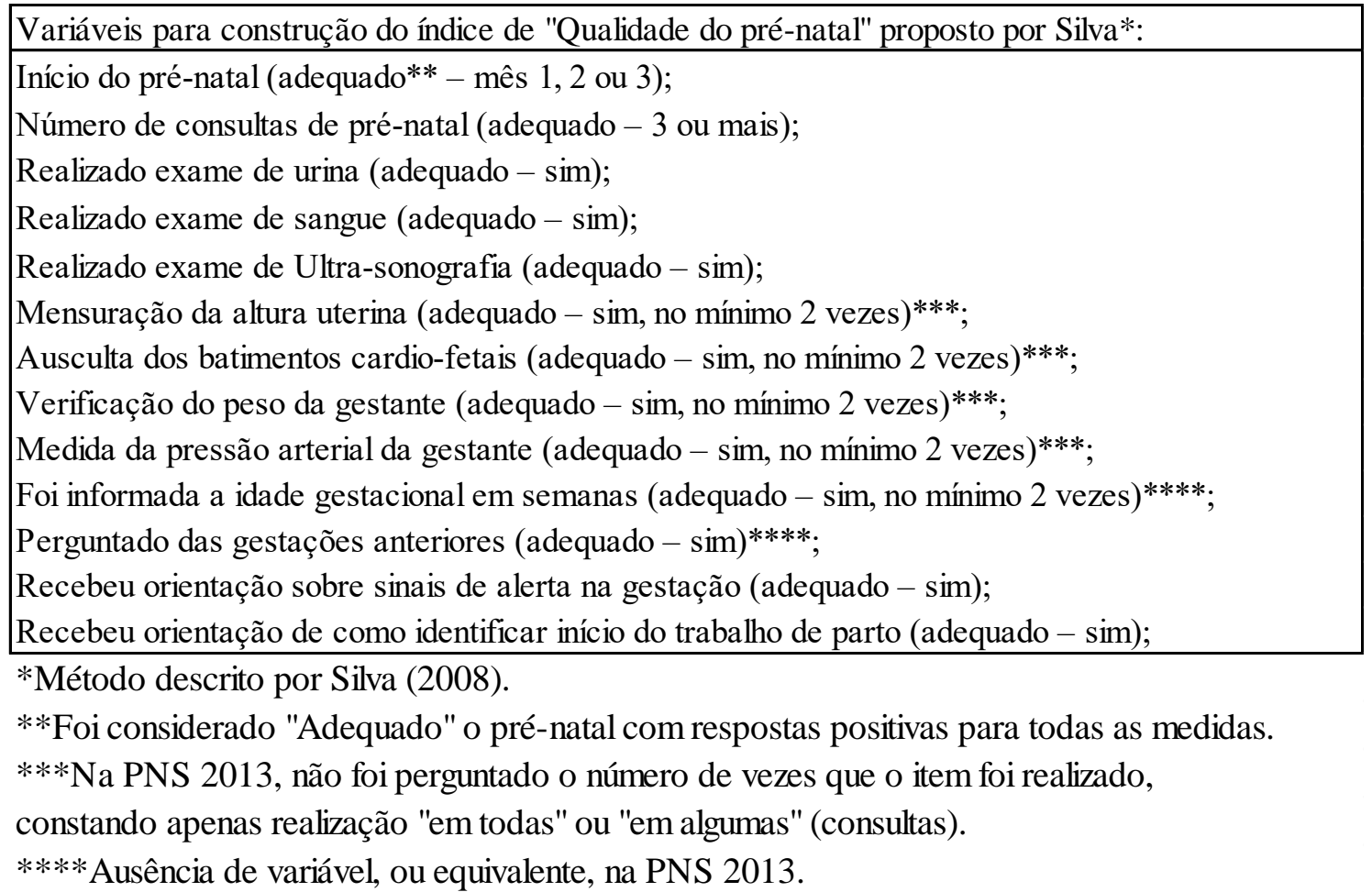

Ao comparar as distribuições percentuais das mães brasileiras segundo os quatro desfechos - "PHPN simples", "Takeda", "Silva" e "menos de sete consultas" (Tabela 4), foi verificado que há variações importantes na classificação das mães nas categorias de pré-natal "Adequado" e "Inadequado". Comparando as distribuições das mães que foram classificadas na categoria de pré-natal "Adequado", tomando como referência da comparação o índice "PHPN simples" (59,25\%; IC95\% 55,5\%-62,9\%), o "índice de Silva" (54,21\%; IC95\% 50,4\%-58,0\%), que também estima adequação da qualidade da assistência pré-natal, apresentou menor variação (e negativa) de -8,51\%, além de sobreposição do intervalo de confiança $95 \%$, enquanto a comparação com o "índice de Takeda" (80,41\%; IC95\% 77,3\%-83,2\%), que estima adequação da utilização da assistência, revelou uma variação maior (e positiva) de 35,70\%, e não sobreposição dos intervalos de confiança 95\%; a comparação com a "realização de menos de sete consultas" (72,20\%; IC95\% 68,8\%-75,4\%) também apresentou uma 
variação maior (e positiva) de 21,8\%, e não sobreposição dos intervalos de confiança $95 \%$.

Tabela 4. Distribuições percentuais de mães brasileiras de 2011 a 2013 segundo adequação da assistência pré-natal e índice de avaliação. Calculado com peso amostral. PNS, 2013.

\begin{tabular}{|c|c|c|c|c|c|}
\hline \multirow{2}{*}{$\begin{array}{l}\text { Índice de avaliação da } \\
\text { assistência pré-natal }\end{array}$} & \multicolumn{4}{|c|}{ Adequação (\%) } & \multirow[b]{2}{*}{ Total } \\
\hline & Adequado & IC95\% & Inadequado & IC95\% & \\
\hline PHPN simples & \multirow{2}{*}{\multicolumn{2}{|c|}{$\begin{array}{l}59,25(55,5-62,9) \\
\text { referência }\end{array}$}} & \multicolumn{2}{|c|}{$40,75(37,1-44,6)$} & 100,00 \\
\hline variação (\%) & & & \multicolumn{2}{|c|}{ referência } & \\
\hline Takeda & \multicolumn{2}{|c|}{$80,41(77,3-83,2)$} & \multicolumn{2}{|c|}{$19,59(16,8-22,7)$} & 100,00 \\
\hline variação (\%) & \multicolumn{2}{|l|}{35,71} & \multicolumn{2}{|l|}{$-51,93$} & \\
\hline Silva & \multicolumn{2}{|c|}{$54,21(50,4-58,0)$} & \multicolumn{2}{|c|}{$45,79(42,0-49,6)$} & 100,00 \\
\hline variação (\%) & \multicolumn{2}{|c|}{$-8,51$} & \multicolumn{2}{|l|}{12,37} & \\
\hline Menos de sete consultas & \multicolumn{2}{|c|}{$72,20(68,8-75,4)$} & \multicolumn{2}{|c|}{$27,80(24,6-31,2)$} & 100,00 \\
\hline variação (\%) & \multicolumn{2}{|l|}{21,86} & $-31,78$ & & \\
\hline
\end{tabular}

\subsection{Autoavaliação da saúde e maternidade}

A variável autoavaliação da saúde foi incluída na modelagem após a realização de comparações para verificar a presença de indícios, com os dados da PNS 2013, de diferenças na autoavaliação da saúde de mulheres conforme a presença de história reprodutiva.

Ao comparar o grupo de mulheres sem história reprodutiva, grupo de referência da Tabela 5, ao grupo de mulheres com história reprodutiva, é verificado que, em geral, para todas as faixas etárias, proporções maiores de mulheres que avaliam sua saúde como "Muito boa" e "Boa" e menores das que a avaliam como "Ruim" e "Muito Ruim" no primeiro grupo. Também é verificado que no grupo de avaliação "Muito boa" apenas o intervalo de confiança 95\% da faixa etária "18 a 29 anos" não apresenta sobreposição em relação ao intervalo de referência do grupo de mulheres sem história reprodutiva, enquanto no grupo "Boa" apenas o da faixa etária "40 a 49 anos"; no grupo 
"Regular" nenhum dos intervalos dos grupos se sobrepõem, na categoria "Ruim" o intervalo da faixa de "18 a 29" não se sobrepõe e no grupo "Muito ruim" todos os intervalos de todas as faixas se sobrepõem.

Entretanto, quando o grupo de mulheres com história reprodutiva é dividido entre "recente (2011 a 2013)" e "anterior (antes de 2011)", são verificadas diferenças, sendo que o grupo com história reprodutiva recente das faixas etárias de 30 a 39 e 40 a 49 anos apresenta proporções maiores de mulheres que avaliam sua saúde como "Muito boa" e "Boa" e menores proporções de mulheres que avaliam sua saúde como "Ruim" e "Muito Ruim", em relação às mulheres sem história reprodutiva, apesar da maioria dos intervalos de confiança 95\% se sobrepor em relação aos intervalos de referências do grupo de mulheres sem história reprodutiva, com exceção para a faixa etária de "18 a 29 anos", em que não há sobreposição do intervalo na categoria "Muito boa".

Já o grupo com história reprodutiva anterior apresentou variações percentuais menores de mulheres que avaliam sua saúde como "Muito boa" e "Boa" e maiores variações percentuais de mulheres que avaliam sua saúde como "Regular", "Ruim" e "Muito Ruim", comparadas às do grupo de mulheres sem história reprodutiva, sendo que no grupo de avaliação "Muito boa" apenas o intervalo de confiança 95\% da faixa etária de "18 a 19 anos" não apresenta sobreposição em relação ao intervalo de referência do grupo de mulheres sem história reprodutiva, enquanto no grupo "Boa" apenas o intervalo da faixa de "40 a 49 anos" e no grupo "Regular" nenhum dos intervalos dos grupos se sobrepõem; na categoria "Ruim" apenas o intervalo da faixa etária de "18 a 29" não se sobrepõe e no grupo "Muito ruim" também. 
Tabela 5. Distribuição percentual de mulheres brasileiras segundo história reprodutiva, faixa etária e autoavaliação da saúde. Calculado com peso amostral. PNS, 2013.

\begin{tabular}{|c|c|c|c|c|c|c|c|c|c|c|}
\hline \multirow{2}{*}{$\begin{array}{c}\text { Faixa Etária } \\
\text { / Grupo }\end{array}$} & \multicolumn{10}{|c|}{ Autoavaliação da Saúde } \\
\hline & Muito boa & variação (\%) & Boa & variação (\%) & Regular & variação (\%) & Ruim & variação $(\%)$ & Muito Ruim & ação (\%) \\
\hline \multicolumn{11}{|c|}{ Mulheres sem história reprodutiva } \\
\hline 18 a 29 & 19,36 & referência & 61,99 & referência & 17,6 & referência & 0,94 & referência & 0,12 & referência \\
\hline IC95\% & $(17,1-21,8)$ & \multicolumn{2}{|c|}{ 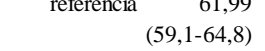 } & \multicolumn{2}{|c|}{$(15,5-19,9)$} & \multicolumn{2}{|c|}{$(0,6-1,4)$} & \multicolumn{3}{|c|}{$(0,0-0,3)$} \\
\hline 30 a 39 & 17,77 & referência & 60,84 & referência & 18,44 & referência & 2,12 & referência & 0,83 & \multirow[t]{2}{*}{ referência } \\
\hline IC95\% & $(14,4-21,8)$ & \multicolumn{2}{|c|}{$(56,2-65,3)$} & \multicolumn{2}{|c|}{$(15,3-22,1)$} & \multicolumn{2}{|c|}{$(1,3-3,5)$} & \multicolumn{2}{|r|}{$(0,2-2,9)$} & \\
\hline 40 a 49 & 12,89 & referência & 58,26 & referência & 23,12 & referência & 5,03 & referência & 0,7 & referência \\
\hline IC95\% & $(9,7-17,0)$ & \multicolumn{2}{|c|}{$(52,6-63,7)$} & \multicolumn{2}{|c|}{$(18,9-28,0)$} & \multicolumn{2}{|c|}{$(3,2-7,8)$} & \multicolumn{3}{|c|}{$(0,3-1,6)$} \\
\hline Total & 18,19 & referência & 61,26 & referência & 18,48 & referência & 1,71 & referência & & \multirow[t]{2}{*}{ referência } \\
\hline IC95\% & $(16,5-20,1)$ & \multicolumn{2}{|c|}{$(59,0-63,5)$} & \multicolumn{2}{|c|}{$(16,8-20,3)$} & \multicolumn{2}{|c|}{$(1,3-2,2)$} & \multicolumn{2}{|r|}{$(0,2-0,7)$} & \\
\hline \multicolumn{11}{|c|}{ Mulheres com história reprodutiva** } \\
\hline 18 a 29 & 13,03 & $-32,7$ & 61,4 & $-1,0$ & 22,88 & 30,0 & 2,23 & 137,2 & 0,47 & 291,7 \\
\hline IC95\% & $(11,3-14,9)^{*}$ & \multicolumn{2}{|c|}{$(58,4-64,3)$} & \multicolumn{2}{|c|}{$(20,2-25,8)^{*}$} & \multicolumn{2}{|c|}{$(1,6-3,1)^{*}$} & & $(0,0-0,9)$ & \\
\hline 30 a 39 & 15,01 & $-15,5$ & 56,78 & $-6,7$ & 24,4 & 32,3 & 3,38 & 59,4 & 0,43 & $-48,2$ \\
\hline IC95\% & $(13,4-16,7)$ & & 1,6-59,0) & & $22,6-26,3)^{*}$ & & $(2,4-4,7)$ & & $(0,2-0,8)$ & \\
\hline 40 a 49 & 11,72 & $-9,1$ & 49,68 & $-14,7$ & 32,05 & 38,6 & 5,54 & 10,1 & 1,02 & 45,7 \\
\hline IC95\% & $(10,2-13,5)$ & & $2-52,2)^{*}$ & & $29,7-34,5)^{*}$ & & $(4,6-6,7)$ & & $(0,7-1,6)$ & \\
\hline Total & 13,34 & $-26,7$ & 55,49 & $-9,4$ & 26,68 & 44,4 & 3,84 & 124,6 & 0,65 & 85,7 \\
\hline IC95\% & $(12,4-14,4)^{*}$ & & $0-56,9)^{*}$ & & $25,4-28,0)^{*}$ & & $(3,3-4,5)^{*}$ & & $(0,5-0,9)$ & \\
\hline Mulheres com & $n$ história repro & odutiva recente & $11-2013)$ & )** & & & & & & \\
\hline 18 a 29 & 12,1 & $-37,5$ & 63,12 & 1,8 & 22,27 & 26,5 & 2,12 & 125,5 & 0,39 & 225,0 \\
\hline IC95\% & $(9,3-15,7)^{*}$ & & $, 8-68,1)$ & & $(17,9-27,4)$ & & $(1,2-3,8)$ & & $(0,0-1,5)$ & \\
\hline 30 a 39 & 22,53 & 26,8 & 57,43 & $-5,6$ & 17,93 & $-2,8$ & 1,84 & $-13,2$ & 0,27 & $-67,5$ \\
\hline IC95\% & $(16,9-29,4)$ & & $, 6-64,0)$ & & $(13,7-23,1)$ & & $(0,6-5,7)$ & & $(0,0-0,8)$ & \\
\hline 40 a 49 & 14,59 & 13,2 & 59,88 & 2,8 & 23,37 & 1,1 & 2,16 & $-57,1$ & 0 & \\
\hline IC95\% & $(5,0-35,5)$ & & $, 1-76,9)$ & & $(10,9-43,1)$ & & $(0,5-8,8)$ & & - & \\
\hline Total & 15,85 & $-12,9$ & 61,01 & $-0,4$ & 20,79 & 12,5 & 2,02 & 18,1 & 0,33 & $-5,7$ \\
\hline IC95\% & $(13,0-19,1)$ & & $6,9-64,9)$ & & $(17,6-24,4)$ & & $(1,2-3,4)$ & & $(0,1-0,9)$ & \\
\hline Mulheres com & $n$ história repro & odutiva anterior & ntes de 20 & $011)^{* *}$ & & & & & & \\
\hline 18 a 29 & 13,39 & $-30,8$ & 60,73 & $-2,0$ & 23,11 & 31,3 & 2,28 & 142,6 & 0,5 & 316,7 \\
\hline IC95\% & $(11,4-15,7)^{*}$ & & $, 1-64,2)$ & & $19,9-26,7)^{*}$ & & $(1,6-3,3)^{*}$ & & $(0,3-1,0)^{*}$ & \\
\hline 30 a 39 & 14,11 & $-20,6$ & 56,7 & $-6,8$ & 25,17 & 36,5 & 3,56 & 67,9 & 0,45 & $-45,8$ \\
\hline IC95\% & $(12,5-15,9)$ & & (,3-59,0) & & $23,3-27,2)^{*}$ & & $(2,5-5,0)$ & & $(0,2-0,9)$ & \\
\hline 40 a 49 & 11,69 & $-9,3$ & 49,55 & $-15,0$ & 32,15 & 39,1 & 5,58 & 10,9 & 1,03 & 47,1 \\
\hline IC95\% & $(10,1-13,5)$ & & $0-52,1)^{*}$ & & $29,8-34,6)^{*}$ & & $(4,6-6,8)$ & & $(0,7-1,6)$ & \\
\hline Total & 13,01 & $-28,5$ & 54,75 & $-10,6$ & 27,47 & 48,6 & 4,08 & 138,6 & 0,69 & 97,1 \\
\hline IC95\% & $(12,0-14,1)^{*}$ & & $2-56,3)^{*}$ & & $26,1-28,9)^{*}$ & & $(3,5-4,8)^{*}$ & & $(0,5-1,0)$ & \\
\hline
\end{tabular}

\subsection{Distribuições percentuais da amostra segundo variáveis do modelo}

Ao comparar, na Tabela 6, as distribuições percentuais das mães brasileiras entre os grupos de qualidade da assistência pré-natal mensurada pelo método "PHPN - simples" segundo as variáveis selecionadas para o modelo teórico do estudo (Figura 2), em geral, foram observados percentuais menores de mães com qualidade do prénatal adequada em categorias das variáveis observadas geralmente associadas a desfechos negativos, sendo que para a variável renda média domiciliar per capita (em reais), por exemplo, o percentual de mães do grupo de qualidade adequada com renda 
na categoria de 0 a 300 reais $(29,40 \%$; IC95\% 25,2\%-34,0\%) foi $68,8 \%$ menor em relação ao percentual de mães do grupo de qualidade inadequada $(49,64 \%$; IC95\% $43,9 \%-55,4 \%)$.

Entretanto, para alguns casos, foram observadas diferenças pequenas entre os grupos, como no caso da variável "Presença de morador com 60 anos ou mais" em que foi observada variação percentual de $0,3 \%$ entre os grupos, indicando baixo poder discriminatório da variável. Para outras, foram encontradas diferenças de forma invertida ao que seria esperado, como no caso das variáveis observadas "Hipertensão arterial" e "Diabetes" (que compõem o constructo "Intercorrências"), em que o grupo de mães com assistência pré-natal adequada apresenta percentuais superiores (respectivamente $9,3 \%$ e $18,8 \%$ maiores) em relação ao grupo de qualidade inadequada quanto a presença dessas condições de risco; e também no grupo de condições reprodutivas em que há um percentual 15,6\% maior de mães com gestações precoces ou tardias no grupo de qualidade adequada. 
Tabela 6. Percentuais de mães brasileiras da amostra com último parto entre 2011 e 2013 segundo variáveis do modelo teórico proposto e qualidade da assistência pré-natal (método PHPN simples). Calculado com peso amostral. PNS, 2013.

\begin{tabular}{|c|c|c|c|c|c|}
\hline \multirow{2}{*}{ Variáve is do modelo } & \multicolumn{4}{|c|}{ Qualidade da assistência pré-natal (\%) } & \multirow[b]{2}{*}{ Variação \% } \\
\hline & Adequada & IC95\% & Inade quada & IC95\% & \\
\hline \multicolumn{6}{|c|}{ Variáveis observadas para formação dos } \\
\hline \multicolumn{6}{|c|}{ constructos (componente de mensuração): } \\
\hline \multicolumn{6}{|c|}{ 1. Vulnerabilidade Socioeconômica } \\
\hline \multicolumn{6}{|c|}{ Número de pessoas por cômodo } \\
\hline 1 & 28,19 & $(24,1-32,7)$ & 25,20 & $(20,6-30,4)$ & 10,6 \\
\hline 2 & 38,73 & $(33,6-44,1)$ & 35,69 & $(30,2-41,6)$ & 7,8 \\
\hline 3 ou mais & 33,08 & $(28,6-37,9)$ & 39,11 & $(33,7-44,8)$ & $-18,2$ \\
\hline \multicolumn{6}{|c|}{$\begin{array}{l}\text { Renda média domiciliar per capita (em } \\
\text { reais) }\end{array}$} \\
\hline 901 ou mais & 23,04 & $(19,3-27,3)$ & 12,98 & $(9,3-17,9)$ & 43,7 \\
\hline 601 a 900 & 15,37 & $(11,3-20,6)$ & 8,09 & $(5,5-11,7)$ & 47,4 \\
\hline 301 a 600 & 32,19 & $(27,6-37,1)$ & 29,29 & $(24,3-34,8)$ & 9,0 \\
\hline 0 a 300 & 29,40 & $(25,2-34,0)$ & 49,64 & $(43,9-55,4)$ & $-68,8$ \\
\hline \multicolumn{6}{|c|}{ Escolaridade do responsável pelo } \\
\hline \multicolumn{6}{|c|}{ sustento familiar no domicílio } \\
\hline Superior completo & 13,26 & $(10,4-16,8)$ & 5,13 & $(3,6-7,3)$ & 61,3 \\
\hline Superior incompleto & 4,73 & $(3,1-7,2)$ & 4,91 & $(3,0-8,0)$ & $-3,8$ \\
\hline Médio completo & 33,66 & $(29,1-38,6)$ & 25,02 & $(20,3-30,5)$ & 25,7 \\
\hline Médio incompleto & 5,81 & $(4,1-8,1)$ & 5,75 & $(3,9-8,4)$ & 1,0 \\
\hline Fundamental completo & 11,58 & $(8,7-15,3)$ & 11,01 & $(8,2-14,7)$ & 4,9 \\
\hline Fundamental incompleto & 21,80 & $(17,4-26,9)$ & 33,79 & $(28,5-39,5)$ & $-55,0$ \\
\hline Sem instrução & 9,16 & $(6,7-12,5)$ & 14,38 & $(10,3-19,8)$ & $-57,0$ \\
\hline \multicolumn{6}{|l|}{ Escolaridade da mãe } \\
\hline Superior completo & 15,15 & $(12,1-18,8)$ & 7,41 & $(4,6-11,9)$ & 51,1 \\
\hline Superior incompleto & 3,44 & $(2,2-5,4)$ & 5,04 & $(2,9-8,8)$ & $-46,5$ \\
\hline Médio completo & 42,69 & $(37,4-48,0)$ & 28,70 & $(23,8-34,2)$ & 32,8 \\
\hline Médio incompleto & 8,95 & $(6,7-11,9)$ & 12,18 & $(8,8-16,6)$ & $-36,1$ \\
\hline Fundamental completo & 13,02 & $(9,9-16,9)$ & 14,70 & $(11,4-18,8)$ & $-12,9$ \\
\hline Fundamental incompleto & 12,46 & $(9,8-15,8)$ & 24,35 & $(19,8-29,6)$ & $-95,4$ \\
\hline Sem instrução & 4,30 & $(2,9-6,5)$ & 7,62 & $(5,0-11,5)$ & $-77,2$ \\
\hline
\end{tabular}


Tabela 6. Percentuais de mães brasileiras da amostra com último parto entre 2011 e 2013 segundo variáveis do modelo teórico proposto e qualidade da assistência pré-natal (método PHPN simples). Calculado com peso amostral. PNS, 2013. "continuação"

\begin{tabular}{|c|c|c|c|c|c|}
\hline \multirow{2}{*}{ Variáveis do modelo } & \multicolumn{4}{|c|}{ Qualidade da assistência pré-natal (\%) } & \multirow[b]{2}{*}{ Variação \% } \\
\hline & Adequada & IC95\% & Inadequada & IC95\% & \\
\hline \multicolumn{6}{|l|}{$\underline{\text { Variáveis observadas para formação dos }}$} \\
\hline \multicolumn{6}{|l|}{ constructos (componente de mensuração): } \\
\hline \multicolumn{6}{|l|}{ 2. Vulnerabilidade Familiar } \\
\hline Família nuclear (\% não) & 17,62 & $(13,6-22,5)$ & 19,17 & $(15,2-21,8)$ & $-8,8$ \\
\hline \multicolumn{6}{|l|}{ Presença de morador com 60 anos ou } \\
\hline mais no domicílio (\% sim) & 5,96 & $(3,8-9,3)$ & 5,94 & $(3,9-9,0)$ & 0,3 \\
\hline \multicolumn{6}{|c|}{$\begin{array}{l}\text { Mãe do recém-nascido responsável pelo } \\
\text { sustento familiar do domicílio (\% sim) }\end{array}$} \\
\hline & 28,73 & $(24,7-33,1)$ & 28,13 & $(23,6-33,2)$ & 2,1 \\
\hline \multicolumn{6}{|l|}{ 3. Intercorrências } \\
\hline Hipertensão arterial (\% sim) & 19,83 & $(16,0-24,3)$ & 17,98 & $(13,9-22,9)$ & 9,3 \\
\hline Diabetes (\% sim) & 7,09 & $(4,5-11,0)$ & 5,76 & $(3,4-9,7)$ & 18,8 \\
\hline \multicolumn{6}{|l|}{ 4. Condições reprodutivas } \\
\hline \multicolumn{6}{|l|}{ Idade da mãe igual ou superior a 35} \\
\hline \multicolumn{6}{|l|}{ anos ou igual ou inferior a 18 anos (\% } \\
\hline $\operatorname{sim})$ & 17,34 & $(14,1-21,2)$ & 14,64 & $(11,1-19,1)$ & 15,6 \\
\hline \multicolumn{6}{|l|}{ Nascidos vivos pré-termo anteriores } \\
\hline 0 & 78,87 & $(74,5-82,7)$ & 79,84 & $(74,2-84,5)$ & $-1,2$ \\
\hline 1 & 19,37 & $(15,7-23,7)$ & 16,97 & $(12,7-22,4)$ & 12,4 \\
\hline 2 ou mais & 1,76 & $(0,9-3,3)$ & 3,19 & $(1,6-6,3)$ & $-81,3$ \\
\hline \multicolumn{6}{|l|}{ Nascidos vivos com baixo peso ao } \\
\hline \multicolumn{6}{|l|}{ nascer anteriores } \\
\hline 0 & 86,68 & $(82,9-89,7)$ & 84,32 & $(80,2-87,2)$ & 2,7 \\
\hline 1 & 12,10 & $(9,2-15,8)$ & 13,68 & $(10,5-17,7)$ & $-13,1$ \\
\hline 2 ou mais & 1,22 & $(0,6-2,5)$ & 2,00 & $(1,1-3,6)$ & $-63,9$ \\
\hline \multicolumn{6}{|l|}{ Número de partos anteriores } \\
\hline 0 & 0,00 & - & 0,00 & - & - \\
\hline 1 & 78,65 & $(74,4-82,4)$ & 70,24 & $(65,0-75,0)$ & 10,7 \\
\hline 2 ou mais & 21,35 & $(17,6-25,6)$ & 29,76 & $(25,0-35,0)$ & $-39,4$ \\
\hline \multicolumn{6}{|c|}{ Variáveis observadas (componente estrutural): } \\
\hline \multicolumn{6}{|l|}{ Auto-avaliação da Saúde } \\
\hline Muito boa & 18,44 & $(14,7-22,9)$ & 11,54 & $(8,3-15,8)$ & 37,4 \\
\hline Boa & 61,69 & $(56,5-66,6)$ & 57,89 & $(52,0-63,6)$ & 6,2 \\
\hline Regular & 17,42 & $(13,8-21,7)$ & 27,18 & $(22,0-33,1)$ & $-56,0$ \\
\hline Ruim & 2,40 & $(1,3-4,5)$ & 2,69 & $(1,4-5,0)$ & $-12,1$ \\
\hline Muito ruim & 0,00 & - & 0,70 & $(0,2-2,1)$ & - \\
\hline Planejamento da Gravidez (\% não) & 93,87 & $(91,1-95,8)$ & 89,93 & $(84,6-93,6)$ & 4,2 \\
\hline Total & $\mathbf{1 0 0 , 0 0}$ & & $\mathbf{1 0 0 , 0 0}$ & & \\
\hline
\end{tabular}


O modelo inicial de equações estruturais com base no modelo teórico proposto por OLIVEIRA (2014) (Figura 5) com estimador WLSMV e sem peso amostral apresentou baixos índices de qualidade de ajuste $(\mathrm{CFI}=0,756$; $\mathrm{TLI}=0,685)$ valor de referência para ajuste adequado $(\geq 0,950)$ e problemas de estimação. No componente de mensuração, grande parte das variáveis indicadoras que formaram os constructos apresentaram cargas fatoriais relativamente baixas $(<0,200)$ e heterogêneas e no componente estrutural poucos efeitos foram estatisticamente significantes. Não houve convergência do modelo com aplicação do peso amostral.

Figura 5. Diagrama representando o componente estrutural da modelagem com equações estruturais realizada para o desfecho "Inadequação da Assistência Pré-Natal - PHPN Simples (sem peso amostral). Modelo proposto por OLIVEIRA (2014). Estimador WLSMV.

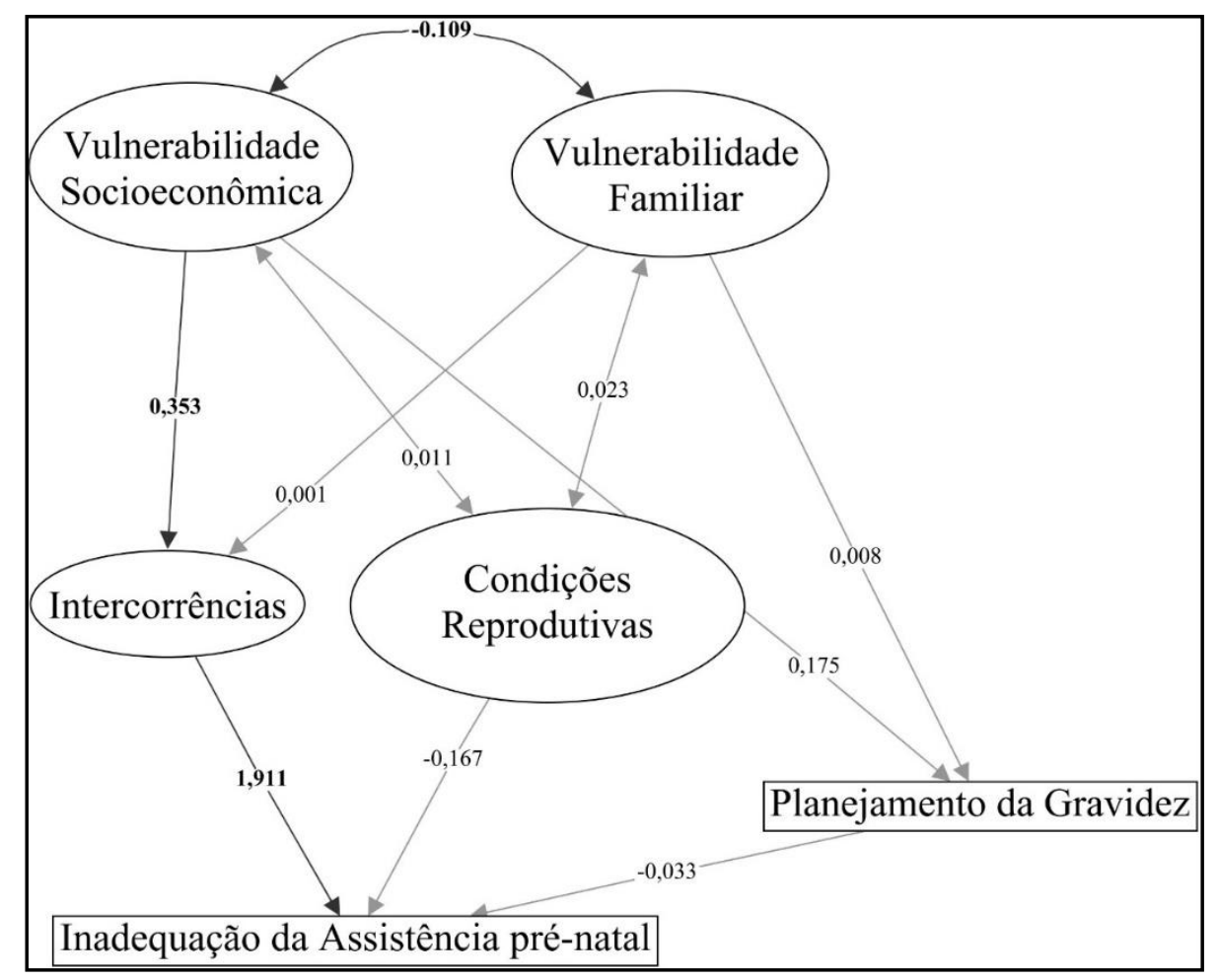

Efeitos estatisticamente significantes ( $\mathrm{p}$-valor $\leq 0,05)$ representados em negrito e com flechas na cor preta.

Estimador WLSMV. Índices de ajuste do modelo: CFI= 0,756; TLI= 0,685; RMSEA=0,084 IC90\%(0,08-0,09). 
Considerando esses resultados iniciais, o Quadro 6 apresenta outras variáveis que foram incluídas no modelo teórico proposto por OLIVEIRA (2014), entretanto que não foram consideradas nos modelos finais para os dados do estudo realizado em Londrina em 2008:

Quadro 6. Variáveis adicionadas posteriormente aos modelos.

\begin{tabular}{|c|c|}
\hline Variável criada & Variáveis da PNS de 2013 envolvidas em sua criação \\
\hline Raça/cor da mãe & $\mathrm{c} 009$ \\
\hline $\begin{array}{l}\text { Presença de ocupação da mãe } \\
\text { (sim/não) }\end{array}$ & $\mathrm{e} 011$ \\
\hline Idade do responsável do domicílio & $\mathrm{c} 008, \mathrm{c} 004$ \\
\hline Acabamento da moradia (sim/não) & $\mathrm{a} 002$ \\
\hline $\begin{array}{l}\text { Mãe diagnosticada com doença } \\
\text { crônica (sim/não) }\end{array}$ & $\begin{array}{l}\text { q002, q030, q060, q063, q068, q074, q079, q088, q092, } \\
\text { q110, q116, q120, q124, q128 }\end{array}$ \\
\hline $\begin{array}{l}\text { Presença de criança com menos de } \\
10 \text { anos no domicílio (sim/não) }\end{array}$ & $\mathrm{c} 008$ \\
\hline $\begin{array}{l}\text { IMC binário - categoria de risco* } \\
(\operatorname{sim} / \text { não) }\end{array}$ & p00101, p00401 \\
\hline $\begin{array}{l}\text { Realização de tratamento para } \\
\text { engravidar ( }(\mathrm{sim} / \text { não) }\end{array}$ & r037 \\
\hline Depressão anterior (sim/não) & q092, q093, r04903 \\
\hline $\begin{array}{l}\text { saúde em relação a como outro } \\
\text { morador do domicilio a avalia } \\
\text { (sim/não) }\end{array}$ & n001, j001 \\
\hline Ausência de apoio social (sim/não) & $\mathrm{m} 014, \mathrm{~m} 015$ \\
\hline
\end{tabular}

*Foram consideradas categorias de risco IMC $<16.0$ e IMC $\geq 30.0$ (OMS, 1995).

A Tabela 7 apresenta modelos de regressão logística simples considerando todas as variáveis consideradas para a análise, com inclusão das novas variáveis, como regressoras e a inadequação da assistência pré-natal obtida pelo método PHPN simples como variável resposta.

Comparados aos modelos sem uso de peso amostral, muitos dos regressores deixam de ser significantes estatisticamente (a 5\% de significância) nos modelos com peso amostral, como "Número de pessoas por cômodo servindo de dormitório", "Idade em anos do responsável pelo sustento familiar", "Família não-nuclear", "Mãe responsável 
pelo sustento familiar no domicílio", "Mãe diagnosticada com doença crônica", "Multiparidade" e "Filho com baixo peso ao nascer anterior".

Alguns dos regressores estatisticamente significantes e com odds ratios mais expressivos em relação à variável resposta "Inadequação da assistência pré-natal - PHPN simples" foram "Renda média domiciliar per capita em reais", "Raça/cor da mãe", "Escolaridade do responsável pelo sustento familiar", "Escolaridade da mãe" e "Autoavaliação da saúde" (apesar de altas amplitudes dos intervalos de confiança 95\% para algumas categorias).

Tabela 7. Resumo dos modelos de regressão logística simples considerando todas as variáveis consideradas na análise como regressoras e inadequação do pré-natal - método PHPN simples como variável resposta. Modelos com e sem peso amostral.

\begin{tabular}{|c|c|c|c|c|c|c|}
\hline \multirow{3}{*}{ Variáveis } & \multicolumn{6}{|c|}{ Modelos de Regressão Logística Simples } \\
\hline & \multicolumn{3}{|c|}{ Sempesos amostrais } & \multicolumn{3}{|c|}{ Com pesos amostrais } \\
\hline & OR & p-valor & IC95\% & OR & p-valor & IC95\% \\
\hline \multirow{2}{*}{\multicolumn{7}{|c|}{$\begin{array}{l}\text { Inadequação da assistência Pré-Natal - PHPN Simples= } \\
\text { (VSE - Vulnerabilidade Socioeconômica) }\end{array}$}} \\
\hline & & & & & & \\
\hline \multicolumn{7}{|c|}{ Número de pessoas por cômodo servindo de dormitório } \\
\hline 0 a 2 & 1,00 & & & 1,00 & & \\
\hline 2 a 3 & 1,32 & 0,023 & $(1,0-1,7)$ & 1,03 & 0,880 & $(0,7-1,5)$ \\
\hline 3 a 4 & 1,43 & 0,007 & $(1,1-1,9)$ & 1,15 & 0,517 & $(0,8-1,7)$ \\
\hline 4 a 5 & 1,75 & 0,001 & $(1,3-2,4)$ & 1,66 & 0,085 & $(0,9-3,0)$ \\
\hline $5+$ & 2,44 & 0,000 & $(1,6-3,8)$ & 1,45 & 0,251 & $(0,8-2,7)$ \\
\hline \multicolumn{7}{|l|}{ Renda média domiciliar per capita em reais } \\
\hline$<500$ & 1,00 & & & 1,00 & & \\
\hline 500 a 1000 & 0,51 & 0,000 & $(0,4-0,6)$ & 0,39 & 0,000 & $(0,3-0,6)$ \\
\hline 1000 a 1500 & 0,43 & 0,000 & $(0,3-0,6)$ & 0,57 & 0,061 & $(0,3-1,0)$ \\
\hline 1500 a 2000 & 0,38 & 0,004 & $(0,2-0,7)$ & 0,78 & 0,689 & $(0,2-2,6)$ \\
\hline 2000 a 2500 & 0,31 & 0,002 & $(0,2-0,6)$ & 0,30 & 0,036 & $(0,1-0,9)$ \\
\hline $2500+$ & 0,22 & 0,000 & $(0,1-0,4)$ & 0,17 & 0,000 & $(0,1-0,4)$ \\
\hline \multicolumn{7}{|c|}{ Escolaridade do responsável pelo sustento familiar } \\
\hline Superior completo & 1,00 & & & 1,00 & & \\
\hline Superior incompleto ou equivalente & 1,61 & 0,068 & $(1,0-2,7)$ & 2,68 & 0,015 & $(1,2-6,0)$ \\
\hline Médio completo ou equivalente & 1,50 & 0,023 & $(1,1-2,1)$ & 1,92 & 0,016 & $(1,1-3,3)$ \\
\hline Médio incompleto ou equivalente & 1,79 & 0,012 & $(1,1-2,8)$ & 2,56 & 0,007 & $(1,3-5,0)$ \\
\hline Fundamental completo ou equivalente & 2,24 & 0,000 & $(1,5-3,3)$ & 2,46 & 0,004 & $(1,3-4,6)$ \\
\hline Fundamental incompleto ou equivalente & 3,02 & 0,000 & $(2,1-4,3)$ & 4,01 & 0,000 & $(2,3-6,9)$ \\
\hline Sem instrução & 2,75 & 0,000 & $(1,8-4,2)$ & 4,06 & 0,000 & $(2,1-7,8)$ \\
\hline \multicolumn{7}{|l|}{ Escolaridade da mãe } \\
\hline Superior completo & 1,00 & & & 1,00 & & \\
\hline Superior incompleto ou equivalente & 2,80 & 0,000 & $(1,7-4,7)$ & 2,99 & 0,020 & $(1,2-7,5)$ \\
\hline Médio completo ou equivalente & 2,16 & 0,000 & $(1,5-3,1)$ & 1,37 & 0,316 & $(0,7-2,6)$ \\
\hline Médio incompleto ou equivalente & 3,24 & 0,000 & $(2,1-4,9)$ & 2,78 & 0,005 & $(1,4-5,7)$ \\
\hline Fundamental completo ou equivalente & 3,51 & 0,000 & $(2,4-5,2)$ & 2,31 & 0,016 & $(1,2-4,6)$ \\
\hline Fundamental incompleto ou equivalente & 4,86 & 0,000 & $(3,3-7,1)$ & 4,00 & 0,000 & $(2,1-7,7)$ \\
\hline Sem instrução & 4,72 & 0,000 & $(2,9-7,6)$ & 3,62 & 0,002 & $(1,6-8,2)$ \\
\hline \multicolumn{7}{|l|}{ Raça cor da mãe } \\
\hline Branca & 1,00 & & & 1,00 & & \\
\hline Preta & 1,81 & 0,001 & $(1,3-2,6)$ & 2,23 & 0,004 & $(1,3-3,9)$ \\
\hline Amarela & 1,34 & 0,487 & $(0,6-3,1)$ & 1,40 & 0,614 & $(0,4-5,1)$ \\
\hline Parda & 1,68 & 0,000 & $(1,4-2,1)$ & 1,99 & 0,000 & $(1,4-2,8)$ \\
\hline Indígena & 3,76 & 0,017 & $(1,3-11,1)$ & 3,93 & 0,101 & $(0,8-20,2)$ \\
\hline
\end{tabular}


Tabela 7. Resumo dos modelos de regressão logística simples considerando todas as variáveis consideradas na análise como regressoras e inadequação do pré-natal - método PHPN simples como variável resposta. Modelos com e sem peso amostral.

"continuação"

\begin{tabular}{|c|c|c|c|c|c|c|}
\hline \multirow{3}{*}{ Variáveis } & \multicolumn{6}{|c|}{ Modelos de Regressão Logística Simples } \\
\hline & \multicolumn{3}{|c|}{ Sem pesos amostrais } & \multicolumn{3}{|c|}{ Compesos amostrais } \\
\hline & $\mathrm{OR}$ & p-valor & IC95\% & OR & p-valor & $\mathrm{IC} 95 \%$ \\
\hline Mãe sem ocupação & 1,89 & 0,000 & $(1,6-2,3)$ & 1,89 & 0,000 & $(1,4-2,6)$ \\
\hline \multicolumn{7}{|l|}{ Idade em anos do responsável pelo sustento familiar } \\
\hline$<20$ & 1,00 & & & 1,00 & & \\
\hline 20 a 29 & 0,77 & 0,376 & $(0,4-1,4)$ & 0,95 & 0,907 & $(0,4-2,2)$ \\
\hline 30 a 39 & 0,53 & 0,029 & $(0,3-0,9)$ & 0,70 & 0,406 & $(0,3-1,6)$ \\
\hline 40 a 49 & 0,55 & 0,057 & $(0,3-0,0)$ & 0,97 & 0,940 & $(0,4-2,4)$ \\
\hline 50 a 59 & 0,51 & 0,049 & $(0,3-1,0)$ & 0,63 & 0,397 & $(0,2-1,8)$ \\
\hline $60+$ & 0,79 & 0,546 & $(0,4-1,7)$ & 0,94 & 0,910 & $(0,3-2,9)$ \\
\hline \multicolumn{7}{|l|}{ (VF - Vulnerabilidade Familiar) } \\
\hline Família não-nuclear & 1,22 & 0,08 & $(1,0-1,5)$ & 1,21 & 0,318 & $(0,8-1,8)$ \\
\hline Mãe responsável pelo sustento familiar no domicílio & 1,21 & 0,050 & $(1,0-1,5)$ & 0,97 & 0,853 & $(0,7-1,3)$ \\
\hline Mãe diagnosticada com doença crônica & 0,76 & 0,013 & $(0,6-0,9)$ & 0,80 & 0,238 & $(0,6-1,2)$ \\
\hline Presença de idoso no domicílio & 1,14 & 0,541 & $(0,7-1,8)$ & 0,99 & 0,988 & $(0,5-1,9)$ \\
\hline $\begin{array}{l}\text { Presença de criança com menos de } 10 \text { anos do domicílio } \\
\text { (Intercorrências na gestação) }\end{array}$ & 1,13 & 0,644 & $(0,7-1,9)$ & 1,23 & 0,576 & $(0,6-2,5)$ \\
\hline Hipertensão arterial & 0,83 & 0,119 & $(0,7-1,0)$ & 0,89 & 0,555 & $(0,6-1,3)$ \\
\hline Diabetes & 0,80 & 0,276 & $(0,5-1,2)$ & 0,80 & 0,555 & $(0,4-1,7)$ \\
\hline \multicolumn{7}{|l|}{ (Características reprodutivas maternas) } \\
\hline Idade da mãe $<=18$ ou $>=35$ anos & 0,92 & 0,489 & $(0,7-1,2)$ & 0,82 & 0,331 & $(0,5-1,2)$ \\
\hline Multiparidade & 1,35 & 0,002 & $(1,1-1,6)$ & 1,27 & 0,146 & $(0,9-1,8)$ \\
\hline Filho com baixo peso ao nascer anterior & 1,31 & 0,040 & $(1,0-1,7)$ & 1,21 & 0,360 & $(0,8-1,8)$ \\
\hline Filho pré-termo anterior & 0,84 & 0,136 & $(0,7-1,1)$ & 0,94 & 0,772 & $(0,6-1,4)$ \\
\hline IMC binário-Categorias de risco & 1,74 & 0,000 & $(1,4-2,1)$ & 1,66 & 0,002 & $(1,2-2,3)$ \\
\hline Tratamento para engravidar - Nunca realizado & 0,94 & 0,659 & $(0,7-1,3)$ & 0,90 & 0,668 & $(0,6-1,4)$ \\
\hline \multicolumn{7}{|l|}{ (Características psicossociais) } \\
\hline \multicolumn{7}{|l|}{ Autoavaliação da saúde } \\
\hline Muito bom & 1,00 & & & 1,00 & & \\
\hline Bom & 1,44 & 0,012 & $(1,1-1,9)$ & 1,50 & 0,088 & $(0,9-2,4)$ \\
\hline Regular & 1,94 & 0,000 & $(1,4-2,7)$ & 2,49 & 0,001 & $(1,4-4,3)$ \\
\hline Ruim & 2,15 & 0,030 & $(1,1-4,3)$ & 1,79 & 0,252 & $(0,7-4,8)$ \\
\hline Muito Ruim & 11,59 & 0,024 & $(1,4-97,8)$ & 27,90 & 0,004 & $(2,8-276,0)$ \\
\hline Depressão anterior & 0,82 & 0,365 & $(0,5-1,3)$ & 0,67 & 0,262 & $(0,3-1,3)$ \\
\hline Discordância da autoavaliação da saúde em relação a outro morador & 0,95 & 0,811 & $(0,6-1,4)$ & 1,21 & 0,546 & $(0,6-2,3)$ \\
\hline Apoio social - ausência & 1,22 & 0,272 & $(0,9-1,7)$ & 1,80 & 0,039 & $(1,0-3,1)$ \\
\hline \multicolumn{7}{|l|}{ (Variáveis observadas do modelo) } \\
\hline Planejamento da gravidez & 0,95 & 0,796 & $(0,7-1,4)$ & 0,58 & 0,093 & $(0,3-1,1)$ \\
\hline Residir em UF com baixa cobertura de assistência pré-natal & 1,70 & 0,000 & $(1,4-2,1)$ & 1,81 & 0,000 & $(1,3-2,5)$ \\
\hline Residir em UF com baixa qualidade de assistência pré-natal & 2,25 & 0,000 & $(1,7-2,9)$ & 2,48 & 0,000 & $(1,7-3,6)$ \\
\hline
\end{tabular}


A Tabela 8 apresenta as análises fatoriais confirmatórias (AFC) para formação das variáveis latentes propostas no modelo teórico inicial.

Em geral, somente a variável latente "VSE - Vulnerabilidade Socioeconômica" se mostrou mais consistente, com índices de ajuste razoáveis e cargas fatoriais das variáveis indicadoras mais próximas, exceto da variável "Idade em anos do responsável pelo sustento familiar", que apresentou carga fatorial no modelo sem peso amostral com sinal oposto às das outras indicadoras e não foi estatisticamente significante no modelo com aplicação do peso amostral. Outros modelos de variáveis latentes inicialmente propostas apresentaram problemas de estimação e alguns não convergiram, como "VF vulnerabilidade familiar", tanto sem a aplicação do peso amostral quanto com a aplicação. 
Tabela 8. Resumo das análises fatoriais confirmatórias para formação das variáveis latentes do modelo teórico com adição das novas variáveis (componente de mensuração dos modelos com equações estruturais) com e sem peso amostral. Estimador WLSMV.

\begin{tabular}{|c|c|c|c|c|c|c|c|c|c|c|c|c|}
\hline \multirow{3}{*}{ Variáveis latentes } & \multicolumn{6}{|c|}{ Estimador WLS- Sem pesos amostrais } & \multicolumn{6}{|c|}{ Estimador WLS - Com pesos amostrais } \\
\hline & & & Estimativa & & & & & & Estimativa & & & \\
\hline & Estimativa & p-valor & padronizada & CFI & TLI & RMSEA & Estimativa & p-valor & padronizada & CFI & TLI & RMSEA \\
\hline$\overline{(V S E \text { - Vulnerabilidade Socioeconômica) }}$ & & & & 0,955 & 0,937 & 0,097 & & & & 0,962 & 0,947 & 0,048 \\
\hline Número de pessoas por comôdo servindo de dormitório & 1,000 & - & 0,335 & & & & 1,000 & - & 0,331 & & & \\
\hline Renda média domiciliar per capita em reais & 1,271 & 0,000 & 0,742 & & & & 1,493 & 0,000 & 0,713 & & & \\
\hline Escolaridade do responsável pelo sustento familiar & 2,655 & 0,000 & 0,543 & & & & 3,000 & 0,000 & 0,567 & & & \\
\hline Escolaridade da mãe & 2,554 & 0,000 & 0,557 & & & & 2,811 & 0,000 & 0,581 & & & \\
\hline Raça cor da mãe & 1,345 & 0,000 & 0,457 & & & & 2,202 & 0,000 & 0,614 & & & \\
\hline Mãe sem ocupação & 2,304 & 0,000 & 0,661 & & & & 1,649 & 0,000 & 0,504 & & & \\
\hline Idade em anos do responsável pelo sustento familiar & $-1,888$ & 0,008 & $-0,066$ & & & & 0,555 & 0,710 & 0,017 & & & \\
\hline Acabamento da moradia & 0,987 & 0,000 & 0,353 & & & & 1,397 & 0,000 & 0,443 & & & \\
\hline (VF - Vulnerabilidade Familiar) & & & & * & * & * & & & & * & * & $*$ \\
\hline Família não-nuclear & 1,000 & - & 1,000 & & & & 1,000 & - & 0,464 & & & \\
\hline Mãe responsável pelo sustento familiar no domicílio & 0,001 & - & 0,390 & & & & 2,339 & - & 1,000 & & & \\
\hline Mãe diagnosticada com doença crônica & $-0,001$ & - & $-0,253$ & & & & $-0,644$ & - & $-0,320$ & & & \\
\hline Presença de idoso no domicílio & 0,001 & - & 0,279 & & & & $-0,399$ & - & $-0,204$ & & & \\
\hline Presença de criança com menos de 10 anos do domicílio & 0,000 & - & 0,121 & & & & 0,123 & - & 0,064 & & & \\
\hline (Intercorrências na gestação) & & & & $*$ & $*$ & $*$ & & & & 1,000 & 1,000 & 0,000 \\
\hline Hipertensão arterial & 1,000 & - & 0,680 & & & & 1,000 & - & 0,669 & & & \\
\hline Diabetes & 0,692 & - & 0,539 & & & & 0,805 & - & 0,587 & & & \\
\hline (Características reprodutivas maternas) & & & & 0,946 & 0,909 & 0,045 & & & & 0,980 & 0,967 & 0,016 \\
\hline Idade da mãe $<=18$ ou $>=35$ anos & 1,000 & - & 0,111 & & & & 1,000 & - & 0,033 & & & \\
\hline Multiparidade & 23,467 & 0,335 & 0,934 & & & & 51,513 & 0,684 & 0,865 & & & \\
\hline Filho com baixo peso ao nascer anterior & 10,341 & 0,049 & 0,755 & & & & 43,179 & 0,692 & 0,823 & & & \\
\hline Filho pré-termo anterior & 2,001 & 0,041 & 0,217 & & & & 3,847 & 0,643 & 0,128 & & & \\
\hline IMC binário- Categorias de risco & 0,565 & 0,134 & 0,063 & & & & 0,626 & 0,784 & 0,021 & & & \\
\hline Tratamento para engravidar - Nunca realizado & $-0,979$ & 0,211 & $-0,108$ & & & & $-2,243$ & 0,691 & $-0,075$ & & & \\
\hline (Características psicossociais) & & & & 0,941 & 0,823 & 0,019 & & & & 1,000 & 4,426 & 0,000 \\
\hline Autoavaliação da saúde & 1,000 & - & 0,547 & & & & 1,000 & - & 0,630 & & & \\
\hline Depressão anterior & 0,450 & 0,109 & 0,283 & & & & 0,254 & 0,598 & 0,202 & & & \\
\hline Discordância da autoavaliação da saúde em relação a outro morador & 0,708 & 0,106 & 0,420 & & & & 0,377 & 0,584 & 0,292 & & & \\
\hline Apoio social - ausência & 0,164 & 0,398 & 0,107 & & & & 0,041 & 0,829 & 0,034 & & & \\
\hline
\end{tabular}


A partir dos resultados observados das Tabelas 7 e 8 foi realizada a seleção das variáveis para os modelos de equações estruturais finais. O Quadro 7 apresenta o resultado da seleção e o tipo de variável assumido no modelo final.

Quadro 7. Variáveis selecionadas e tipo de variável assumido para a modelagem com equações estruturais.

\begin{tabular}{|c|c|c|}
\hline Variável & $\begin{array}{c}\text { Variável } \\
\text { selecionada } \\
\text { para a MEE }\end{array}$ & $\begin{array}{c}\text { Componente } \\
\text { do modelo } \\
\text { final }\end{array}$ \\
\hline \multicolumn{3}{|l|}{ Iniciais } \\
\hline Número de pessoas por cômodo servindo de dormitório & Não & \\
\hline Renda média domiciliar per capita em reais & $\operatorname{Sim}$ & Mensuração \\
\hline Escolaridade do responsável pelo sustento familiar no domicilio & Sim & Mensuração \\
\hline Escolaridade da mãe & Sim & Mensuração \\
\hline Família nuclear & Sim & Mensuração \\
\hline Presença de morador com 60 anos ou mais no domicílio & Não & \\
\hline Mãe responsável pelo sustento familiar do domicílio & Sim & Mensuração \\
\hline Hipertensão arterial & Sim & Estrutural \\
\hline Diabetes & Não & \\
\hline Idade da mãe igual ou superior a 35 anos ou igual ou inferior a 18 anos & Não & \\
\hline Filho pré-termo anterior & Não & \\
\hline Filho com baixo peso ao nascer anterior & Sim & Estrutural \\
\hline Multiparidade & Sim & Estrutural \\
\hline Autoavaliação da saúde & Sim & Estrutural \\
\hline Planejamento da gravidez & Sim & Estrutural \\
\hline Inadequação da assistência pré-natal - PHPN Simples & Sim & Estrutural \\
\hline Inadequação da assistência pré-natal - Takeda & Sim & Estrutural \\
\hline Inadequação da assistência pré-natal - Silva & $\mathrm{Sim}$ & Estrutural \\
\hline Realização de menos de sete consultas de pré-natal & Sim & Estrutural \\
\hline \multicolumn{3}{|l|}{ Adicionadas posteriormente } \\
\hline Raça cor da mãe & Sim & Estrutural \\
\hline Mãe com ocupação & $\mathrm{Sim}$ & Estrutural \\
\hline Idade do responsável do domicílio & Não & \\
\hline Acabamento da moradia & Não & \\
\hline Mãe diagnosticada com doença crônica & Sim & Estrutural \\
\hline Presença de criança com menos de 10 anos no domicílio & Não & \\
\hline IMC binário - categoria de risco & $\operatorname{Sim}$ & Estrutural \\
\hline Realização de tratamento para engravidar & Não & \\
\hline $\begin{array}{l}\text { Discordância da autoavaliação da saúde em relação a como outro } \\
\text { morador do domicilio a avalia }\end{array}$ & Não & \\
\hline Ausência de apoio social & Não & \\
\hline
\end{tabular}


A Tabela 9 apresenta os modelos com e sem aplicação de peso amostral para o desfecho "Inadequação do pré-natal - PHPN simples" com estimador WLSMV.

Os dois modelos apresentaram índices de ajuste satisfatórios, de acordo com os valores de referência considerados.

No componente de mensuração do modelo, as variáveis observadas indicadoras que formam a variável latente "VSE - Vulnerabilidade Socioeconômica" apresentam cargas fatoriais consideráveis (todas $\geq 0,400$ nas colunas de estimativas padronizadas), sendo que a variável "Renda média domiciliar per capita em desvios padrão" apresenta carga mais elevada $(0,816$ no modelo sem peso amostral e 0,784 no modelo com peso amostral).

No componente estrutural, a variável latente independente VSE é responsável tanto pela maioria dos efeitos estatisticamente significantes (exceto em relação à variável planejamento da gravidez no modelo com peso amostral) quanto pelos efeitos mais fortes sobre outras covariáveis. Além da VSE, ter diagnóstico de doença crônica apresentou efeito estatisticamente significante sobre a autoavaliação da saúde (aumentando a probabilidade de avaliação negativa), em ambos os modelos. Para a variável planejamento da gravidez, no modelo sem peso amostral família não-nuclear apresentou efeito estatisticamente significante, enquanto no modelo com peso amostral nenhum efeito foi significante.

No modelo sem peso amostral, apresentaram efeitos estatisticamente significantes sobre o desfecho de inadequação do pré-natal segundo o método PHPN simples as variáveis: VSE, mãe responsável pelo sustento familiar, diagnóstico de doença crônica e hipertensão arterial. 
No modelo com peso amostral, apenas as variáveis VSE e planejamento da gravidez apresentaram efeitos estatisticamente significantes sobre o desfecho.

Tabela 9. Resumo dos modelos com e sem peso amostral para o desfecho "Inadequação da Assistência Pré-Natal - PHPN Simples". Estimador WLSMV.

\begin{tabular}{|c|c|c|c|c|c|c|}
\hline \multirow{2}{*}{ Variáveis } & \multicolumn{3}{|c|}{$\begin{array}{c}\text { Estimador WLSMV-Sem pesos } \\
\text { amostrais }\end{array}$} & \multicolumn{3}{|c|}{$\begin{array}{c}\text { Estimador WLSMV - Com pesos } \\
\text { amostrais }\end{array}$} \\
\hline & Estimativa & p-valor & $\begin{array}{c}\text { Estimativa } \\
\text { padronizada }\end{array}$ & Estimativa & p-valor & $\begin{array}{c}\text { Estimativa } \\
\text { padronizada }\end{array}$ \\
\hline \multicolumn{6}{|l|}{ Componente de Mensuração - Constructos } & VSE - Vulne rabilidade Socioeconômica \\
\hline Renda média domiciliar per capita em desvios padrão & 1,000 & - & 0,794 & 1,000 & - & 0,761 \\
\hline Escolaridade do responsável pelo sustento familiar & 1,838 & 0,000 & 0,512 & 1,756 & 0,000 & 0,533 \\
\hline Escolaridade da mãe & 1,759 & 0,000 & 0,520 & 1,647 & 0,000 & 0,541 \\
\hline Raça cor da mãe & 0,966 & 0,000 & 0,447 & 1,322 & 0,000 & 0,595 \\
\hline Mãe com ocupação & 1,541 & 0,000 & 0,624 & 0,997 & 0,000 & 0,488 \\
\hline \multicolumn{7}{|l|}{ Componente Estrutural } \\
\hline \multicolumn{7}{|l|}{ Autoavaliação da Saúde= } \\
\hline VSE - Vulnerabilidade Socioeconômica & 0,889 & 0,000 & 0,412 & 0,975 & 0,000 & 0,475 \\
\hline Familia não nuclear & 0,115 & 0,106 & 0,042 & 0,128 & 0,458 & 0,045 \\
\hline Mãe responsável pelo sustento familiar no domicílio & 0,008 & 0,897 & 0,003 & $-0,021$ & 0,839 & $-0,008$ \\
\hline Mãe diagnosticada com doença crônica & 0,398 & 0,000 & 0,150 & 0,301 & 0,016 & 0,111 \\
\hline \multicolumn{7}{|l|}{ Plane jamento da gravide $\mathrm{z}=$} \\
\hline VSE - Vulnerabilidade Socioeconômica & 0,202 & 0,034 & 0,103 & 0,114 & 0,418 & 0,063 \\
\hline Autoavaliação da Saúde & $-0,015$ & 0,742 & $-0,017$ & $-0,069$ & 0,459 & $-0,079$ \\
\hline Familia não nuclear & 0,263 & 0,035 & 0,107 & 0,271 & 0,312 & 0,110 \\
\hline Mãe responsável pelo sustento familiar no domicílio & $-0,007$ & 0,937 & $-0,004$ & 0,046 & 0,795 & 0,020 \\
\hline Mãe diagnosticada com doença crônica & $-0,001$ & 0,990 & $-0,001$ & $-0,094$ & 0,570 & $-0,040$ \\
\hline \multicolumn{7}{|l|}{ Filho com baixo peso ao nascer anterior= } \\
\hline VSE - Vulnerabilidade Socioeconômica & 0,263 & 0,000 & 0,135 & 0,354 & 0,000 & 0,194 \\
\hline \multicolumn{7}{|l|}{ Multiparidade $=$} \\
\hline VSE - Vulnerabilidade Socioeconômica & 0,792 & 0,000 & 0,379 & 0,556 & 0,000 & 0,298 \\
\hline \multicolumn{7}{|l|}{ Hipertensão arterial= } \\
\hline VSE - Vulnerabilidade Socioeconômica & 0,376 & 0,000 & 0,191 & 0,295 & 0,009 & 0,163 \\
\hline \multicolumn{7}{|l|}{ IMC - Categorias de risco $=$} \\
\hline VSE - Vulnerabilidade Socioeconômica & 1,088 & 0,000 & 0,491 & 0,920 & 0,000 & 0,458 \\
\hline \multicolumn{7}{|c|}{ Inadequação da assistência Pré-Natal - PHPN Simples= } \\
\hline VSE - Vulnerabilidade Socioeconômica & 0,822 & 0,000 & 0,387 & 0,620 & 0,000 & 0,318 \\
\hline Família não nuclear & 0,041 & 0,600 & 0,015 & 0,055 & 0,709 & 0,020 \\
\hline Mãe responsável pelo sustento familiar no domicílio & 0,135 & 0,040 & 0,060 & $-0,006$ & 0,955 & $-0,003$ \\
\hline Mãe diagnosticada com doença crônica & $-0,198$ & 0,011 & $-0,076$ & $-0,183$ & 0,140 & $-0,071$ \\
\hline Planejamento da gravidez & $-0,061$ & 0,295 & $-0,057$ & $-0,197$ & 0,018 & $-0,182$ \\
\hline Autoavaliação da Saúde & 0,003 & 0,929 & 0,003 & 0,030 & 0,649 & 0,032 \\
\hline Filho com baixo peso ao nascer anterior & 0,058 & 0,228 & 0,053 & 0,007 & 0,928 & 0,006 \\
\hline Multiparidade & $-0,032$ & 0,454 & $-0,032$ & $-0,002$ & 0,980 & $-0,002$ \\
\hline Hipertensão arterial & $-0,134$ & 0,004 & $-0,124$ & $-0,097$ & 0,191 & $-0,090$ \\
\hline IMC - Categorias de risco & 0,035 & 0,415 & 0,037 & 0,048 & 0,488 & 0,049 \\
\hline \multicolumn{7}{|l|}{ Correlações } \\
\hline Escolaridade Resp, domicílio e Escolaridade da mãe & 1,493 & 0,000 & 0,626 & 1,220 & 0,000 & 0,543 \\
\hline \multirow[t]{2}{*}{ Família não nuclear e VSE } & 0,019 & 0,001 & 0,091 & 0,033 & 0,000 & 0,144 \\
\hline & \multicolumn{6}{|c|}{ Índices de Ajuste do Modelo } \\
\hline CFI & 0,954 & & & 0,977 & & \\
\hline TLI & 0,935 & & & 0,968 & & \\
\hline RMSEA & 0,050 & IC $90 \%(0$ & $, 05-0,06)$ & 0,019 & $90 \%(0,0$ & $0,02)$ \\
\hline
\end{tabular}


A Tabela 10 apresenta os modelos com e sem aplicação de peso amostral para o desfecho "Inadequação do pré-natal - Takeda” com estimador WLSMV.

Os dois modelos também apresentaram índices de ajuste satisfatórios, de acordo com os valores de referência considerados.

Os componentes de mensuração e estrutural dos modelos apresentaram cargas fatoriais e efeitos próximos aos dos modelos anteriores.

No modelo sem peso amostral, assim como no modelo para o desfecho PHPN simples, as variáveis VSE, mãe responsável pelo sustento familiar, diagnóstico de doença crônica e hipertensão arterial apresentaram efeitos estatisticamente significantes sobre o desfecho de inadequação do pré-natal segundo o índice de Takeda.

No modelo com peso amostral, apenas a variável VSE apresentou efeito estatisticamente significante sobre o desfecho. 
Tabela 10. Resumo dos modelos com e sem peso amostral para o desfecho "Inadequação da Assistência Pré-Natal - Índice de Takeda”. Estimador WLSMV.

\begin{tabular}{|c|c|c|c|c|c|c|}
\hline \multirow{2}{*}{ Variáveis } & \multicolumn{3}{|c|}{$\begin{array}{c}\text { Estimador WLSMV-Sem pesos } \\
\text { amostrais }\end{array}$} & \multicolumn{3}{|c|}{$\begin{array}{c}\text { Estimador WLSMV - Com pesos } \\
\text { amostrais }\end{array}$} \\
\hline & Estimativa & p-valor & $\begin{array}{c}\text { Estimativa } \\
\text { padronizada }\end{array}$ & Estimativa & p-valor & $\begin{array}{l}\text { Estimativa } \\
\text { padronizada }\end{array}$ \\
\hline \multicolumn{7}{|l|}{ Componente de Mensuração - Constructos } \\
\hline \multicolumn{7}{|l|}{ VSE - Vulne rabilidade Socioeconômica } \\
\hline Renda média domiciliar per capita em desvios padrão & 1,000 & - & 0,816 & 1,000 & - & 0,784 \\
\hline Escolaridade do responsável pelo sustento familiar & 1,746 & 0,000 & 0,500 & 1,661 & 0,000 & 0,519 \\
\hline Escolaridade da mãe & 1,669 & 0,000 & 0,506 & 1,554 & 0,000 & 0,526 \\
\hline Raça cor da mãe & 0,933 & 0,000 & 0,444 & 1,238 & 0,000 & 0,582 \\
\hline Mãe com ocupação & 1,445 & 0,000 & 0,609 & 0,926 & 0,000 & 0,472 \\
\hline \multicolumn{7}{|l|}{ Componente Estrutural } \\
\hline \multicolumn{7}{|l|}{ Autoavaliação da Saúde= } \\
\hline VSE - Vulnerabilidade Socioeconômica & 0,863 & 0,000 & 0,411 & 0,939 & 0,000 & 0,472 \\
\hline Família não nuclear & 0,115 & 0,106 & 0,042 & 0,132 & 0,440 & 0,047 \\
\hline Mãe responsável pelo sustento familiar no domicílio & 0,008 & 0,897 & 0,003 & $-0,020$ & 0,839 & $-0,008$ \\
\hline Mãe diagnosticada com doença crônica & 0,397 & 0,000 & 0,150 & 0,302 & 0,016 & 0,112 \\
\hline \multicolumn{7}{|l|}{ Plane jamento da gravide $z=$} \\
\hline VSE - Vulnerabilidade Socioeconômica & 0,194 & 0,034 & 0,102 & 0,107 & 0,425 & 0,061 \\
\hline Autoavaliação da Saúde & $-0,015$ & 0,752 & $-0,016$ & $-0,067$ & 0,467 & $-0,077$ \\
\hline Família não nuclear & 0,263 & 0,035 & 0,107 & 0,273 & 0,309 & 0,111 \\
\hline Mãe responsável pelo sustento familiar no domicílio & $-0,007$ & 0,937 & $-0,004$ & 0,045 & 0,796 & 0,020 \\
\hline Mãe diagnosticada com doença crônica & $-0,001$ & 0,990 & $-0,001$ & $-0,095$ & 0,568 & $-0,040$ \\
\hline \multicolumn{7}{|l|}{ Filho com baixo peso ao nascer anterior= } \\
\hline VSE - Vulnerabilidade Socioeconômica & 0,263 & 0,000 & 0,134 & 0,340 & 0,000 & 0,193 \\
\hline \multicolumn{7}{|l|}{ Multiparidade $=$} \\
\hline VSE - Vulnerabilidade Socioeconômica & 0,792 & 0,000 & 0,378 & 0,538 & 0,000 & 0,297 \\
\hline \multicolumn{7}{|l|}{ Hipertensão arterial $=$} \\
\hline VSE - Vulnerabilidade Socioeconômica & 0,376 & 0,000 & 0,193 & 0,292 & 0,009 & 0,166 \\
\hline \multicolumn{7}{|l|}{ IMC - Categorias de risco $=$} \\
\hline VSE - Vulnerabilidade Socioeconômica & 1,088 & 0,000 & 0,489 & 0,894 & 0,000 & 0,459 \\
\hline \multicolumn{7}{|l|}{ Inadequação da assistência Pré-Natal - Takeda= } \\
\hline VSE - Vulnerabilidade Socioeconômica & 1,212 & 0,000 & 0,550 & 1,180 & 0,000 & 0,574 \\
\hline Família não nuclear & 0,105 & 0,269 & 0,037 & 0,054 & 0,790 & 0,019 \\
\hline Mãe responsável pelo sustento familiar no domicílio & 0,199 & 0,010 & 0,083 & $-0,019$ & 0,891 & $-0,007$ \\
\hline Mãe diagnosticada com doença crônica & $-0,200$ & 0,034 & $-0,072$ & $-0,129$ & 0,427 & $-0,046$ \\
\hline Planejamento da gravidez & $-0,110$ & 0,112 & $-0,095$ & $-0,207$ & 0,098 & $-0,176$ \\
\hline Autoavaliação da Saúde & $-0,047$ & 0,321 & $-0,045$ & $-0,079$ & 0,361 & $-0,077$ \\
\hline Filho com baixo peso ao nascer anterior & 0,093 & 0,093 & 0,080 & $-0,042$ & 0,633 & $-0,036$ \\
\hline Multiparidade & $-0,056$ & 0,282 & $-0,052$ & $-0,078$ & 0,348 & $-0,068$ \\
\hline Hipertensão arterial & $-0,199$ & 0,001 & $-0,173$ & $-0,155$ & 0,141 & $-0,132$ \\
\hline IMC - Categorias de risco & $-0,061$ & 0,251 & $-0,059$ & $-0,004$ & 0,963 & $-0,004$ \\
\hline \multicolumn{7}{|l|}{ Correlações } \\
\hline Escolaridade Resp, domicílio e Escolaridade da mãe & 1,535 & 0,000 & 0,632 & 1,268 & 0,000 & 0,553 \\
\hline \multirow[t]{2}{*}{ Família não nuclear e VSE } & 0,020 & 0,001 & 0,092 & 0,034 & 0,000 & 0,142 \\
\hline & \multicolumn{6}{|c|}{ Índices de Ajuste do Modelo } \\
\hline CFI & 0,953 & & & 0,979 & & \\
\hline TLI & 0,934 & & & 0,970 & & \\
\hline RMSEA & 0,050 & IC $90 \%(0$ & $0,05-0,06)$ & 0,018 & IC $90 \%$ & $, 01-0,02)$ \\
\hline
\end{tabular}


A Tabela 11 apresenta os modelos com e sem aplicação de peso amostral para o desfecho "Inadequação do pré-natal - Silva" com estimador WLSMV.

Os dois modelos também apresentaram índices de ajuste satisfatórios, de acordo com os valores de referência considerados.

Os componentes de mensuração e estrutural dos modelos apresentaram cargas fatoriais e efeitos próximos aos dos modelos anteriores.

Em ambos os modelos, além da VSE apenas a variável de hipertensão arterial apresentou efeito estatisticamente significante sobre o desfecho de inadequação do prénatal segundo o índice de Silva, o que também é observado no modelo com peso amostral. 
Tabela 11. Resumo dos modelos com e sem peso amostral para o desfecho "Inadequação da Assistência Pré-Natal - Índice proposto por Silva”. Estimador WLSMV.

\begin{tabular}{|c|c|c|c|c|c|c|}
\hline \multirow{2}{*}{ Variáveis } & \multicolumn{3}{|c|}{$\begin{array}{c}\text { Estimador WLSMV-Sem pesos } \\
\text { amostrais }\end{array}$} & \multicolumn{3}{|c|}{$\begin{array}{c}\text { Estimador WLSMV - Com pesos } \\
\text { amostrais }\end{array}$} \\
\hline & Estimativa & p-valor & $\begin{array}{l}\text { Estimativa } \\
\text { padronizada }\end{array}$ & Estimativa & p-valor & $\begin{array}{l}\text { Estimativa } \\
\text { padronizada }\end{array}$ \\
\hline \multicolumn{7}{|l|}{ Componente de Mensuração - Constructos } \\
\hline \multicolumn{7}{|l|}{ VSE - Vulne rabilidade Socioeconômica } \\
\hline Renda média domiciliar per capita em desvios padrão & 1,000 & - & 0,804 & 1,000 & - & 0,775 \\
\hline Escolaridade do responsável pelo sustento familiar & 1,804 & 0,000 & 0,507 & 1,705 & 0,000 & 0,523 \\
\hline Escolaridade da mãe & 1,721 & 0,000 & 0,513 & 1,598 & 0,000 & 0,532 \\
\hline Raça cor da mãe & 0,956 & 0,000 & 0,445 & 1,276 & 0,000 & 0,586 \\
\hline Mãe com ocupação & 1,500 & 0,000 & 0,617 & 0,963 & 0,000 & 0,481 \\
\hline \multicolumn{7}{|l|}{ Componente Estrutural } \\
\hline \multicolumn{7}{|l|}{ Autoavaliação da Saúde= } \\
\hline VSE - Vulnerabilidade Socioeconômica & 0,879 & 0,000 & 0,412 & 0,957 & 0,000 & 0,473 \\
\hline Família não nuclear & 0,115 & 0,106 & 0,042 & 0,129 & 0,450 & 0,046 \\
\hline Mãe responsável pelo sustento familiar no domicílio & 0,008 & 0,897 & 0,003 & $-0,021$ & 0,839 & $-0,008$ \\
\hline Mãe diagnosticada com doença crônica & 0,397 & 0,000 & 0,150 & 0,303 & 0,015 & 0,112 \\
\hline \multicolumn{7}{|l|}{ Plane jamento da gravide $\mathrm{z}=$} \\
\hline VSE - Vulnerabilidade Socioeconômica & 0,199 & 0,034 & 0,103 & 0,112 & 0,414 & 0,063 \\
\hline Autoavaliação da Saúde & $-0,015$ & 0,746 & $-0,016$ & $-0,069$ & 0,460 & $-0,079$ \\
\hline Família não nuclear & 0,263 & 0,035 & 0,107 & 0,266 & 0,320 & 0,110 \\
\hline Mãe responsável pelo sustento familiar no domicílio & $-0,007$ & 0,937 & $-0,004$ & 0,046 & 0,795 & 0,020 \\
\hline Mãe diagnosticada com doença crônica & $-0,001$ & 0,989 & $-0,001$ & $-0,094$ & 0,569 & $-0,040$ \\
\hline \multicolumn{7}{|l|}{ Filho com baixo peso ao nascer anterior= } \\
\hline VSE - Vulnerabilidade Socioeconômica & 0,260 & 0,000 & 0,134 & 0,346 & 0,000 & 0,194 \\
\hline \multicolumn{7}{|l|}{ Multiparidade $=$} \\
\hline VSE - Vulnerabilidade Socioeconômica & 0,783 & 0,000 & 0,379 & 0,547 & 0,000 & 0,297 \\
\hline \multicolumn{7}{|l|}{ Hipertensão arterial $=$} \\
\hline VSE - Vulnerabilidade Socioeconômica & 0,374 & 0,000 & 0,192 & 0,293 & 0,009 & 0,165 \\
\hline \multicolumn{7}{|l|}{ IMC - Categorias de risco } \\
\hline VSE - Vulnerabilidade Socioeconômica & 1,075 & 0,000 & 0,490 & 0,907 & 0,000 & 0,459 \\
\hline \multicolumn{7}{|l|}{ Inadequação da assis tência Pré-Natal - Silva= } \\
\hline VSE - Vulnerabilidade Socioeconômica & 0,676 & 0,000 & 0,338 & 0,855 & 0,000 & 0,490 \\
\hline Familia não nuclear & 0,006 & 0,940 & $-0,018$ & $-0,044$ & 0,784 & $-0,027$ \\
\hline Mãe responsável pelo sustento familiar no domicílio & 0,113 & 0,077 & 0,051 & $-0,004$ & 0,975 & 0,005 \\
\hline Mãe diagnosticada com doença crônica & $-0,112$ & 0,136 & $-0,029$ & $-0,056$ & 0,676 & $-0,016$ \\
\hline Planejamento da gravidez & $-0,059$ & 0,302 & $-0,024$ & $-0,182$ & 0,103 & $-0,127$ \\
\hline Autoavaliação da Saúde & 0,010 & 0,782 & 0,001 & 0,033 & 0,639 & $-0,021$ \\
\hline Filho com baixo peso ao nascer anterior & 0,050 & 0,293 & $-0,003$ & 0,057 & 0,483 & 0,032 \\
\hline Multiparidade & $-0,051$ & 0,218 & $-0,072$ & $-0,112$ & 0,110 & $-0,122$ \\
\hline Hipertensão arterial & $-0,148$ & 0,001 & $-0,130$ & $-0,191$ & 0,020 & $-0,212$ \\
\hline IMC - Categorias de risco & 0,039 & 0,369 & 0,025 & 0,018 & 0,815 & $-0,023$ \\
\hline \multicolumn{7}{|l|}{ Correlações } \\
\hline Escolaridade Resp, domicilio e Escolaridade da mãe & 1,509 & 0,000 & 0,629 & 1,245 & 0,000 & 0,550 \\
\hline \multirow[t]{2}{*}{ Família não nuclear e VSE } & 0,020 & 0,001 & 0,092 & 0,033 & 0,000 & 0,143 \\
\hline & \multicolumn{6}{|c|}{ Índices de Ajuste do Modelo } \\
\hline CFI & 0,953 & & & 0,980 & & \\
\hline TLI & 0,934 & & & 0,972 & & \\
\hline RMSEA & 0,050 & $\mathrm{IC} 90 \%(\mathrm{C}$ & $0,05-0,06)$ & 0,018 & IC $90 \%(($ & $0,01-0,02)$ \\
\hline
\end{tabular}


A Tabela 12 apresenta os modelos com e sem aplicação de peso amostral para o desfecho "Realização de menos de sete consultas de pré-natal" com estimador WLSMV.

Os dois modelos também apresentaram índices de ajuste satisfatórios, de acordo com os valores de referência considerados.

Os componentes de mensuração e estrutural dos modelos apresentaram cargas fatoriais e efeitos próximos aos dos modelos anteriores.

No modelo sem peso amostral, as variáveis VSE, diagnóstico de doença crônica e hipertensão arterial apresentaram efeitos estatisticamente significantes sobre o desfecho realização de menos de sete consultas de pré-natal.

No modelo com peso amostral, apenas a variável VSE apresentou efeito estatisticamente significante sobre o desfecho. 
Tabela 12. Resumo dos modelos com e sem peso amostral para o desfecho "Realização de menos de sete consultas de pré-natal”. Estimador WLSMV.

\begin{tabular}{|c|c|c|c|c|c|c|}
\hline \multirow{2}{*}{ Variáveis } & \multicolumn{3}{|c|}{$\begin{array}{c}\text { Estimador WLSMV- Sem pesos } \\
\text { amostrais }\end{array}$} & \multicolumn{3}{|c|}{$\begin{array}{c}\text { Estimador WLSMV - Com pesos } \\
\text { amostrais } \\
\end{array}$} \\
\hline & Estimativa & $\mathrm{p}$-valor & $\begin{array}{c}\text { Estimativa } \\
\text { padronizada }\end{array}$ & Estimativa 1 & p-valor & $\begin{array}{l}\text { Estimativa } \\
\text { padronizada }\end{array}$ \\
\hline \multicolumn{7}{|l|}{ Componente de Mensuração - Constructos } \\
\hline \multicolumn{7}{|l|}{ VSE - Vulne rabilidade Socioeconômica } \\
\hline Renda média domiciliar per capita em desvios padrão & 1,000 & - & 0,812 & 1,000 & - & 0,779 \\
\hline Escolaridade do responsável pelo sustento familiar & 1,761 & 0,000 & 0,502 & 1,677 & 0,000 & 0,521 \\
\hline Escolaridade da mãe & 1,686 & 0,000 & 0,509 & 1,576 & 0,000 & 0,530 \\
\hline Raça cor da mãe & 0,965 & 0,000 & 0,454 & 1,270 & 0,000 & 0,589 \\
\hline Mãe com ocupação & 1,440 & 0,000 & 0,606 & 0,925 & 0,000 & 0,469 \\
\hline \multicolumn{7}{|l|}{ Componente Estrutural } \\
\hline \multicolumn{7}{|l|}{ Autoavaliação da Saúde= } \\
\hline VSE - Vulnerabilidade Socioeconômica & 0,868 & 0,000 & 0,411 & 0,947 & 0,000 & 0,473 \\
\hline Família não nuclear & 0,115 & 0,108 & 0,042 & 0,131 & 0,445 & 0,046 \\
\hline Mãe responsável pelo sustento familiar no domicílio & 0,008 & 0,897 & 0,003 & $-0,020$ & 0,839 & $-0,008$ \\
\hline Mãe diagnosticada com doença crônica & 0,397 & 0,000 & 0,150 & 0,302 & 0,016 & 0,112 \\
\hline \multicolumn{7}{|l|}{ Plane jamento da gravide $\mathrm{z}=$} \\
\hline VSE - Vulnerabilidade Socioeconômica & 0,195 & 0,034 & 0,102 & 0,108 & 0,426 & 0,061 \\
\hline Autoavaliação da Saúde & $-0,015$ & 0,751 & $-0,016$ & $-0,068$ & 0,466 & $-0,077$ \\
\hline Familia não nuclear & 0,263 & 0,035 & 0,107 & 0,275 & 0,307 & 0,111 \\
\hline Mãe responsável pelo sustento familiar no domicílio & $-0,007$ & 0,937 & $-0,004$ & 0,045 & 0,796 & 0,020 \\
\hline Mãe diagnosticada com doença crônica & $-0,001$ & 0,989 & $-0,001$ & $-0,096$ & 0,564 & $-0,040$ \\
\hline \multicolumn{7}{|l|}{ Filho com baixo peso ao nascer anterior= } \\
\hline VSE - Vulnerabilidade Socioeconômica & 0,257 & 0,000 & 0,135 & 0,343 & 0,000 & 0,193 \\
\hline \multicolumn{7}{|l|}{ Multiparidade $=$} \\
\hline VSE - Vulnerabilidade Socioeconômica & 0,774 & 0,000 & 0,379 & 0,543 & 0,000 & 0,297 \\
\hline \multicolumn{7}{|l|}{ Hipertensão arterial= } \\
\hline VSE - Vulnerabilidade Socioeconômica & 0,371 & 0,000 & 0,193 & 0,292 & 0,009 & 0,165 \\
\hline \multicolumn{7}{|l|}{ IMC - Categorias de risco $=$} \\
\hline VSE - Vulnerabilidade Socioeconômica & 1,061 & 0,000 & 0,489 & 0,901 & 0,000 & 0,459 \\
\hline \multicolumn{7}{|l|}{ Realização de menos de sete consultas de pré-natal= } \\
\hline VSE - Vulnerabilidade Socioeconômica & 1,070 & 0,000 & 0,492 & 1,017 & 0,000 & 0,514 \\
\hline Família não nuclear & 0,042 & 0,629 & 0,015 & $-0,001$ & 0,995 & 0,000 \\
\hline Mãe responsável pelo sustento familiar no domicîlio & 0,092 & 0,190 & 0,039 & $-0,153$ & 0,187 & $-0,061$ \\
\hline Mãe diagnosticada com doença crônica & $-0,197$ & 0,020 & $-0,072$ & $-0,135$ & 0,311 & $-0,051$ \\
\hline Planejamento da gravidez & 0,013 & 0,842 & 0,011 & $-0,043$ & 0,681 & $-0,039$ \\
\hline Autoavaliação da Saúde & 0,001 & 0,983 & 0,001 & $-0,029$ & 0,677 & $-0,030$ \\
\hline Filho com baixo peso ao nascer anterior & 0,095 & 0,065 & 0,083 & $-0,020$ & 0,799 & $-0,018$ \\
\hline Multiparidade & $-0,030$ & 0,514 & $-0,029$ & $-0,101$ & 0,168 & $-0,093$ \\
\hline Hipertensão arterial & $-0,185$ & 0,001 & $-0,164$ & $-0,156$ & 0,078 & $-0,139$ \\
\hline IMC - Categorias de risco & $-0,026$ & 0,579 & $-0,026$ & $-0,022$ & 0,757 & $-0,022$ \\
\hline \multicolumn{7}{|l|}{ Correlações } \\
\hline Escolaridade Resp, domicilio e Escolaridade da mãe & 1,528 & 0,000 & 0,631 & 1,259 & 0,000 & 0,551 \\
\hline \multirow[t]{2}{*}{ Família não nuclear e VSE } & 0,020 & 0,001 & 0,092 & 0,034 & 0,000 & 0,143 \\
\hline & \multicolumn{6}{|c|}{ Índices de Ajuste do Modelo } \\
\hline CFI & 0,951 & & & 0,977 & & \\
\hline TLI & 0,931 & & & 0,967 & & \\
\hline RMSEA & 0,052 & IC90\%( & $0,05-0,06)$ & $0,019 \mathrm{I}$ & IC90\%(( & $0,01-0,02)$ \\
\hline
\end{tabular}


A Tabela 13 apresenta os modelos com e sem aplicação de peso amostral para o desfecho "Inadequação do pré-natal - PHPN simples" com estimador MLR, estimador de máxima verossimilhança robusta, que apresenta os valores de odds ratio das regressões logísticas do modelo estrutural.

No componente estrutural, a variável latente independente VSE é responsável tanto pela maioria dos efeitos estatisticamente significantes (exceto em relação à variável planejamento da gravidez no modelo com peso amostral) quanto pelos efeitos mais fortes sobre as outras covariáveis.

Além da VSE, ter diagnóstico de doença crônica apresentou efeito estatisticamente significante sobre a autoavaliação da saúde (aumentando a probabilidade de avaliação negativa), em ambos os modelos. Para a variável planejamento da gravidez, no modelo sem peso amostral família não-nuclear apresentou efeito estatisticamente significante, enquanto no modelo com peso amostral nenhum efeito foi significante.

No modelo sem peso amostral, apresentaram efeitos estatisticamente significantes sobre o desfecho de inadequação do pré-natal segundo o método PHPN simples as variáveis: VSE $(\mathrm{OR}=5,65)$, mãe responsável pelo sustento familiar $(\mathrm{OR}=1,23)$ e hipertensão arterial $(\mathrm{OR}=0,68)$.

No modelo com peso amostral, apenas as variáveis VSE $(\mathrm{OR}=4,79)$ e planejamento da gravidez $(\mathrm{OR}=0,54)$ apresentaram efeitos estatisticamente significantes sobre o desfecho. 
Tabela 13. Resumo dos modelos com e sem peso amostral para o desfecho "Inadequação da Assistência Pré-Natal - PHPN Simples”. Estimador MLR.

\begin{tabular}{|c|c|c|c|c|c|c|}
\hline \multirow[t]{2}{*}{ Variáveis } & \multicolumn{3}{|c|}{$\begin{array}{c}\text { Estimador MLR- Sem pesos } \\
\text { amostrais }\end{array}$} & \multicolumn{3}{|c|}{$\begin{array}{c}\text { Estimador MLR - Com pesos } \\
\text { amostrais }\end{array}$} \\
\hline & Estimativa & p-valor & OR & Estimativa & p-valor & OR \\
\hline \multicolumn{7}{|l|}{ Componente de Mensuração - Constructos } \\
\hline \multicolumn{7}{|l|}{ VSE - Vulne rabilidade Socioeconômica } \\
\hline Renda média domiciliar per capita em desvios padrão & 1,000 & - & & 1,000 & - & \\
\hline Escolaridade do responsável pelo sustento familiar & 2,256 & 0,000 & & 2,163 & 0,000 & \\
\hline Escolaridade da mãe & 2,258 & 0,000 & & 2,100 & 0,000 & \\
\hline Raça cor da mãe & 1,849 & 0,000 & & 2,077 & 0,000 & \\
\hline Mãe com ocupação & 2,148 & 0,000 & & 1,663 & 0,001 & \\
\hline \multicolumn{7}{|l|}{ Componente Estrutural } \\
\hline \multicolumn{7}{|l|}{ Autoavaliação da Saúde= } \\
\hline VSE - Vulnerabilidade Socioeconômica & 1,864 & 0,000 & 6,45 & 1,964 & 0,000 & 7,13 \\
\hline Família não nuclear & 0,180 & 0,147 & 1,20 & 0,169 & 0,480 & 1,18 \\
\hline Mãe responsável pelo sustento familiar no domicîlio & $-0,053$ & 0,615 & 0,95 & $-0,092$ & 0,619 & 0,91 \\
\hline Mãe diagnosticada com doença crônica & 0,823 & 0,000 & 2,28 & 0,701 & 0,005 & 2,02 \\
\hline \multicolumn{7}{|l|}{ Plane jamento da gravide $\mathrm{z}=$} \\
\hline VSE - Vulnerabilidade Socioeconômica & 0,439 & 0,039 & 1,55 & 0,139 & 0,697 & 1,15 \\
\hline Autoavaliação da Saúde & $-0,061$ & 0,711 & 0,94 & $-0,173$ & 0,525 & 0,84 \\
\hline Família não nuclear & 0,529 & 0,038 & 1,70 & 0,576 & 0,335 & 1,78 \\
\hline Mãe responsável pelo sustento familiar no domicîlio & $-0,099$ & 0,594 & 0,91 & 0,072 & 0,842 & 1,08 \\
\hline Mãe diagnosticada com doença crônica & 0,004 & 0,985 & 1,00 & $-0,211$ & 0,527 & 0,81 \\
\hline \multicolumn{7}{|l|}{ Filho com baixo peso ao nascer anterior= } \\
\hline VSE - Vulnerabilidade Socioeconômica & 0,590 & 0,015 & 1,80 & 0,797 & 0,003 & 2,22 \\
\hline \multicolumn{7}{|l|}{ Multiparidade $=$} \\
\hline VSE - Vulnerabilidade Socioeconômica & 1,436 & 0,000 & 4,20 & 0,917 & 0,001 & 2,50 \\
\hline \multicolumn{7}{|l|}{ Hipertensão arterial= } \\
\hline VSE - Vulnerabilidade Socioeconômica & 0,736 & 0,000 & 2,09 & 0,588 & 0,006 & 1,80 \\
\hline \multicolumn{7}{|l|}{ IMC - Categorias de risco $=$} \\
\hline VSE - Vulnerabilidade Socioeconômica & 2,197 & 0,000 & 9,00 & 1,765 & 0,000 & 5,84 \\
\hline \multicolumn{7}{|l|}{ Inadequação da assistência Pré-Natal - PHPN Simples= } \\
\hline VSE - Vulnerabilidade Socioeconômica & 1,732 & 0,000 & 5,65 & 1,567 & 0,002 & 4,79 \\
\hline Família não nuclear & $-0,003$ & 0,984 & 1,00 & $-0,096$ & 0,635 & 0,91 \\
\hline Mãe responsável pelo sustento familiar no domicilio & 0,209 & 0,050 & 1,23 & $-0,011$ & 0,950 & 0,99 \\
\hline Mãe diagnosticada com doença crônica & $-0,212$ & 0,097 & 0,81 & $-0,172$ & 0,399 & 0,84 \\
\hline Planejamento da gravidez & $-0,220$ & 0,274 & 0,80 & $-0,624$ & 0,026 & 0,54 \\
\hline Autoavaliação da Saúde & 0,017 & 0,846 & 1,02 & 0,052 & 0,738 & 1,05 \\
\hline Filho com baixo peso ao nascer anterior & 0,174 & 0,223 & 1,19 & $-0,024$ & 0,918 & 0,98 \\
\hline Multiparidade & $-0,109$ & 0,377 & 0,90 & $-0,036$ & 0,841 & 0,96 \\
\hline Hipertensão arterial & $-0,388$ & 0,003 & 0,68 & $-0,246$ & 0,234 & 0,78 \\
\hline IMC - Categorias de risco & 0,080 & 0,501 & 1,08 & 0,056 & 0,771 & 1,06 \\
\hline \multicolumn{7}{|l|}{ Correlações } \\
\hline Escolaridade Resp. domicîlio e Escolaridade da mãe & 1,254 & 0,000 & & 0,983 & 0,000 & \\
\hline \multirow[t]{2}{*}{ Família não nuclear e VSE } & 0,022 & 0,000 & & 0,041 & 0,000 & \\
\hline & \multicolumn{6}{|c|}{ Índices de Ajuste do Modelo } \\
\hline Akaike (AIC) & 38413,215 & & & 39142,505 & & \\
\hline Bayesian (BIC) & 38689,389 & & & 39418,679 & & \\
\hline
\end{tabular}


A Tabela 14 apresenta os modelos com e sem aplicação de peso amostral para o desfecho "Inadequação do pré-natal - Takeda" com estimador MLR.

Os componentes de mensuração e estrutural dos modelos apresentaram cargas fatoriais e efeitos próximas aos dos modelos anteriores.

No modelo sem peso amostral, apresentaram efeitos estatisticamente significantes sobre o desfecho de inadequação do pré-natal segundo o índice de Takeda simples as variáveis: VSE $(\mathrm{OR}=8,49)$, mãe responsável pelo sustento familiar $(\mathrm{OR}=1,33)$ e hipertensão arterial $(\mathrm{OR}=0,59)$.

No modelo com peso amostral, apenas a variável VSE $(\mathrm{OR}=8,01)$ apresentou efeitos estatisticamente significantes sobre o desfecho. 
Tabela 14. Resumo dos modelos com e sem peso amostral para o desfecho "Inadequação da Assistência Pré-Natal - Índice de Takeda". Estimador MLR.

\begin{tabular}{|c|c|c|c|c|c|c|}
\hline \multirow{2}{*}{ Variáveis } & \multicolumn{3}{|c|}{$\begin{array}{c}\text { Estimador MLR- Sem pesos } \\
\text { amostrais }\end{array}$} & \multicolumn{3}{|c|}{$\begin{array}{c}\text { Estimador MLR - Com pesos } \\
\text { amostrais } \\
\end{array}$} \\
\hline & Estimativa & p-valor & OR & Estimativa & p-valor & OR \\
\hline \multicolumn{7}{|l|}{$\overline{\text { Componente de Mensuração - Constructos }}$} \\
\hline \multicolumn{7}{|l|}{ VSE - Vulne rabilidade Socioeconômica } \\
\hline Renda média domiciliar per capita em desvios padrão & 1,000 & - & & 1,000 & - & \\
\hline Escolaridade do responsável pelo sustento familiar & 2,186 & 0,000 & & 2,133 & 0,000 & \\
\hline Escolaridade da mãe & 2,181 & 0,000 & & 2,066 & 0,000 & \\
\hline Raça cor da mãe & 1,874 & 0,000 & & 2,082 & 0,000 & \\
\hline Mãe com ocupação & 2,089 & 0,000 & & 1,589 & 0,002 & \\
\hline \multicolumn{7}{|l|}{ Componente Estrutural } \\
\hline \multicolumn{7}{|l|}{ Autoavaliação da Saúde= } \\
\hline VSE - Vulnerabilidade Socioeconômica & 1,845 & 0,000 & 6,33 & 1,962 & 0,000 & 7,12 \\
\hline Família não nuclear & 0,179 & 0,150 & 1,20 & 0,167 & 0,484 & 1,18 \\
\hline Mãe responsável pelo sustento familiar no domicîlio & $-0,054$ & 0,611 & 0,95 & $-0,089$ & 0,628 & 0,92 \\
\hline Mãe diagnosticada com doença crônica & 0,824 & 0,000 & 2,28 & 0,700 & 0,005 & 2,01 \\
\hline \multicolumn{7}{|l|}{ Plane jamento da gravide $\mathrm{z}=$} \\
\hline VSE - Vulnerabilidade Socioeconômica & 0,422 & 0,041 & 1,53 & 0,133 & 0,702 & 1,14 \\
\hline Autoavaliação da Saúde & $-0,058$ & 0,723 & 0,94 & $-0,172$ & 0,527 & 0,84 \\
\hline Família não nuclear & 0,530 & 0,037 & 1,70 & 0,577 & 0,335 & 1,78 \\
\hline Mãe responsável pelo sustento familiar no domicîlio & $-0,099$ & 0,591 & 0,91 & 0,072 & 0,842 & 1,08 \\
\hline Mãe diagnosticada com doença crônica & 0,004 & 0,985 & 1,00 & $-0,211$ & 0,527 & 0,81 \\
\hline \multicolumn{7}{|l|}{ Filho com baixo peso ao nascer anterior= } \\
\hline VSE - Vulnerabilidade Socioeconômica & 0,580 & 0,017 & 1,79 & 0,795 & 0,003 & 2,22 \\
\hline \multicolumn{7}{|l|}{ Multiparidade $=$} \\
\hline VSE - Vulnerabilidade Socioeconômica & 1,418 & 0,000 & 4,13 & 0,912 & 0,001 & 2,49 \\
\hline \multicolumn{7}{|l|}{ Hipertensão arterial= } \\
\hline VSE - Vulnerabilidade Socioeconômica & 0,733 & 0,000 & 2,08 & 0,590 & 0,006 & 1,80 \\
\hline \multicolumn{7}{|l|}{ IMC - Categorias de risco= } \\
\hline VSE - Vulnerabilidade Socioeconômica & 2,193 & 0,000 & 8,96 & 1,769 & 0,000 & 5,86 \\
\hline \multicolumn{7}{|l|}{ Inadequação da assistência Pré-Natal - Takeda= } \\
\hline VSE - Vulnerabilidade Socioeconômica & 2,139 & 0,000 & 8,49 & 2,080 & 0,000 & 8,01 \\
\hline Família não nuclear & 0,132 & 0,366 & 1,14 & $-0,080$ & 0,723 & 0,92 \\
\hline Mãe responsável pelo sustento familiar no domicílio & 0,286 & 0,024 & 1,33 & $-0,016$ & 0,937 & 0,98 \\
\hline Mãe diagnosticada com doença crônica & $-0,248$ & 0,116 & 0,78 & $-0,092$ & 0,727 & 0,91 \\
\hline Planejamento da gravidez & $-0,372$ & 0,105 & 0,69 & $-0,572$ & 0,126 & 0,57 \\
\hline Autoavaliação da Saúde & $-0,004$ & 0,970 & 1,00 & $-0,003$ & 0,986 & 1,00 \\
\hline Filho com baixo peso ao nascer anterior & 0,312 & 0,052 & 1,37 & $-0,089$ & 0,720 & 0,92 \\
\hline Multiparidade & $-0,079$ & 0,576 & 0,92 & $-0,125$ & 0,551 & 0,88 \\
\hline Hipertensão arterial & $-0,532$ & 0,001 & 0,59 & $-0,329$ & 0,244 & 0,72 \\
\hline IMC - Categorias de risco & $-0,081$ & 0,567 & 0,92 & 0,071 & 0,752 & 1,07 \\
\hline \multicolumn{7}{|l|}{ Correlações } \\
\hline Escolaridade Resp, domicílio e Escolaridade da mãe & 1,288 & 0,000 & & 0,993 & 0,000 & \\
\hline \multirow[t]{2}{*}{ Família não nuclear e VSE } & 0,022 & 0,000 & & 0,041 & 0,000 & \\
\hline & \multicolumn{6}{|c|}{ Índices de Ajuste do Modelo } \\
\hline Akaike (AIC) & 37898,010 & & & 38492,567 & & \\
\hline Bayesian (BIC) & 38174,184 & & & 38768,741 & & \\
\hline
\end{tabular}


A Tabela 15 apresenta os modelos com e sem aplicação de peso amostral para o desfecho "Inadequação do pré-natal - Silva" com estimador MLR.

Os componentes de mensuração e estrutural dos modelos apresentaram cargas fatoriais e efeitos próximas aos dos modelos anteriores.

No modelo sem peso amostral, apresentaram efeitos estatisticamente significantes sobre o desfecho de inadequação do pré-natal segundo o índice de Silva simples as variáveis: VSE $(\mathrm{OR}=3,42)$, mãe responsável pelo sustento familiar $(\mathrm{OR}=1,23)$ e hipertensão arterial $(\mathrm{OR}=0,69)$.

No modelo com peso amostral, as variáveis VSE (OR=8,01), hipertensão arterial $(\mathrm{OR}=0,55)$ e multiparidade $(\mathrm{OR}=0,69)$ apresentaram efeitos estatisticamente significantes sobre o desfecho. 
Tabela 15. Resumo dos modelos com e sem peso amostral para o desfecho "Inadequação da Assistência Pré-Natal - Índice proposto por Silva”. Estimador MLR.

\begin{tabular}{|c|c|c|c|c|c|c|}
\hline \multirow[t]{2}{*}{ Variáveis } & \multicolumn{3}{|c|}{$\begin{array}{c}\text { Estimador MLR-Sem pesos } \\
\text { amostrais }\end{array}$} & \multicolumn{3}{|c|}{$\begin{array}{c}\text { Estimador MLR - Com pesos } \\
\text { amostrais }\end{array}$} \\
\hline & Estimativa & p-valor & OR & Estimativa & p-valor & OR \\
\hline \multicolumn{7}{|l|}{ Componente de Mensuração - Constructos } \\
\hline \multicolumn{7}{|l|}{ VSE - Vulne rabilidade Socioeconômica } \\
\hline Renda média domiciliar per capita em desvios padrão & 1,000 & - & & 1,000 & - & \\
\hline Escolaridade do responsável pelo sustento familiar & 2,241 & 0,000 & & 2,098 & 0,000 & \\
\hline Escolaridade da mãe & 2,216 & 0,000 & & 2,042 & 0,000 & \\
\hline Raça cor da mãe & 1,845 & 0,000 & & 2,056 & 0,000 & \\
\hline Mãe com ocupação & 2,076 & 0,000 & & 1,631 & 0,002 & \\
\hline \multicolumn{7}{|l|}{ Componente Estrutural } \\
\hline \multicolumn{7}{|l|}{ Autoavaliação da Saúde= } \\
\hline VSE - Vulnerabilidade Socioeconômica & 1,860 & 0,000 & 6,42 & 1,957 & 0,000 & 7,08 \\
\hline Família não nuclear & 0,179 & 0,150 & 1,20 & 0,175 & 0,463 & 1,19 \\
\hline Mãe responsável pelo sustento familiar no domicîlio & $-0,053$ & 0,615 & 0,95 & $-0,095$ & 0,608 & 0,91 \\
\hline Mãe diagnosticada com doença crônica & 0,824 & 0,000 & 2,28 & 0,703 & 0,005 & 2,02 \\
\hline \multicolumn{7}{|l|}{ Plane jamento da gravide $z=$} \\
\hline VSE - Vulnerabilidade Socioeconômica & 0,431 & 0,041 & 1,54 & 0,134 & 0,697 & 1,14 \\
\hline Autoavaliação da Saúde & $-0,060$ & 0,716 & 0,94 & $-0,173$ & 0,526 & 0,84 \\
\hline Família não nuclear & 0,529 & 0,038 & 1,70 & 0,577 & 0,335 & 1,78 \\
\hline Mãe responsável pelo sustento familiar no domicîlio & $-0,099$ & 0,593 & 0,91 & 0,072 & 0,843 & 1,08 \\
\hline Mãe diagnosticada com doença crônica & 0,004 & 0,985 & 1,00 & $-0,211$ & 0,528 & 0,81 \\
\hline \multicolumn{7}{|l|}{ Filho com baixo peso ao nascer anterior= } \\
\hline VSE - Vulnerabilidade Socioeconômica & 0,585 & 0,015 & 1,79 & 0,790 & 0,003 & 2,20 \\
\hline \multicolumn{7}{|l|}{ Multiparidade $=$} \\
\hline VSE - Vulnerabilidade Socioeconômica & 1,423 & 0,000 & 4,15 & 0,908 & 0,001 & 2,48 \\
\hline \multicolumn{7}{|l|}{ Hipertensão arterial= } \\
\hline VSE - Vulnerabilidade Socioeconômica & 0,736 & 0,000 & 2,09 & 0,587 & 0,006 & 1,80 \\
\hline \multicolumn{7}{|l|}{ IMC - Categorias de risco= } \\
\hline VSE - Vulnerabilidade Socioeconômica & 2,191 & 0,000 & 8,94 & 1,754 & 0,000 & 5,78 \\
\hline \multicolumn{7}{|l|}{ Inade quação da assistência Pré-Natal - Silva= } \\
\hline VSE - Vulnerabilidade Socioeconômica & 1,231 & 0,000 & 3,42 & 1,697 & 0,000 & 5,46 \\
\hline Família não nuclear & $-0,132$ & 0,272 & 0,88 & $-0,310$ & 0,127 & 0,73 \\
\hline Mãe responsável pelo sustento familiar no domicîlio & 0,206 & 0,046 & 1,23 & 0,060 & 0,715 & 1,06 \\
\hline Mãe diagnosticada com doença crônica & 0,007 & 0,956 & 1,01 & 0,147 & 0,459 & 1,16 \\
\hline Planejamento da gravidez & $-0,098$ & 0,608 & 0,91 & $-0,379$ & 0,298 & 0,69 \\
\hline Autoavaliação da Saúde & 0,019 & 0,820 & 1,02 & 0,005 & 0,975 & 1,01 \\
\hline Filho com baixo peso ao nascer anterior & 0,024 & 0,865 & 1,02 & 0,099 & 0,667 & 1,10 \\
\hline Multiparidade & $-0,192$ & 0,081 & 0,83 & $-0,368$ & 0,040 & 0,69 \\
\hline Hipertensão arterial & $-0,371$ & 0,003 & 0,69 & $-0,600$ & 0,002 & 0,55 \\
\hline IMC - Categorias de risco & 0,082 & 0,467 & 1,09 & 0,010 & 0,958 & 1,01 \\
\hline \multicolumn{7}{|l|}{ Correlações } \\
\hline Escolaridade Resp, domicilio e Escolaridade da mãe & 1,262 & 0,000 & & 1,012 & 0,000 & \\
\hline \multirow[t]{2}{*}{ Família não nuclear e VSE } & 0,023 & 0,000 & & 0,041 & 0,000 & \\
\hline & \multicolumn{6}{|c|}{ Índices de Ajuste do Modelo } \\
\hline Akaike (AIC) & 38504,120 & & & 39185,333 & & \\
\hline Bayesian (BIC) & 38780,294 & & & 39461,507 & & \\
\hline
\end{tabular}


A Tabela 16 apresenta os modelos com e sem aplicação de peso amostral para o desfecho "Realização de menos de sete consultas de pré-natal” com estimador MLR.

Os componentes de mensuração e estrutural dos modelos apresentaram cargas fatoriais e efeitos próximos aos dos modelos anteriores.

No modelo sem peso amostral, apresentaram efeitos estatisticamente significantes sobre o desfecho de inadequação do pré-natal segundo a realização de menos de sete consultas simples as variáveis: VSE $(\mathrm{OR}=6,63)$, filho com baixo peso anterior $(\mathrm{OR}=1,36)$ e hipertensão arterial $(\mathrm{OR}=0,62)$.

No modelo com peso amostral, apenas a variável VSE $(\mathrm{OR}=5,94)$ apresentou efeito estatisticamente significante sobre o desfecho. 
Tabela 16. Resumo dos modelos com e sem peso amostral para o desfecho "Realização de menos de sete consultas de pré-natal". Estimador MLR.

\begin{tabular}{|c|c|c|c|c|c|c|}
\hline \multirow[t]{2}{*}{ Variáveis } & \multicolumn{3}{|c|}{$\begin{array}{l}\text { Estimador MLR- Sem pesos } \\
\text { amostrais }\end{array}$} & \multicolumn{3}{|c|}{$\begin{array}{c}\text { Estimador MLR - Com pesos } \\
\text { amostrais } \\
\end{array}$} \\
\hline & Estimativa & p-valor & OR & Estimativa & p-valor & OR \\
\hline \multicolumn{7}{|l|}{ Componente de Mensuração - Constructos } \\
\hline \multicolumn{7}{|l|}{ VSE - Vulne rabilidade Socioeconômica } \\
\hline Renda média domiciliar per capita em desvios padrão & 1,000 & - & & 1,000 & - & \\
\hline Escolaridade do responsável pelo sustento familiar & 2,218 & 0,000 & & 2,143 & 0,000 & \\
\hline Escolaridade da mãe & 2,223 & 0,000 & & 2,098 & 0,000 & \\
\hline Raça cor da mãe & 1,966 & 0,000 & & 2,156 & 0,000 & \\
\hline Mãe com ocupação & 2,026 & 0,000 & & 1,533 & 0,002 & \\
\hline \multicolumn{7}{|l|}{ Componente Estrutural } \\
\hline \multicolumn{7}{|l|}{ Autoavaliação da Saúde= } \\
\hline VSE - Vulnerabilidade Socioeconômica & 1,865 & 0,000 & 6,46 & 1,982 & 0,000 & 7,26 \\
\hline Família não nuclear & 0,178 & 0,152 & 1,20 & 0,165 & 0,490 & 1,18 \\
\hline Mãe responsável pelo sustento familiar no domicílio & $-0,057$ & 0,593 & 0,95 & $-0,093$ & 0,614 & 0,91 \\
\hline Mãe diagnosticada com doença crônica & 0,823 & 0,000 & 2,28 & 0,699 & 0,005 & 2,01 \\
\hline \multicolumn{7}{|l|}{ Plane jamento da gravide $z=$} \\
\hline VSE - Vulnerabilidade Socioeconômica & 0,429 & 0,042 & 1,54 & 0,135 & 0,704 & 1,14 \\
\hline Autoavaliação da Saúde & $-0,059$ & 0,719 & 0,94 & $-0,172$ & 0,527 & 0,84 \\
\hline Familia não nuclear & 0,530 & 0,038 & 1,70 & 0,577 & 0,334 & 1,78 \\
\hline Mãe responsável pelo sustento familiar no domicîlio & $-0,099$ & 0,592 & 0,91 & 0,072 & 0,842 & 1,08 \\
\hline Mãe diagnosticada com doença crônica & 0,004 & 0,986 & 1,00 & $-0,211$ & 0,526 & 0,81 \\
\hline \multicolumn{7}{|l|}{ Filho com baixo peso ao nascer anterior= } \\
\hline VSE - Vulnerabilidade Socioeconômica & 0,594 & 0,015 & 1,81 & 0,804 & 0,003 & 2,23 \\
\hline \multicolumn{7}{|l|}{ Multiparidade $=$} \\
\hline VSE - Vulnerabilidade Socioeconômica & 1,435 & 0,000 & 4,20 & 0,922 & 0,001 & 2,51 \\
\hline \multicolumn{7}{|l|}{ Hipertensão arterial= } \\
\hline VSE - Vulnerabilidade Socioeconômica & 0,738 & 0,000 & 2,09 & 0,588 & 0,006 & 1,80 \\
\hline \multicolumn{7}{|l|}{ IMC - Categorias de risco $=$} \\
\hline VSE - Vulnerabilidade Socioeconômica & 2,201 & 0,000 & 9,03 & 1,771 & 0,000 & 5,87 \\
\hline \multicolumn{7}{|l|}{ Realização de menos de sete consultas de pré-natal= } \\
\hline VSE - Vulnerabilidade Socioeconômica & 1,892 & 0,000 & 6,63 & 1,781 & 0,000 & 5,94 \\
\hline Família não nuclear & 0,066 & 0,622 & 1,07 & $-0,131$ & 0,540 & 0,88 \\
\hline Mãe responsável pelo sustento familiar no domicílio & 0,108 & 0,341 & 1,11 & $-0,230$ & 0,198 & 0,80 \\
\hline Mãe diagnosticada com doença crônica & $-0,225$ & 0,102 & 0,80 & $-0,088$ & 0,693 & 0,92 \\
\hline Planejamento da gravidez & 0,057 & 0,792 & 1,06 & $-0,036$ & 0,919 & 0,97 \\
\hline Autoavaliação da Saúde & 0,068 & 0,471 & 1,07 & 0,031 & 0,839 & 1,03 \\
\hline Filho com baixo peso ao nascer anterior & 0,309 & 0,038 & 1,36 & $-0,056$ & 0,808 & 0,95 \\
\hline Multiparidade & $-0,027$ & 0,826 & 0,97 & $-0,228$ & 0,219 & 0,80 \\
\hline Hipertensão arterial & $-0,484$ & 0,001 & 0,62 & $-0,355$ & 0,136 & 0,70 \\
\hline IMC - Categorias de risco & 0,012 & 0,923 & 1,01 & 0,032 & 0,867 & 1,03 \\
\hline \multicolumn{7}{|l|}{ Correlações } \\
\hline Escolaridade Resp, domicilio e Escolaridade da mãe & 1,275 & 0,000 & & 0,987 & 0,000 & \\
\hline \multirow[t]{2}{*}{ Família não nuclear e VSE } & 0,022 & 0,000 & & 0,041 & 0,000 & \\
\hline & \multicolumn{6}{|c|}{ Índices de Ajuste do Modelo } \\
\hline Akaike (AIC) & 38240,817 & & & 38850,646 & & \\
\hline Bayesian (BIC) & 38516,991 & & & 39126,820 & & \\
\hline
\end{tabular}




\subsubsection{Outros modelos}

\subsubsection{Assistência pré-natal como variável latente}

O desfecho "Inadequação da Assistência Pré-Natal - Índice proposto por Silva" (que também foi a medida de adequação da assistência pré-natal empregada no modelo proposto por Oliveira (2014)), também foi considerado como variável latente a partir de análise fatorial confirmatória (AFC) considerando o conjunto de variáveis utilizado para sua construção (Quadro 5). A variável “Aferição da pressão arterial” não foi incluída como variável indicadora para o constructo porque quase nenhuma mãe do módulo S da PNS 2013 não teve o item realizado (Tabela 17).

Tabela 17. Distribuição das mães brasileiras da amostra com último parto entre 2011 e 2013 segundo aferição da pressão arterial durante a assistência pré-natal. Calculado com peso amostral. PNS, 2013.

\begin{tabular}{lrr}
\hline $\begin{array}{l}\text { Teve pressão arterial aferida } \\
\text { durante a assistência pré-natal }\end{array}$ & $\%$ & IC95\% \\
\hline Sim & 99,85 & $(99,6-99,9)$ \\
Não & 0,15 & $(0,1-0,4)$ \\
\hline Total & 100,00 & \\
\hline
\end{tabular}

A Tabela 18 e as Figuras 6 e 7 apresentam os modelos com estimador WLSMV com e sem aplicação de peso amostral para o desfecho Inadequação do pré-natal como constructo a partir do índice de Silva.

Os dois modelos apresentaram índices de ajuste satisfatórios, de acordo com os valores de referência considerados.

No componente de mensuração do modelo, as variáveis observadas indicadoras que formam a variável latente "VSE - Vulnerabilidade Socioeconômica" apresentam cargas fatoriais consideráveis (cargas $\geq 0,400$ nas colunas de estimativas padronizadas), sendo que a variável "Renda média domiciliar per capita em desvios padrão" apresenta 
carga mais elevada ( 0,800 no modelo sem peso amostral e 0,767 no modelo com peso amostral). Em relação à variável latente para o desfecho "Inadequação da Assistência pré-natal - Silva", parte das variáveis indicadoras apresentou cargas fatoriais mais elevadas (em ambos os modelos), como realização de exame urina, realização de exame de sangue, realização de exame de ultrassonografia, aferição da altura uterina e realização de pelo menos três consultas (cargas $\geq 600$ ), enquanto outras variáveis apresentaram cargas mais baixas.

No componente estrutural, a variável latente independente VSE é responsável tanto pela maioria dos efeitos estatisticamente significantes (exceto em relação à variável planejamento da gravidez no modelo com peso amostral) quanto pelos efeitos mais fortes sobre as outras covariáveis. Além da VSE, diagnóstico de doença crônica e família não-nuclear apresentaram efeitos estatisticamente significantes sobre a autoavaliação da saúde para o modelo sem peso amostral, enquanto no modelo com peso amostral o efeito da variável de família não-nuclear não foi significante. Para a variável planejamento da gravidez, no modelo sem peso amostral as variáveis VSE e família nãonuclear apresentaram efeitos estatisticamente significantes, enquanto no modelo com peso amostral nenhum efeito foi significante.

No modelo sem peso amostral, apresentaram efeitos estatisticamente significantes sobre o desfecho de inadequação do pré-natal segundo o índice de Silva (constructo) as variáveis: VSE, diagnóstico de doença crônica e hipertensão arterial.

No modelo com peso amostral, apenas as variáveis VSE e hipertensão arterial apresentaram efeitos estatisticamente significantes sobre o desfecho. 
Tabela 18. Resumo dos modelos com e sem peso amostral para o desfecho "Inadequação da Assistência Pré-Natal - Índice proposto por Silva como variável latente”. Estimador WLSMV.

\begin{tabular}{|c|c|c|c|c|c|c|}
\hline \multirow{2}{*}{ Variáveis } & \multicolumn{3}{|c|}{$\begin{array}{c}\text { Estimador WLSMV- Sem pesos } \\
\text { amostrais }\end{array}$} & \multicolumn{3}{|c|}{$\begin{array}{c}\text { Estimador WLSMV - Com pesos } \\
\text { amostrais }\end{array}$} \\
\hline & Estimativa & $\mathrm{p}$-valor & $\begin{array}{c}\text { Estimativa } \\
\text { padronizada }\end{array}$ & Estimativa & $\mathrm{p}$-valor & $\begin{array}{c}\text { Estimativa } \\
\text { padronizada }\end{array}$ \\
\hline \multicolumn{7}{|l|}{ Componente de Mensuração - Constructos } \\
\hline \multicolumn{7}{|l|}{ VSE - Vulne rabilidade Socioeconômica } \\
\hline Renda média domiciliar per capita em desvios padrão & 1,000 & - & 0,800 & 1,000 & - & 0,767 \\
\hline Escolaridade do responsável pelo sustento familiar & 1,750 & 0,000 & 0,499 & 1,718 & 0,000 & 0,530 \\
\hline Escolaridade da mãe & 1,711 & 0,000 & 0,511 & 1,621 & 0,000 & 0,542 \\
\hline Raça cor da mãe & 0,954 & 0,000 & 0,441 & 1,278 & 0,000 & 0,586 \\
\hline Mãe com ocupação & 1,542 & 0,000 & 0,633 & 0,931 & 0,000 & 0,473 \\
\hline \multicolumn{7}{|l|}{ Inadequação da Assistência Pré-Natal- Silva } \\
\hline Realização exame de urina & 1,000 & - & 0,697 & 1,000 & - & 0,632 \\
\hline Realização exame de sangue & 0,954 & 0,000 & 0,682 & 1,000 & 0,001 & 0,631 \\
\hline Realização exame de ultrassonografia & 0,990 & 0,000 & 0,691 & 1,349 & 0,011 & 0,657 \\
\hline Aferição da altura uterina & 0,734 & 0,000 & 0,598 & 1,324 & 0,001 & 0,733 \\
\hline Ausculta dos batimentos cardiofetais & 0,922 & 0,000 & 0,716 & 1,134 & 0,000 & 0,762 \\
\hline Aferição peso & 0,527 & 0,003 & 0,427 & 0,751 & 0,004 & 0,525 \\
\hline Orientaçãos sobre sinais e alertas da gravidez & 0,394 & 0,000 & 0,344 & 0,616 & 0,000 & 0,413 \\
\hline Orientações sobre identificar trabalho de parto & 0,421 & 0,000 & 0,352 & 0,765 & 0,000 & 0,499 \\
\hline Início da assistência no primeiro trimestre gestacional & 0,832 & 0,000 & 0,490 & 1,056 & 0,001 & 0,520 \\
\hline Realização de pelo menos três consultas & 1,312 & 0,000 & 0,853 & 1,528 & 0,001 & 0,765 \\
\hline \multicolumn{7}{|l|}{ Componente Estrutural } \\
\hline \multicolumn{7}{|l|}{ Autoavaliação da Saúde = } \\
\hline VSE - Vulnerabilidade Socioeconômica & 0,874 & 0,000 & 0,408 & 0,962 & 0,000 & 0,475 \\
\hline Família não nuclear & 0,218 & 0,002 & 0,082 & 0,132 & 0,443 & 0,046 \\
\hline Mãe responsável pelo sustento familiar no domicîilio & $-0,031$ & 0,598 & $-0,014$ & $-0,020$ & 0,839 & $-0,008$ \\
\hline Mãe diagnosticada com doença crônica & 0,386 & 0,000 & 0,146 & 0,302 & 0,016 & 0,112 \\
\hline \multicolumn{7}{|l|}{ Plane jamento da gravide $z=$} \\
\hline VSE - Vulnerabilidade Socioeconômica & 0,195 & 0,035 & 0,101 & 0,109 & 0,432 & 0,062 \\
\hline Autoavaliação da Saúde & $-0,012$ & 0,786 & $-0,014$ & $-0,068$ & 0,465 & $-0,078$ \\
\hline Família não nuclear & 0,286 & 0,024 & 0,119 & 0,280 & 0,300 & 0,112 \\
\hline Mãe responsável pelo sustento familiar no domicîilio & $-0,058$ & 0,551 & $-0,028$ & 0,045 & 0,797 & 0,021 \\
\hline Mãe diagnosticada com doença crônica & $-0,015$ & 0,889 & $-0,006$ & $-0,096$ & 0,563 & $-0,041$ \\
\hline \multicolumn{7}{|l|}{ Filho com baixo peso ao nascer anterior= } \\
\hline VSE - Vulnerabilidade Socioeconômica & 0,258 & 0,001 & 0,133 & 0,348 & 0,000 & 0,194 \\
\hline \multicolumn{7}{|l|}{ Multiparidade $=$} \\
\hline VSE - Vulnerabilidade Socioeconômica & 0,843 & 0,000 & 0,402 & 0,550 & 0,000 & 0,298 \\
\hline \multicolumn{7}{|l|}{ Hipertensão arte rial= } \\
\hline VSE - Vulnerabilidade Socioeconômica & 0,365 & 0,000 & 0,186 & 0,294 & 0,009 & 0,164 \\
\hline \multicolumn{7}{|l|}{ IMC - Categorias de risco $=$} \\
\hline VSE - Vulnerabilidade Socioeconômica & 1,059 & 0,000 & 0,483 & 0,912 & 0,000 & 0,459 \\
\hline \multicolumn{7}{|l|}{ Inadequação da assistência Pré-Natal - Silva (constructo)= } \\
\hline VSE - Vulnerabilidade Socioeconômica & 0,889 & 0,000 & 0,472 & 0,798 & 0,000 & 0,596 \\
\hline Família não nuclear & 0,114 & 0,157 & 0,037 & $-0,101$ & 0,504 & $-0,080$ \\
\hline Mãe responsável pelo sustento familiar no domicîilio & 0,078 & 0,227 & 0,027 & $-0,091$ & 0,297 & $-0,060$ \\
\hline Mãe diagnosticada com doença crônica & $-0,216$ & 0,008 & $-0,112$ & $-0,123$ & 0,237 & $-0,067$ \\
\hline Planejamento da gravidez & $-0,064$ & 0,233 & $-0,048$ & $-0,037$ & 0,600 & 0,014 \\
\hline Autoavaliação da Saúde & 0,032 & 0,370 & 0,056 & 0,071 & 0,118 & 0,138 \\
\hline Filho com baixo peso ao nascer anterior & 0,030 & 0,504 & $-0,022$ & $-0,027$ & 0,594 & $-0,035$ \\
\hline Multiparidade & $-0,040$ & 0,305 & $-0,059$ & $-0,052$ & 0,309 & $-0,075$ \\
\hline Hipertensão arterial & $-0,221$ & 0,000 & $-0,263$ & $-0,247$ & 0,002 & $-0,380$ \\
\hline IMC - Categorias de risco & 0,032 & 0,439 & 0,076 & 0,036 & 0,432 & 0,032 \\
\hline \multicolumn{7}{|l|}{ Correlações } \\
\hline Escolaridade Resp, domicilio e Escolaridade da mãe & 1,504 & 0,000 & 0,630 & 1,231 & 0,000 & 0,544 \\
\hline Orient, Sinais e alertas com Orient, Identificar trab, de parto & 0,827 & 0,000 & 0,825 & 0,841 & 0,000 & 0,842 \\
\hline \multirow[t]{2}{*}{ Família não nuclear e VSE } & - & - & - & 0,033 & 0,000 & 0,145 \\
\hline & & & Índices de Aju & ste do Mode & & \\
\hline CFI & 0,945 & & & 0,952 & & \\
\hline TLI & 0,935 & & & 0,943 & & \\
\hline RMSEA & 0,034 & IC90\%(0 & $, 03-0,04)$ & 0,016 & IC90\% (0 & $0,01-0,02)$ \\
\hline
\end{tabular}


Figura 6. Diagrama representando o componente estrutural da modelagem com equações estruturais realizada para o desfecho "Inadequação da Assistência Pré-Natal - índice proposto por Silva" como variável latente. Calculado sem peso amostral. Estimador WLSMV.

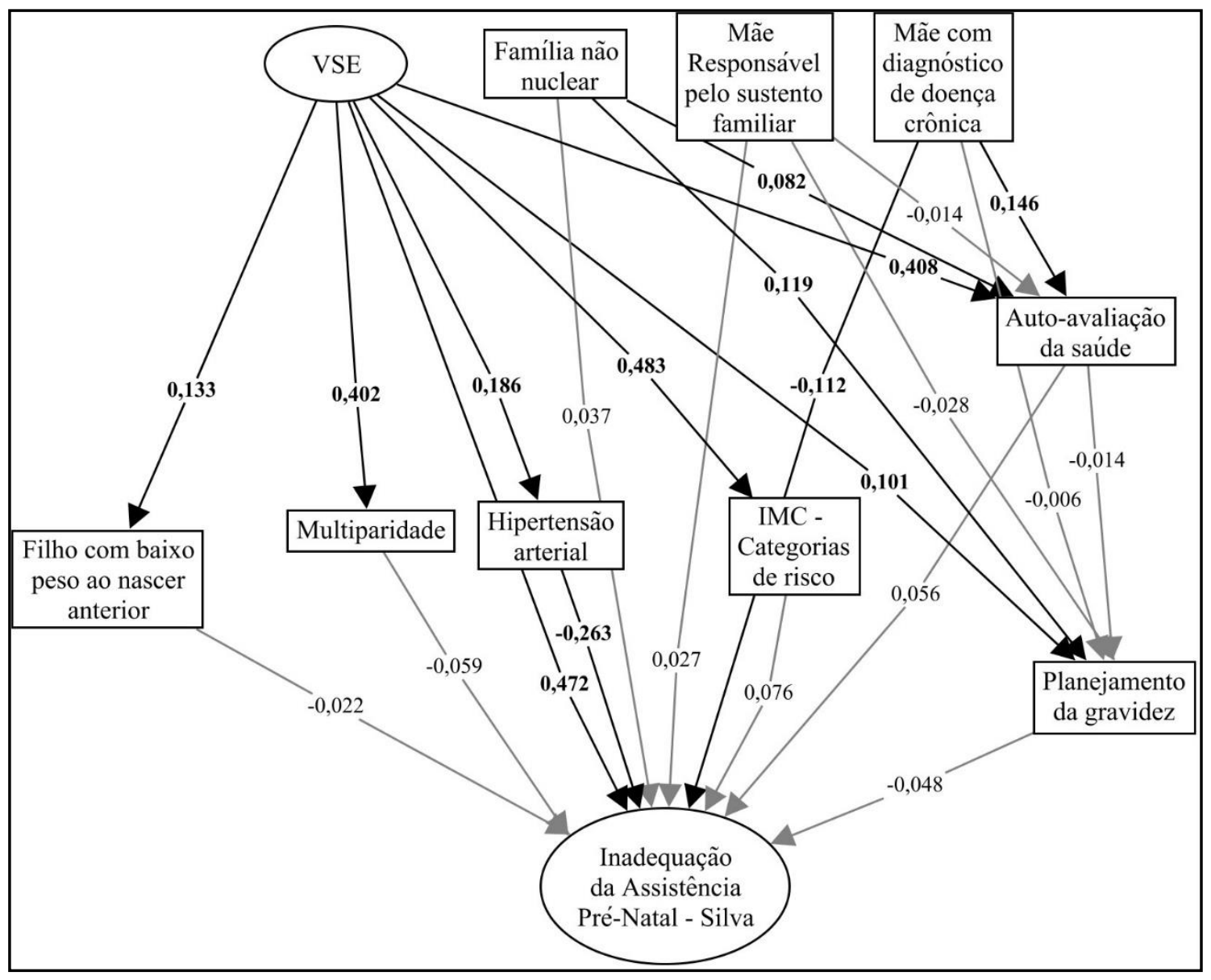

Índices de ajuste: CFI=0,945; TLI=0,935; RMSEA=0,034 IC90\%(0,03-0,04).

Efeitos estatisticamente significantes ( $\mathrm{p}$-valor $\leq 0,05$ ) representados em negrito e com flechas na cor preta. 
Figura 7. Diagrama representando o componente estrutural da modelagem com equações estruturais realizada para o desfecho "Inadequação da Assistência Pré-Natal - índice proposto por Silva” como variável latente. Calculado com peso amostral. Estimador WLSMV.

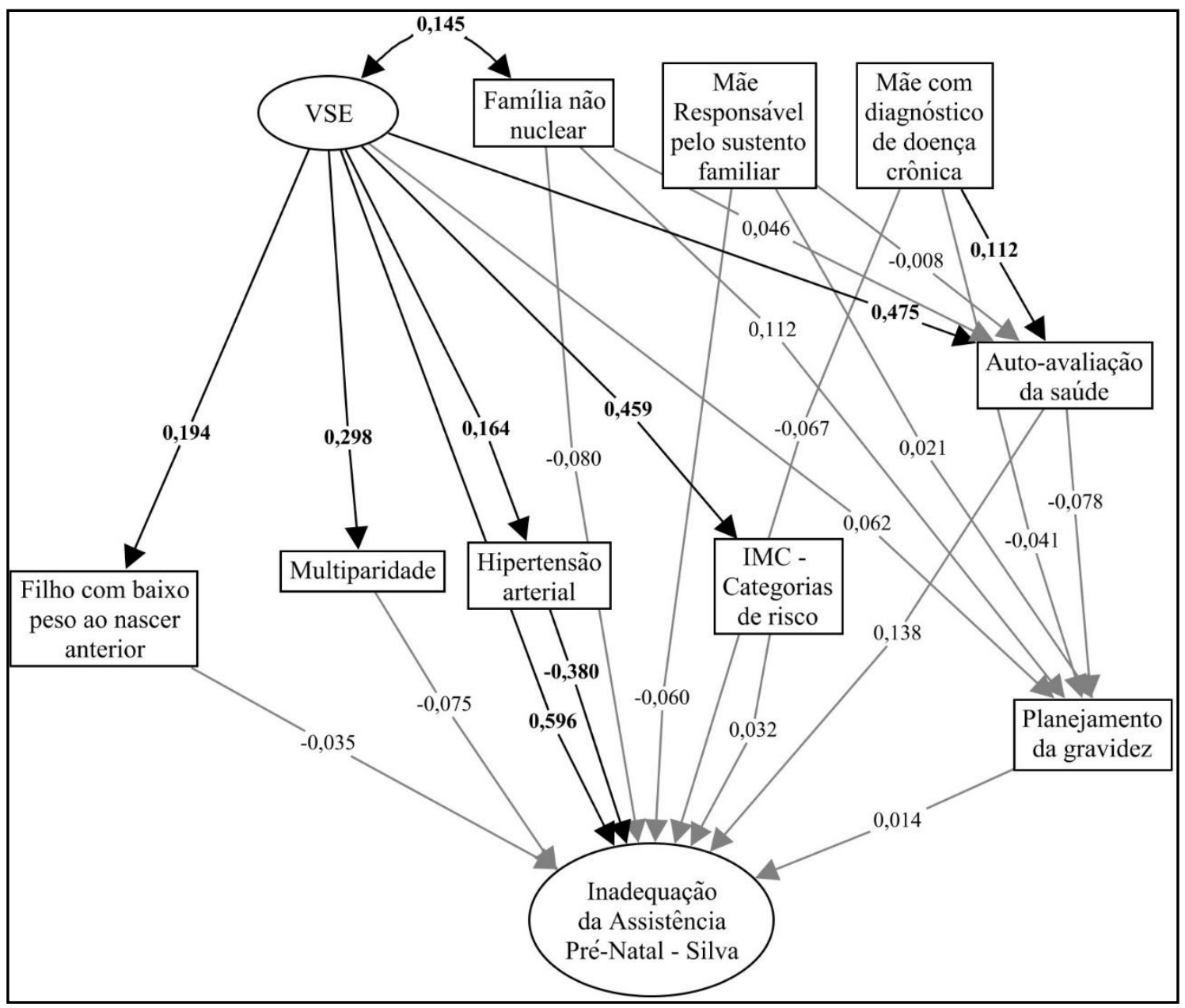

Índices de ajuste: CFI=0,952; TLI=0,943; RMSEA=0,016 IC90\%(0,01-0,02).

Efeitos estatisticamente significantes ( $\mathrm{p}$-valor $\leq 0,05$ ) representados em negrito e com flechas na cor preta.

4.6.1.2 Proposta de Modelos separados - sub-amostras SUS e não-SUS

Com o intuito de se construir modelos separados da MEE para população usuária do SUS e para população usuária da saúde suplementar, foram realizadas tentativas, a partir de variáveis disponíveis na PNS 2013, para delimitar esses dois grupos.

A Figura 8 apresenta Diagramas de Venn com diferentes combinações de variáveis para indicar a realização das consultas de pré-natal através do SUS e a realização 
de consultas de pré-natal através da Saúde Suplementar. Variáveis indicadoras de população segundo uso ou não-uso do SUS durante a assistência pré-natal: "Todas/Nenhuma Consulta(s) de pré-natal realizada(s) pelo SUS" - criadas a partir da variável "As consultas foram feitas através do SUS?" (“s008”); "Maioria das consultas de pré-natal realizadas em Estabelecimentos SUS/ Estabelecimento Não-SUS” - criadas a partir da variável "Onde foi realizada a maioria das consultas do pré-natal?" (“s005”); e "Sem pagamento de valor e sem cobertura/ Pagamento de valor ou cobertura de algum Plano de Saúde ao realizar as consultas de pré-natal” - criadas a partir das variáveis "As consultas do pré-natal foram cobertas por algum plano de saúde?” (“s006”) e "A senhora pagou algum valor pelas consultas do pré-natal?” (“s007”). A área de intersecção principal compartilhada por todas as variáveis representa o grupo em que há concordância na classificação relativa ao uso ou não uso do SUS durante a assistência. Os grupos delimitados por essa intersecção são os que foram considerados como "população predominantemente usuária do SUS durante a assistência pré-natal" e "população predominantemente usuária da Saúde Suplementar durante a assistência pré-natal”.

É verificado que, segundo essa delimitação:

- A sub-amostra de mães brasileiras com último parto entre 2011 e 2013 usuárias do SUS predominantemente é composta de 1.269 observações que, com aplicação do peso amostral, representam 67,4\% (IC95\% 61,1\%-73,6\%) das mulheres desse módulo (sendo que o total de 1.851 observações representa cerca de 3.818.936 mulheres com a amostragem complexa);

- A sub-amostra de mães brasileiras com último parto entre 2011 e 2013 usuárias predominantemente da Saúde Suplementar é composta de 394 observações que, com o peso amostral, representam 25,2\% (IC95\% 21,1\%-29,3\%) das mães do módulo S; 
- E que as 188 observações restantes, que representam, com o peso amostral, 7,4\% (IC95\% 5,9\%-9,3\%) das mães brasileiras, constituiriam o grupo de mães com utilização mista (SUS e Saúde Suplementar) durante as consultas de pré-natal ou com possíveis inconsistências nas respostas às perguntas relativas às variáveis consideradas (problemas de aferição).

O mapa temático da Figura 9 apresenta a distribuição relativa (calculada com peso amostral) das mães brasileiras segundo a variável "Uso Predominante da Saúde Suplementar durante as consultas de pré-natal” (gerada a partir da delimitação descrita), segundo Unidade da Federação de Residência.

Figura 8. Diagramas de Venn - Delimitação das sub-amostras de mães brasileiras com último parto entre 2011 e 2013 segundo uso do SUS durante as consultas da assistência pré-natal. Calculado com peso amostral. PNS, 2013.

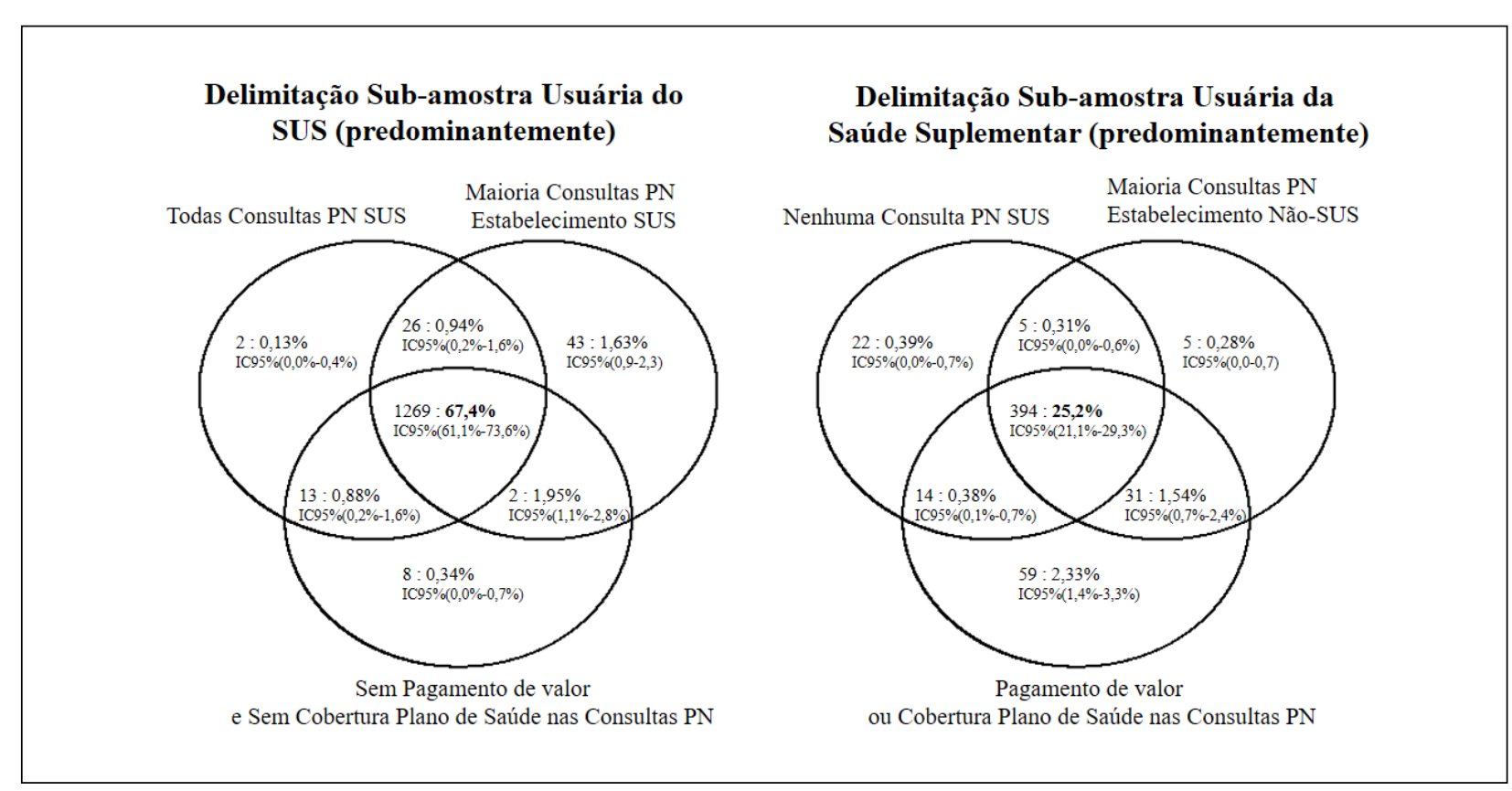


Figura 9. Mapa temático - Percentual de mães brasileiras da amostra com último parto entre 2011 e 2013 com uso predominante da saúde suplementar durante as consultas de pré-natal por Unidade da Federação de Residência. Calculado com peso amostral. PNS, 2013.

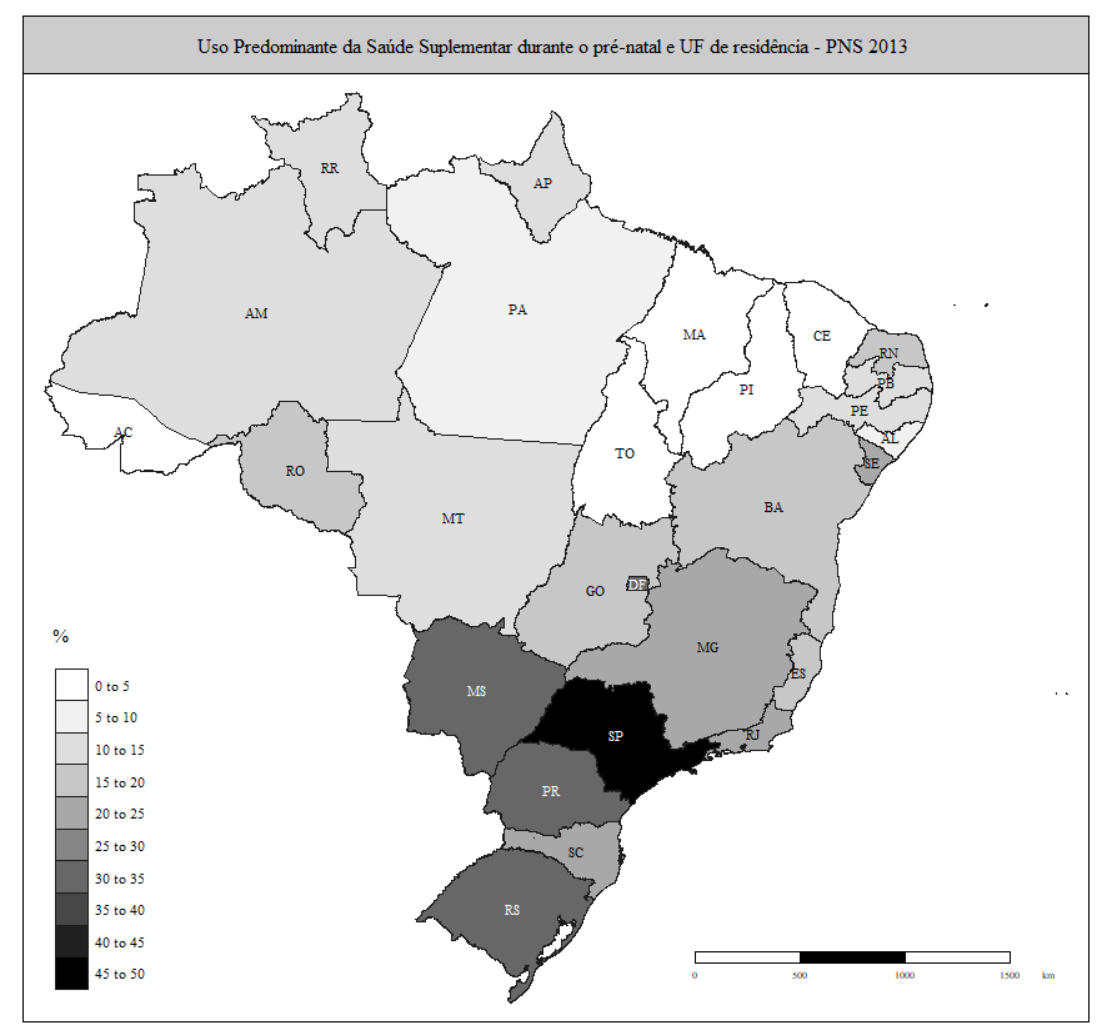

A Tabela 19 apresenta os modelos com estimador WLSMV com e sem aplicação de peso amostral para o desfecho Inadequação do pré-natal PHPN simples apenas para a população exclusivamente usuária SUS.

Os dois modelos apresentaram índices de ajuste CFI e TLI abaixo aos valores de referência considerados.

No componente de mensuração do modelo, as variáveis observadas indicadoras que formam a variável latente "VSE - Vulnerabilidade Socioeconômica" escolaridade do responsável pelo sustento familiar e raça/cor da mãe apresentaram cargas fatoriais mais baixas $(\leq 0,400)$ em ambos os modelos em relação aos modelos considerando todas as mães brasileiras da amostra com último parto entre 2011 e 2013; aumentando a heterogeneidade entre as cargas fatoriais. 
No componente estrutural, a variável latente independente VSE permaneceu responsável por grande parte dos efeitos estatisticamente significantes e mais fortes sobre as outras covariáveis; apesar de, no modelo sem peso amostral, não ter sido significante para autoavaliação da saúde e planejamento, e no modelo com peso amostral não ter sido significante para planejamento e hipertensão arterial. No modelo sem peso amostral apenas diagnóstico de doença crônica foi estatisticamente significante para autoavaliação. Para a variável planejamento da gravidez, em ambos os modelos nenhuma variável apresentou efeito estatisticamente significante.

No modelo sem peso amostral, apresentaram efeitos estatisticamente significantes sobre o desfecho de inadequação do pré-natal segundo o método de PHPN simples as variáveis: VSE, mãe responsável pelo sustento familiar (p-valor=0,053), diagnóstico de doença crônica e hipertensão arterial.

No modelo com peso amostral, apenas as variáveis VSE e planejamento da gravidez apresentaram efeitos estatisticamente significantes sobre o desfecho. 
Tabela 19. Resumo dos modelos com e sem peso amostral para o desfecho "Inadequação da Assistência Pré-Natal - PHPN Simples". População usuária SUS (exclusivamente). Estimador WLSMV.

\begin{tabular}{|c|c|c|c|c|c|c|}
\hline \multirow{2}{*}{ Variáveis } & \multicolumn{3}{|c|}{$\begin{array}{c}\text { Estimador WLSMV- Sem pesos } \\
\text { amostrais }\end{array}$} & \multicolumn{3}{|c|}{$\begin{array}{c}\text { Estimador WLSMV - Com pesos } \\
\text { amostrais }\end{array}$} \\
\hline & Estimativa & p-valor & $\begin{array}{c}\text { Estimativa } \\
\text { padronizada }\end{array}$ & Estimativa & p-valor & $\begin{array}{c}\text { Estimativa } \\
\text { padronizada }\end{array}$ \\
\hline \multicolumn{7}{|l|}{ Componente de Mensuração - Constructos } \\
\hline \multicolumn{7}{|l|}{ VSE - Vulnerabilidade Socioeconômica } \\
\hline Renda média domiciliar per capita em desvios padrão & 1,000 & - & 0,701 & 1,000 & - & 0,768 \\
\hline Escolaridade do responsável pelo sustento familiar & 4,435 & 0,000 & 0,371 & 3,083 & 0,000 & 0,337 \\
\hline Escolaridade da mãe & 5,002 & 0,000 & 0,432 & 4,020 & 0,000 & 0,454 \\
\hline Raça cor da mãe & 1,868 & 0,000 & 0,246 & 2,116 & 0,000 & 0,348 \\
\hline Mãe com ocupação & 4,817 & 0,000 & 0,547 & 3,867 & 0,000 & 0,561 \\
\hline \multicolumn{7}{|l|}{ Componente Estrutural } \\
\hline \multicolumn{7}{|l|}{ Autoavaliação da Saúde = } \\
\hline VSE - Vulnerabilidade Socioeconômica & 1,512 & 0,504 & 0,198 & 1,389 & 0,000 & 0,232 \\
\hline Família não nuclear & 0,027 & 0,720 & 0,011 & 0,212 & 0,066 & 0,087 \\
\hline Mãe responsável pelo sustento familiar no domicílio & 0,033 & 0,618 & 0,016 & 0,067 & 0,496 & 0,029 \\
\hline Mãe diagnosticada com doença crônica & 0,410 & 0,000 & 0,166 & 0,382 & 0,002 & 0,154 \\
\hline \multicolumn{7}{|l|}{ Plane jamento da gravide $z=$} \\
\hline VSE - Vulnerabilidade Socioeconômica & $-0,335$ & 0,504 & $-0,045$ & $-0,872$ & 0,123 & $-0,149$ \\
\hline Autoavaliação da Saúde & $-0,003$ & 0,957 & $-0,003$ & $-0,023$ & 0,857 & $-0,023$ \\
\hline Família não nuclear & 0,264 & 0,081 & 0,112 & 0,198 & 0,549 & 0,083 \\
\hline Mãe responsável pelo sustento familiar no domicílio & $-0,043$ & 0,708 & $-0,021$ & 0,218 & 0,406 & 0,096 \\
\hline Mãe diagnosticada com doença crônica & 0,161 & 0,271 & 0,067 & 0,227 & 0,400 & 0,094 \\
\hline \multicolumn{7}{|l|}{ Filho com baixo peso ao nascer anterior= } \\
\hline VSE - Vulnerabilidade Socioeconômica & 0,863 & 0,034 & 0,116 & 0,997 & 0,025 & 0,172 \\
\hline \multicolumn{7}{|l|}{ Multiparidade = } \\
\hline VSE - Vulnerabilidade Socioeconômica & 3,170 & 0,000 & 0,395 & 1,819 & 0,000 & 0,304 \\
\hline \multicolumn{7}{|l|}{ Hipertensão arterial= } \\
\hline VSE - Vulnerabilidade Socioeconômica & 0,672 & 0,064 & 0,091 & 0,203 & 0,642 & 0,036 \\
\hline \multicolumn{7}{|l|}{ IMC - Categorias de risco $=$} \\
\hline VSE - Vulnerabilidade Socioeconômica & 2,903 & 0,000 & 0,367 & 1,785 & 0,000 & 0,298 \\
\hline \multicolumn{7}{|l|}{ Inadequação da assistência Pré-Natal - PHPN Simples= } \\
\hline VSE - Vulnerabilidade Socioeconômica & 2,843 & 0,000 & 0,352 & 1,340 & 0,029 & 0,216 \\
\hline Família não nuclear & $-0,009$ & 0,924 & $-0,003$ & 0,005 & 0,974 & 0,002 \\
\hline Mãe responsável pelo sustento familiar no domicîlio & 0,153 & 0,053 & 0,069 & 0,187 & 0,189 & 0,077 \\
\hline Mãe diagnosticada com doença crônica & $-0,260$ & 0,006 & $-0,100$ & $-0,208$ & 0,192 & $-0,081$ \\
\hline Planejamento da gravidez & $-0,119$ & 0,136 & $-0,110$ & $-0,238$ & 0,012 & $-0,224$ \\
\hline Autoavaliação da Saúde & 0,003 & 0,943 & 0,003 & 0,034 & 0,663 & 0,033 \\
\hline Filho com baixo peso ao nascer anterior & 0,079 & 0,178 & 0,072 & $-0,026$ & 0,773 & $-0,024$ \\
\hline Multiparidade & $-0,090$ & 0,108 & $-0,089$ & 0,016 & 0,833 & 0,016 \\
\hline Hipertensão arterial & $-0,123$ & 0,025 & $-0,113$ & $-0,014$ & 0,879 & $-0,012$ \\
\hline IMC - Categorias de risco & 0,053 & 0,305 & 0,052 & 0,102 & 0,183 & 0,098 \\
\hline \multicolumn{7}{|l|}{ Correlações } \\
\hline Escolaridade Resp, domicilio e Escolaridade da mãe & 1,234 & 0,000 & 0,578 & 1,042 & 0,000 & 0,500 \\
\hline \multirow[t]{2}{*}{ Família não nuclear e VSE } & 0,000 & 0,972 & 0,001 & 0,006 & 0,310 & 0,087 \\
\hline & \multicolumn{6}{|c|}{ Índices de Ajuste do Modelo } \\
\hline CFI & 0,813 & & & 0,842 & & \\
\hline TLI & 0,738 & & & 0,779 & & \\
\hline RMSEA & 0,052 & IC90\%(C & $, 05-0,06)$ & 0,022 & IC90\% $(0,0$ & $02-0,03)$ \\
\hline
\end{tabular}


A Tabela 20 apresenta os modelos com estimador WLSMV com e sem aplicação de peso amostral para o desfecho Inadequação do pré-natal PHPN simples apenas para a população usuária não SUS e usuária "mista".

Os dois modelos apresentaram índices de ajuste satisfatórios de acordo com os valores de referência considerados.

No componente de mensuração do modelo, as variáveis observadas indicadoras que formam a variável latente "VSE - Vulnerabilidade Socioeconômica" escolaridade do responsável pelo sustento familiar e raça/cor da mãe apresentaram, no modelo sem aplicação de peso amostral, cargas fatoriais consideráveis $(\geq 0,400)$, enquanto no modelo com peso amostral todas as cargas foram acima de 0,500; com exceção da variável ocupação da mãe que apresentou carga 0,354 .

No componente estrutural, a variável latente independente VSE permaneceu responsável por grande parte dos efeitos estatisticamente significantes e mais fortes sobre as outras covariáveis; apesar de, em ambos modelos, não ter sido significante para planejamento da gravidez e filho com baixo peso ao nascer anterior. No modelo sem peso amostral VSE e diagnóstico de doença crônica foram estatisticamente significantes para autoavaliação, enquanto no modelo com peso amostral apenas VSE apresentou efeito significante.

No modelo sem peso amostral, apenas VSE apresentou efeito estatisticamente significante sobre o desfecho de inadequação do pré-natal segundo o método de PHPN simples, enquanto no modelo com peso amostral apenas a variável mãe responsável pelo sustento familiar no domicílio apresentou efeito $(-0,172)$ estatisticamente significante. 
Tabela 20. Resumo dos modelos com e sem peso amostral para o desfecho "Inadequação da Assistência Pré-Natal - PHPN Simples". População usuária (exclusivamente ou não) da Saúde Suplementar. Estimador WLSMV.

\begin{tabular}{|c|c|c|c|c|c|c|}
\hline \multirow{2}{*}{ Variáveis } & \multicolumn{3}{|c|}{$\begin{array}{c}\text { Estimador WLSMV- Sem pesos } \\
\text { amostrais }\end{array}$} & \multicolumn{3}{|c|}{$\begin{array}{c}\text { Estimador WLSMV - Com pesos } \\
\text { amostrais }\end{array}$} \\
\hline & Estimativa & p-valor & $\begin{array}{c}\text { Estimativa } \\
\text { padronizada }\end{array}$ & Estimativa & p-valor & $\begin{array}{c}\text { Estimativa } \\
\text { padronizada }\end{array}$ \\
\hline \multicolumn{7}{|l|}{ Componente de Mensuração - Constructos } \\
\hline \multicolumn{7}{|l|}{ VSE - Vulnerabilidade Socioeconômica } \\
\hline Renda média domiciliar per capita em desvios padrão & 1,000 & - & 0,789 & 1,000 & - & 0,780 \\
\hline Escolaridade do responsável pelo sustento familiar & 1,111 & 0,000 & 0,519 & 1,069 & 0,000 & 0,548 \\
\hline Escolaridade da mãe & 1,033 & 0,000 & 0,536 & 0,958 & 0,000 & 0,565 \\
\hline Raça cor da mãe & 0,636 & 0,000 & 0,460 & 0,708 & 0,000 & 0,541 \\
\hline Mãe com ocupação & 0,801 & 0,000 & 0,547 & 0,418 & 0,000 & 0,354 \\
\hline \multicolumn{7}{|l|}{ Componente Estrutural } \\
\hline \multicolumn{7}{|l|}{ Autoavaliação da Saúde = } \\
\hline VSE - Vulnerabilidade Socioeconômica & 0,706 & 0,000 & 0,489 & 0,648 & 0,000 & 0,506 \\
\hline Família não nuclear & 0,299 & 0,045 & 0,090 & $-0,154$ & 0,555 & $-0,047$ \\
\hline Mãe responsável pelo sustento familiar no domicílio & $-0,135$ & 0,239 & $-0,055$ & $-0,194$ & 0,349 & $-0,076$ \\
\hline Mãe diagnosticada com doença crônica & 0,359 & 0,006 & 0,130 & 0,148 & 0,538 & 0,055 \\
\hline \multicolumn{7}{|l|}{ Plane jamento da gravidez= } \\
\hline VSE - Vulnerabilidade Socioeconômica & 0,176 & 0,118 & 0,141 & 0,070 & 0,659 & 0,060 \\
\hline Autoavaliação da Saúde & $-0,003$ & 0,534 & $-0,053$ & $-0,133$ & 0,291 & $-0,146$ \\
\hline Família não nuclear & 0,264 & 0,388 & 0,069 & 0,584 & 0,058 & 0,194 \\
\hline Mãe responsável pelo sustento familiar no domicîlio & $-0,043$ & 0,976 & 0,002 & $-0,229$ & 0,301 & $-0,098$ \\
\hline Mãe diagnosticada com doença crônica & 0,161 & 0,241 & $-0,082$ & $-0,513$ & 0,023 & $-0,209$ \\
\hline \multicolumn{7}{|l|}{ Filho com baixo peso ao nascer anterior= } \\
\hline VSE - Vulnerabilidade Socioeconômica & 0,145 & 0,128 & 0,118 & 0,185 & 0,085 & 0,165 \\
\hline \multicolumn{7}{|l|}{ Multiparidade= } \\
\hline VSE - Vulnerabilidade Socioeconômica & 0,489 & 0,000 & 0,370 & 0,331 & 0,006 & 0,288 \\
\hline \multicolumn{7}{|l|}{ Hipertensão arterial= } \\
\hline VSE - Vulnerabilidade Socioeconômica & 0,258 & 0,010 & 0,206 & 0,329 & 0,028 & 0,286 \\
\hline \multicolumn{7}{|l|}{ IMC - Categorias de risco $=$} \\
\hline VSE - Vulnerabilidade Socioeconômica & 0,630 & 0,000 & 0,457 & 0,666 & 0,000 & 0,517 \\
\hline \multicolumn{7}{|l|}{ Inadequação da assistência Pré-Natal - PHPN Simples= } \\
\hline VSE - Vulnerabilidade Socioeconômica & 0,246 & 0,000 & 0,190 & 0,300 & 0,204 & 0,252 \\
\hline Família não nuclear & 0,165 & 0,313 & 0,055 & 0,042 & 0,874 & 0,014 \\
\hline Mãe responsável pelo sustento familiar no domicílio & 0,041 & 0,730 & 0,019 & $-0,408$ & 0,033 & $-0,172$ \\
\hline Mãe diagnosticada com doença crônica & $-0,013$ & 0,926 & $-0,005$ & 0,013 & 0,951 & 0,005 \\
\hline Planejamento da gravidez & 0,072 & 0,474 & 0,069 & $-0,123$ & 0,410 & $-0,120$ \\
\hline Autoavaliação da Saúde & 0,079 & 0,264 & 0,088 & 0,077 & 0,577 & 0,083 \\
\hline Filho com baixo peso ao nascer anterior & $-0,050$ & 0,589 & $-0,048$ & 0,067 & 0,677 & 0,063 \\
\hline Multiparidade & 0,058 & 0,456 & 0,059 & $-0,041$ & 0,724 & $-0,040$ \\
\hline Hipertensão arterial & $-0,096$ & 0,276 & $-0,093$ & $-0,225$ & 0,104 & $-0,218$ \\
\hline IMC - Categorias de risco & 0,047 & 0,547 & 0,050 & $-0,050$ & 0,725 & $-0,054$ \\
\hline \multicolumn{7}{|l|}{ Correlações } \\
\hline Escolaridade Resp, domic1lio e Escolaridade da mãe & 1,129 & 0,000 & 0,570 & 0,948 & 0,000 & 0,505 \\
\hline \multirow[t]{2}{*}{ Família não nuclear e VSE } & 0,039 & 0,014 & 0,135 & 0,063 & 0,026 & 0,197 \\
\hline & \multicolumn{6}{|c|}{ Índices de Ajuste do Modelo } \\
\hline CFI & 0,954 & & & 0,986 & & \\
\hline TLI & 0,935 & & & 0,981 & & \\
\hline RMSEA & 0,045 & IC90\%(C & $0,04-0,05)$ & $0,011 \mathrm{I}$ & [C90\% $(0$, & $-0,03)$ \\
\hline
\end{tabular}




\section{Discussão}

\subsection{Cobertura e qualidade}

Quando comparada à cobertura, a qualidade da assistência pré-natal aferida pelo método "PHPN simples" na PNS 2013 apresenta valores mais baixos (Figura 4), resultado semelhante aos observados em revisão realizada por NUNES et al. (2016), sendo observado que o aumento da cobertura da assistência não é acompanhado pelo aumento da qualidade da assistência recebida pelas gestantes.

\subsection{Autoavaliação da saúde e presença de história reprodutiva}

Ao comparar a presença de história reprodutiva e autoavaliação da saúde foi observado que, enquanto a autoavaliação de mães com história reprodutiva recente seria, em geral, melhor (aumento de avaliações "Muito boa" e "boa" e diminuição de "Regular", "Ruim" e "Muito ruim") ou não diferentes da avaliação de mulheres sem história reprodutiva, a autoavaliação de mães com história há mais tempo seria pior (diminuição de avaliações "Muito boa" e "boa" e aumento de "Regular", "Ruim" e "Muito ruim") quando comparada à de mulheres sem história reprodutiva; sugerindo que, em um primeiro momento, as mães recentes tenderiam a avaliar sua saúde de forma melhor em relação às mulheres que nunca tiveram filhos, e, posteriormente, ocorreria uma inversão, sendo que as mães há mais tempo tenderiam a avaliar sua saúde de forma pior em relação às mulheres que nunca tiveram filhos. Esses resultados são semelhantes aos evidenciados em estudos realizados na Suécia sobre a relação da maternidade e a autoavaliação da saúde (SCHYTT e INGEGERD, 2011; SCHYTT et al., 2005) e reforçam a relevância da inclusão dessa variável no modelo proposto de fatores de risco 
para inadequação da assistência pré-natal, tendo em vista que pode apresentar mudanças com a presença de história reprodutiva.

\subsection{Comparação de diferentes índices para avaliação do pré-natal}

Ao comparar a classificação das mães entre "Adequado" e "Inadequado", segundo os diferentes índices considerados - PHPN simples, Índice de Takeda, Índice de Silva e realização de menos de sete consultas -, amplas variações foram observadas. Isso seria, entretanto, esperado, ao considerar que os diferentes índices estão aferindo diferentes aspectos da assistência pré-natal. Assim, o método de Silva que estaria mensurando o mesmo aspecto da assistência pré-natal que o do PHPN simples (a qualidade considerando também o conteúdo das consultas) é o que apresenta menores variações percentuais na classificação das mães quando comparados (Tabela 6) (proporção de mães com pré-natal adequado 8,5\% menor e proporção de mães com pré-natal inadequado $12,4 \%$ maior).

É interessante ressaltar também que a comparação com emprego de mais índices seria necessária para observar melhor as diferenças entre eles e agrupá-los entre os diferentes aspectos da assistência que estariam mensurando, além dos que puderam ser calculados a partir dos dados da PNS 2013, sendo que, por exemplo, o único índice para medir adequação da utilização da assistência que dispomos, o de Takeda, que é uma modificação do índice de Kessner, não leva em consideração a realização de consultas de acordo com o que seria esperado para determinada idade gestacional e o índice do PHPN que empregamos (PHPN simples) é incompleto. Os modelos de equações estruturais com os vários desfechos apresentaram diferenças em relação aos caminhos causais envolvidos, o que poderia sugerir que os índices refletem diferentes aspectos da assistência pré-natal. 
Por exemplo, a dimensão da utilização da assistência poderia sofrer maiores variações relacionadas a aspectos individuais das mães, enquanto a da qualidade (que envolve procedimentos e orientações recebidos) estaria relacionada também a aspectos a nível agregado e territorial; imaginando-se um cenário em que determinados procedimentos e exames não estivessem sendo oferecidos pelos serviços de pré-natal em determinado território, por mais que as gestantes ali utilizassem a assistência pré-natal adequadamente (com início até o primeiro mês e número de consultas adequado para sua idade gestacional), a qualidade da assistência não apresentaria ganhos, visto que, para isso, a realização daqueles procedimentos e exames seria necessária.

Assim, a escolha de um índice para se avaliar a adequação da assistência pré-natal populacionalmente deve ser cuidadosamente realizada, considerando a população de interesse, objetivos de estudo e os dados disponíveis.

\subsection{Modelos de equações estruturais}

\subsubsection{Considerações sobre a modelagem}

Muitas das variáveis latentes inicialmente propostas não foram satisfatórias nos modelos e foi decidido pela inclusão de parte das variáveis inicialmente consideradas para o componente de mensuração, em forma de variáveis indicadoras, diretamente no modelo estrutural em forma de variáveis observadas. Mesmo as variáveis latentes mantidas nos modelos finais, como a VSE e o desfecho em forma de variável latente "Inadequação da Assistência pré-natal”, construída a partir das variáveis empregadas no índice de Silva, não apresentaram variáveis indicadoras de sua composição com cargas fatoriais muito altas, o que indicaria mais que seria adequado formarem em conjunto um único fator. 
Nesse trabalho, foi empregado o modelo reflexivo na construção das variáveis latentes na medida em que se assume, tomando um exemplo, que a maior adequação prénatal levaria a um aumento do número de consultas. Porém, poderia também ter sido empregado o modelo formativo ao se assumir, a partir do exemplo de que o maior número de consultas que leva a uma assistência mais adequada (BORSBOOM et al., 2003).

Aparentemente, o formato reflexivo parece mais razoável, porém os resultados indicaram que algumas variáveis que apresentaram menores correlações que outras dentro do constructo, como em Condições Reprodutivas, sugerissem que o modelo hipotetizado poderia ser outro que considerasse o modelo formativo.

\subsubsection{Orientação dos efeitos}

Alguns efeitos apresentaram sinais que inicialmente poderiam parecer pouco intuitivos, como nos modelos em que a hipertensão arterial foi significativa sobre o desfecho de inadequação da assistência pré-natal e apresentou sinal negativo (como se a presença de hipertensão fosse um "fator de proteção" para a inadequação da assistência pré-natal).

Entretanto, esses efeitos podem ocorrer dessa maneira quando consideramos que não estamos trabalhando com o desfecho da gestação em si, sendo que a hipertensão provavelmente apresentaria efeitos com sinais positivos para desfechos negativos, como prematuridade. Como o desfecho considerado foi a inadequação da assistência pré-natal, que geralmente é incluída nos modelos como variável mediadora, a orientação dos sinais pode ser alterada.

Nesse sentido, por exemplo, a presença de intercorrências na gravidez poderia indicar gestações de risco que necessitassem de um maior número de consultas e maior 
número de procedimentos a serem realizados, acarretando em uma utilização e qualidade da assistência recebida melhor em relação a outras gestantes, sem que necessariamente essa melhoria aparente se refletisse sobre o desfecho da gestação (que não dispomos na PNS 2013) em comparação com gestantes de baixo risco; nessa lógica observamos a composição do Índice de Kotelchuck, por exemplo, que avalia adequação da utilização da assistência e propõe uma categoria extra denominada "Adequate Plus" ou "Muito adequado" que seria referente às gestantes que realizaram um número de consultas muito acima do que seria esperado para sua idade gestacional e por isso mais provavelmente seriam gestantes de alto risco (sendo que esse maior número de consultas e procedimentos indicaria uma assistência adequada, mas provavelmente indicaria fator de risco para o desfecho da gestação em si).

\subsubsection{Modelos sem e com aplicação de peso amostral com estimador MLR}

Nos modelos sem aplicação de peso amostral com o estimador MLR (Tabelas 13 a 16), a vulnerabilidade socioeconômica (VSE) apresentou efeitos estatisticamente significantes tanto para os modelos com aplicação de pesos amostrais quanto sem a aplicação, sendo que para os modelos com estimador MLR, foram observadas $\mathrm{OR} \geq 4,0$ para os quatro desfechos referentes à inadequação da assistência pré-natal. A hipertensão apresentou efeitos estatisticamente significantes para os quatro desfechos; diagnóstico de doença crônica para três dos desfechos (com exceção do índice de Silva); filho com baixo peso anterior apresentou efeito significante com os desfechos índice de Takeda e realização de menos de sete consultas de pré-natal; e mãe responsável pelo sustento familiar no domicílio para dois dos desfechos (com exceção do índice de Silva e 
realização de menos de sete consultas). Essas relações também foram encontradas nos estudos realizados por SILVA (2009) e OLIVEIRA (2014), apesar da não aplicação de pesos amostrais e, também na revisão realizada por SILVEIRA (2014).

Ainda considerando os modelos sem aplicação do peso amostral, a VSE também está associada a ter tido filho anterior com baixo peso, multiparidade, hipertensão arterial, índice de massa corporal (IMC), autoavaliação da saúde e planejamento da gravidez, indicando que este é um fator muito importante e precisa estar presente nas análises da inadequação pré-natal, seu papel recai sobre dimensões distintas (psicossociais e biológicas). Mãe diagnosticada com doença crônica também influencia a autoavaliação em saúde na medida em que um indivíduo com doença crônica afeta sua percepção de saúde levando a um decréscimo na escala de avaliação (MOLARIUS e JANSON, 2005). A família não-nuclear apresentou efeito sobre o planejamento da gravidez o que pode indicar que o suporte afetivo tem um papel na decisão de engravidar, além do VSE (IOM 2007).

Nos modelos com aplicação de peso amostral e estimador MLR, a VSE também apresenta papel importante e semelhante com o que ocorre no modelo sem o peso amostral, exceto sobre o planejamento da gravidez. Apenas em um modelo, usando o índice de Takeda como desfecho, o planejamento da gravidez tem efeito significante. A hipertensão apresentou efeitos estatisticamente significantes para dois dos desfechos índice de PHPN Simples e índice de Silva. Para o modelo com desfechos realização de menos de sete consultas somente a VSE foi significante.

Os modelos com o estimador WLSMV apresentaram algumas diferenças e, embora alguns autores (BYRNE 2013) prefiram a utilização deste estimador, o estimador MLR tem sido mais utilizado por permitir a obtenção da medida de risco, via odds ratio. 
Os resultados apresentados sem o peso amostral, em comparação aos com peso amostral, são mais consistentes com os encontrados na literatura. Isso poderia ser devido à amostragem não ter sido feita especificamente para a população estudada no presente trabalho. O uso de pesos pode levar a estimativas que se refiram a uma população que não está muito bem definida. Dessa forma, o modelo sem pesos amostrais poderia ser mais apropriado em tais situações.

\subsubsection{Outros modelos}

Os modelos "SUS" e "não SUS” apresentaram diferenças em relação aos índices de ajuste dos modelos, composição da variável latente VSE no componente de mensuração e também dos efeitos no componente estrutural, sugerindo que os caminhos causais para a "Inadequação da Assistência pré-natal” não são os mesmos para as duas populações e que modelos diferenciados poderiam ser explorados.

Apesar de não termos considerado modelos multiníveis para a análise final, resultados apresentados na Tabela 7, que apresenta os dos modelos de regressão logística simples, sugerem que residir em UF com cobertura ou qualidade da assistência pré-natal abaixo de $70 \%$ poderia ser fator de risco para inadequação da assistência pré-natal a nível individual $(\mathrm{OR}=1,81$; IC95\% 1,3-2,5; e OR=2,48; IC95\% 1,7-3,6; respectivamente para os modelos com peso amostral), sugerindo caminhos causais multiníveis para a inadequação da assistência pré-natal poderiam ser também explorados.

Houve indícios de que modelos distintos para população usuária SUS e não-SUS, assim como modelos multiníveis, também poderiam ser mais explorados. Ademais, também poderia ser considerada o papel da moderação da variável SUS/não-SUS, como no caso da variável "Mãe responsável pelo sustento familiar no domicílio" que se 
apresentou como fator de risco para SUS (Tabela 19) e fator de proteção para não-SUS (Tabela 20).

\subsection{Limitações do estudo}

Como limitações para este estudo, podemos citar: as 1.851 mães brasileiras do módulo S que constituem a população desse estudo realizaram último parto entre 2011 e 2013, de forma que uma mulher desse grupo de estudo que teve parto em 2011, por exemplo, pode não ter apresentado naquele ano as mesmas condições de vida e características relatadas no ano de 2013, quando foi realizada a pesquisa. Assim, foi considerado para efeito desse estudo o pressuposto de que, desde o momento do último parto, no período delimitado de até três anos (2011-2013) não houve alterações significativas nas condições de vida, pessoais e percepções (representadas pelas respostas às questões de outros módulos da PNS 2013) das mulheres consideradas na população de interesse desse estudo.

Muitos dos efeitos observados nos componentes estruturais das modelagens com equações estruturais realizadas não foram estatisticamente significantes e poucos caminhos hipotetizados se sustentaram. Entretanto, a forma como as variáveis foram aferidas na PNS 2013 (autorrespostas), embora possa ter sido adequada para certos grupos de variáveis (como autoavaliação da saúde e tantas outras), talvez não tenha sido para algumas das variáveis consideradas na análise como: idade gestacional (que não apresentou validade na PNS 2013); realização de procedimentos e exames; data de realização; entre outras. É possível também considerar a introdução de viés de memória, que representa uma dificuldade em avalair dados para essas variáveis que não contam com a maior precisão da aferição feita por meio de dados de registros hospitalares, por 
exemplo, sendo que, no módulo $\mathrm{S}$, por exemplo, algumas das perguntas realizadas às mães remetiam a eventos acontecidos a até dois anos antes da gestação mais recente. 


\section{Conclusões}

A modelagem de equações estruturais permitiu avaliar o efeito de variáveis latentes sobre o desfecho explicitando os caminhos entre as variáveis a partir de um modelo teórico estabelecido.

O papel da VSE se destacou como o fator mais importante para a inadequação da assistência pré-natal e para outras variáveis de naturezas distintas. A hipertensão aparece como um fator a ser considerado, principalmente em modelos sem peso amostral.

Dados de inquéritos com dados públicos e abertos como os da PNS 2013 devem ser explorados ao máximo, considerando o tempo, trabalho e recursos investidos. O potencial de representatividade da amostra da pesquisa para toda a população brasileira permite importantes análises das variáveis presentes, inclusive para estudos analíticos (como os que empregam a MEE). Entretanto, deve ser considerado que a forma como as variáveis são aferidas pode fazer substancial diferença, em especial em relação à resposta dada pelo entrevistado a respeito de eventos muito específicos que ocorreram há mais tempo.

Os diferentes resultados obtidos com a utilização dos quatro índices de inadequação da assistência pré-natal sugerem que diferentes caminhos causais podem estar associados aos diversos aspectos da assistência. 


\section{Referências bibliográficas}

AAP - American Academy of Pediatrics. The American College of Obstetrics and Gynecologists. Guidelines for perinatal care. 5 ed. Washington: AAP/ACOG; 2002.

Alexander GR, Kotelchuck M. Quantifying the adequacy of prenatal care: a comparison of indices. Public Health Rep 1996;111:408-18.

Almeida MFD, Alencar GP, Schoeps D, Novaes HMD, Campbell O, Rodrigues LC. Sobrevida e fatores de risco para mortalidade neonatal em uma coorte de nascidos vivos de muito baixo peso ao nascer, na Região Sul do Município de São Paulo, Brasil. Cad. Saúde Pública 2011:27(6):1088-98.

Andersen RM, Newman JF. Societal and individual determinants of medical care utilization in the United States. Milbank Mem Fund $Q$ 1973; 51:95-124.

Andersen RM. Revisiting the behavioral model and access to medical care: does it matter? J Health SocBehav 1995;36:1-10.

Assunção PL, Novaes HMD, Alencar GP, Melo ASDO, Almeida MFD. Fatores associados ao nascimento pré-termo em Campina Grande, Paraíba, Brasil: um estudo caso-controle. Cad. Saúde Pública 2012: 28(6).

Behrman RE, Butler AS. Preterm birth: causes, consequences and prevention. Washington DC: National Academies Press; 2007.

Brasil. Ministério da Saúde. Programa de Humanização do Pré-Natal e Nascimento. Brasília, DF: Secretaria de Políticas de Saúde; 2000.

Brasil. Ministério da Saúde, Secretaria de Vigilância em Saúde. Saúde Brasil 2004: uma análise da situação de saúde. Brasília (DF); 2004 [acesso em 04 março 2016]; p. 
69-83. Disponível em <bvsms.saude.gov.br/bvs/publicacoes/saude_brasil_ 2004.pdf>.

Bray JH. Family Assessment: current issues in evaluating families. Fam Relations. $1995 ; 44: 469-77$.

Bollen K. Structural equations with latent variables. New York: John Wiley \& Sons, 1989.

Borsboom D, Mellenbergh GJ, Heerden JV. The theoretical status of latent variables. Psychological Review, 2003; 110(2): 203-219.

Byrne BM. Structural equation modeling with Mplus: Basic concepts, applications, and programming. Routledge. 2013.

Cerqueira-Santos E, dos Santos Paludo S, Bensaja dei Schirò ED, Koller SH. Gravidez na adolescência: análise contextual de risco e proteção. Psicologia em estudo 2010; 15(1):73-85.

Cesar JA, Mano PS, Carlotto K, Gonzalez-Chica DA, Mendoza-Sassi RA. Público versus privado: avaliando a assistência à gestação e ao parto no extremo sul do Brasil. Rev Bras Saúde Matern Infant. 2011;11(3):257-63.

Ciol MA, et al. Understanding the use of weights in the analysis of data from multistage surveys. Archives of physical medicine and rehabilitation 2006; 87(2): 299-303.

Cnattingius S. The epidemiology of smoking during pregnancy: smoking prevalence, maternal characteristics, and pregnancy outcomes. Nicotina Res Tob. 2004; 6 Suppl 2: S125-40.

Coimbra LC, Silva AA, Mochel EG, Alves MT, Ribeiro VS, Aragão VM, Bettiol H. Factors associated with inadequacy of prenatal care utilization. Rev. Saúde Pública $2003 ; 37: 456-62$

Damacena GN, et al. O processo de desenvolvimento da Pesquisa Nacional de Saúde no Brasil, 2013. Epidemiologia e Serviços de Saúde 24.2 (2015): 197-206. 
Debessai Y, Costanian C, Roy M, El-Sayed M, Tamim H. Inadequate prenatal care use among Canadian mothers: findings from the Maternity Experiences Survey. Journal of Perinatology, 2016.

de Freitas Ortigara EP, de Barros Carvalho MD, Pelloso SM. Percepção da assistência pré-natal de usuárias do serviço público de saúde. Revista de Enfermagem da UFSM $2015 ; 5(4), 618-627$.

do Nascimento Silva PL; Pessoa DGC \& Lila MF. Análise estatística de dados da PNAD: incorporando a estrutura do plano amostral. Ciência \& Saúde Coletiva 2002; 7(4):659-670.

Donabedian A. Aspects of medical care administration. Boston: Harvard University Press; 1973.

Donabedian A. The quality of care. How can it be assessed? JAMA, 1988; 260:17431748.

Gama SNG, Szwarcwald CL, Leal MC. Experiência de gravidez na adolescência, fatores associados e resultados perinatais entre puérperas de baixa renda. Cad Saúde Pública 2002; 18:153-61.

Goldenberg RL, Culhane JF, Iams JD, Romero R. Epidemiology and causes of preterm birth. Lancet 2008;371(9606):75-84.

Handler A, Issel M, Turnock B. A conceptual framework to measure performance of public health system. Am J Public Health 2001;91:1235-9.

Heaman MI, Sword WA, Akhtar-Danesh N, Bradford A, Tough S, Janssen PA, Helewa ME. Quality of prenatal care questionnaire: instrument development and testing. BMC pregnancy and childbirth 2014, 14(1). 
$\mathrm{Hu}$ L-T, Bentler PM. Cut-off criteria for fit indices in covariance structure analysis: Conventional criteria versus new alternatives. Structural Equation Modeling 1999; $6,1-55$.

IBGE - Instituto Brasileiro de Geografia e Estatística. Pesquisa Nacional de Saúde 2013Percepção do estado de saúde, estilos de vida e doenças crônicas -Brasil, Grandes Regiões e Unidades da Federação. Rio de Janeiro, RJ; 2014.

IOM - Institute of Medicine, Committee on Undestanding Premature Birth an Assuring Healthy Outcomes Board on Health Siences Policy. Preterm Birth: causes, consequences and prevention. Washington: National Academies Press. 2007.

IPEA - Instituto de Pesquisa Econômica Aplicada. Pobreza Multidimensional no Brasil. Rio de Janeiro, RJ; 2006.

Jöreskog KG, Sörbom D. LISREL 8: User's reference guide. Scientific Software International, 1996.

Kambourova MS, Georgieva SL. Inadequate prenatal care as a factor for prematurity at the city of Pleven, Bulgaria. The European Journal of Public Health, 25 (suppl 3), ckv176-215, 2015.

Katz J, et al. Mortality risk in preterm and small-for-gestational-age infants in low-income and middle-income countries: a pooled country analysis. Lancet 2013; 382(9890): $417-425$.

Kotelchuck M. An Evaluation of the Kessner Adequacy of Prenatal Care Index and a Proposed Adequacy of Prenatal Care Utilization Index. American journal of public health 84.9 (1994): 1414-1420.

Kotelchuck M. Overview Of Adequacy Of Prenatal Care Utilization Index; 1994 Available at <http://ncemch.org/databases/HSNRCPDFs/Overview_APCU Index.pdf>, accessed on [2016 Feb 25]. 
Kramer MS, et al. The Contribution of Mild and Moderate Preterm Birth to Infant Mortality; for the Fetal and Infant Health Study Group of the Canadian Perinatal Surveillance System. JAMA. 2000;284(7):843-849.

Kurtzman JH, Wasserman EB, Suter BJ, Glantz JC, Dozier AM. Measuring adequacy of prenatal care: does missing visit information matter?. Birth, 2014; 41(3), 254-261.

Leal MC et al. Birth in Brazil: national survey into labour and birth. Reproductive Health 2012; 9(1): 15 .

Leal MC, Theme-Filha MM, Moura ECD, Cecatti JG, Santos LMP. Atenção ao pré-natal e parto em mulheres usuárias do sistema público de saúde residentes na Amazônia Legal e no Nordeste, Brasil 2010. Revista Brasileira de Saúde Materno Infantil 2015, 15(1), 91-104.

Lei PW, Wu Q. Introduction to structural equation modeling: Issues and practical considerations. Educational Measurement: Issues and Practice 2007; v. 26, n. 3, p. $33-43$.

Li CH. The performance of MLR, USLMV, and WLSMV estimation in structural regression models with ordinal variables. [Tese de doutorado] — Michigan State University; 2014.

Loehlin JC. Latent variable models: An introduction to factor, path, and structural analysis. Lawrence Erlbaum Associates Publishers, 1998.

Marano D, Gama SGN, Domingues RMSM, Souza PRB. Prevalência e fatores associados aos desvios nutricionais em mulheres na fase pré-gestacional em dois municípios do Estado do Rio de Janeiro, Brasil. Revista Brasileira de Epidemiologia jan-mar 2014; 45-58.

Martinelli KG, Neto S, Gama SGND, Oliveira AE. Adequacy process of prenatal care according to the criteria of Humanizing of Prenatal Care and Childbirth Program 
and Stork Network. Revista Brasileira de Ginecologia e Obstetrícia, 2014; 36(2), $56-64$.

McCormick MC, et al. The regionalization of perinatal services: summary of the evaluation of a national demonstration program. Jama 253.6 (1985): 799-804.

Molarius A, Janson S. Self-rated health, chronic diseases, and symptoms among middleaged and elderly men and women. Journal of clinical epidemiology 2002; 55(4), 364-370.

Muglia LJ, Katz M. The enigma of spontaneous preterm birth. N Engl J Med 2010; 362: $529-35$.

Muñoz LA, et al. Vivenciando a maternidade em contextos de vulnerabilidade social: uma abordagem compreensiva da fenomenologia social. Revista Latino-Americana de Enfermagem 21.4 (2013): 913-919.

Muthén LK, Muthén BO. Mplus User’s Guide. Sixth Edition. Los Angeles, CA: Muthén \& Muthén, 2010.

Nunes JT, et al. Qualidade da assistência pré-natal no Brasil: revisão de artigos publicados de 2005 a 2015. Cad. Saúde Colet., Rio de Janeiro, 24 (2): 252-261. 2016.

Oliveira AA. Fatores de risco para nascimento pré-termo - uma análise com modelagem de equações estruturais. [Dissertação de mestrado] — São Paulo: Faculdade de Saúde Pública da USP; 2014.

Ostrove JM, et al. Objective and subjective assessments of socioeconomic status and their relationship to self-rated health in an ethnically diverse sample of pregnant women. Health Psychology 19.6 (2000): 613-618.

OMS - Organização Mundial da Saúde. Physical status: the use and interpretation of anthropometry. Report of a WHO Expert Committee. WHO Technical Report Series 854. Geneva: World Health Organization, 1995. 
Padilha PC, et al. Associação entre o estado nutricional pré-gestacional e a predição do risco de intercorrências gestacionais. Rev Bras Ginecol Obstet. 2007;29(10):511-8. Paris GF, et al. Qualidade da assistência pré-natal nos serviços públicos e privados. Rev bras ginecol obstet (2013): 447-452.

Pereira JC. Bioestatística em outras palavras. Edusp: Fapesp; 2010.

Rasella D, et al. Effect of a conditional cash transfer programme on childhood mortality: a nationwide analysis of Brazilian municipalities. Lancet. 2013; 382(9886):57-64.

Saavedra JS, Cesar JA. Use of different criteria to assess inadequate prenatal care: a population-based study in Southern Brazil. Cadernos de Saúde Pública, 31(5), 1003-1014, 2015.

Sabroza AR, Leal MC, Gama SGN, Costa JV. Perfil sócio-demográfico e psicossocial de puérperas adolescentes do Município do Rio de Janeiro, Brasil - 1999-2001. Cad Saúde Pública, 2004; 20 Suppl 1: S112-20.

Santos Neto ET, Oliveira AE, Zandonade E, Leal MC. Access to prenatal care: assessment of the adequacy of different indices. Cadernos de Saúde Pública, 2013:29(8):1664-1674.

Saunders C, Santos MAS, Padilha PC. A orientação dietética e a qualidade da assistência pré-natal. Rev Bras Ginecol Obstet. 2011; 33(1):9-12.

Schumacker RE, Lomax RG. A begginer's guide to structural equation modeling. Psychology Press, 2004.

Schytt E, Lindmark G, Waldenström U. Physical symptoms after childbirth: prevalence and associations with self-rated health. BJOG: An International Journal of Obstetrics \& Gynaecology 112.2 (2005): 210-217. 
Schytt E, Ingegerd H. Physical and emotional self-rated health among Swedish women and men during pregnancy and the first year of parenthood. Sexual \& reproductive healthcare 2.2 (2011): 57-64.

Serruya SJ, et al. O panorama da atenção pré-natal no Brasil e o Programa de Humanização do Pré-natal e Nascimento. Revista Brasileira de Saúde Materno Infantil, 2004.

Silva AMR. Fatores de risco para nascimentos pré-termo no Município de LondrinaParaná. São Paulo, 2008. [Tese de doutorado] — Faculdade de Saúde Pública — USP.

Silva AMR, Almeida MF, Matsuo T, Soares DA. Fatores de risco para nascimentos prétermo em Londrina - Paraná, Brasil. Cad. Saúde Pública, 2009; 25(10): 2125-38.

Silveira DS, Santos IS, Costa JS. Atenção pré-natal na rede básica: uma avaliação da estrutura e do processo. Cad. Saúde Pública, 2001; 17:131-9.

Silveira DS, Santos IS. Adequação do pré-natal e peso ao nascer: uma revisão sistemática Adequacy of prenatal care and birthweight: a systematic review. Cad. Saúde Pública, 2014; 20(5), 1160-1168.

Skrondal A, Rabe-Hesketh S. Generalized latent variable modeling: multilevel, longitudinal and structural equation models. London: Chapman \& Hall, 2004.

Souza-Júnior PRBD, Freitas MPSD, Antonaci GDA, Szwarcwald CL. Desenho da amostra da Pesquisa Nacional de Saúde 2013. Epidemiologia e Serviços de Saúde, 2015; 24(2), 207-216.

Stringer M. Issues in determining and measuring adequacy of prenatal care. J Perinatol, $1998 ; 18(1): 68-73$.

Succi RCDM, et al. Evaluation of prenatal care at basic health units in the city of São Paulo. Revista latino-americana de enfermagem, 16(6), 986-992. 2008. 
Szwarcwald CL, et al. Pesquisa Nacional de Saúde no Brasil: concepção e metodologia de aplicação. Ciênc. saúde coletiva. 2014, vol.19, n.2, pp.333-342.

Takeda S. Avaliação de unidade de atenção primária: modificação dos indicadores de saúde e qualidade da atenção [Dissertação de Mestrado]. Pelotas: Universidade Federal de Pelotas; 1993.

Tayebi T, Hamzehgardeshi Z, Shirvani MA, Dayhimi M, Danesh M. Relationship between Revised Graduated Index (R-GINDEX) of prenatal care utilization \& preterm labor and low birth weight. Global journal of health science, 2014; 6(3), 131.

Travassos CMR, Martins MS. Uma revisão sobre os conceitos de acesso e utilização de serviços de saúde. Cad. Saúde Pública, Rio de Janeiro, 20 Sup 2:S190-S198. 2004.

Travassos C, Castro MSMD. Determinantes e desigualdades sociais no acesso e na utilização de serviços de saúde. Políticas e sistema de saúde no Brasil, 215-243. 2008.

Tucker J, McGuire W. Epidemiology of preterm birth. BMJ 2005; 329:675-8.

Victora CG, et al. Epidemiologia da desigualdade. Hucitec, 1988.

Yu C-Y, Muthén BO. Evaluation of model fit indices for latent variable models with categorical and continuous outcomes. In annual meeting of the American Educational Research Association, New Orleans, LA. 2002. 


\section{Anexos}

\subsection{Parecer Consubstanciado do Comitê de Ética em Pesquisa - Anexo A}

\section{USP - FACULDADE DE SAÚDE PÚBLICA DA UNIVERSIDADE Platoforma DE SÃO PAULO - FSP/USP}

\section{PARECER CONSUBSTANCIADO DO CEP}

\section{DADOS DO PROJETO DE PESQUISA}

Título da Pesquisa: Comparação de índices de avaliação da assistência pré-natal em base de dados nacional: uma análise com modelagem de equações estruturais

Pesquisador: MATHEUS SOUZA FERREIRA

Área Temática:

Versão: 1

CAAE: 80436717.9 .0000 .5421

Instituição Proponente: Faculdade de Saúde Pública da Universidade de São Paulo - FSP/USP

Patrocinador Principal: Financiamento Próprio

DADOS DO PARECER

Número do Parecer: 2.454.986

Apresentação do Projeto:

Trata-se de projeto de mestrado sob orientação do professor Gizelton Alencar. Serão usados da Pesquisa Nacional de Saúde (PNS) de 2013 que forma tornados públicos pelo IBGE. Assim, não me parece necessário avaliação pelo CEP.

Objetivo da Pesquisa:

Segundo o autor, são objetivos da pesquisa: 1) Comparar resultados de diferentes construções de variáveis que medem adequação da assistência pré-natal, como desfechos, em modelos de equações estruturais e verificar sua relação com fatores de risco propostos empregando-se dados do estudo nacional PNS de 2013 ; 2) Realizar levantamento para identificar os índices que medem a adequação da assistência pré-natal utilizados em estudos nacionais; 3) Calcular e descrever os algoritmos para a construção das variáveis de avaliação da adequação da atenção pré-natal para compará-los descrevendo suas distribuições para os dados da PNS de 2013; 4) Gerar modelos de equações estruturais com o desfecho inadequação da assistência pré-natal obtido de diferentes formas para os dados do estudo PNS de 2013 com variáveis das dimensões: demográfica; socioeconômica; ambiental; estrutura familiar; reprodutivas da gestante; intercorrências na gestação; e variáveis específicas da PNS de 2013, comparando os resultados dos modelos.

Avaliação dos Riscos e Beneficios:

Não há risco, pois os dados são públicos e sem nomes para identificação.

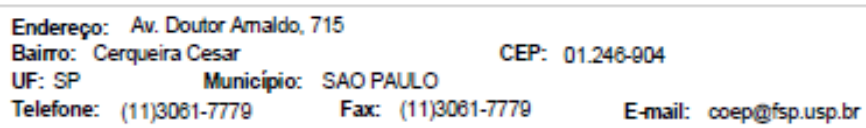




\section{USP - FACULDADE DE SAÚDE PÚBLICA DA UNIVERSIDADE DE SÃO PAULO - FSP/USP}

Continuaçso do Parecer: 2.454 .986

Comentários e Considerações sobre a Pesquisa:

Pesquisa Adequada

Considerações sobre os Termos de apresentação obrigatória:

Documentação apresenta adequada.

Recomendações:

não há.

Conclusões ou Pendências e Lista de Inadequações:

Aprovado

Considerações Finais a critério do CEP:

Este parecer foi elaborado baseado nos documentos abaixo relacionados:

\begin{tabular}{|c|c|c|c|c|}
\hline Tipo Documento & Arquivo & Postagem & Autor & Situação \\
\hline $\begin{array}{l}\text { Informações Básicas } \\
\text { do Proieto }\end{array}$ & $\begin{array}{l}\text { PB_INFORMAÇŌES_BÁSICAS_DO_P } \\
\text { ROJETO } 1021117 \text { dff }\end{array}$ & $\begin{array}{c}20 / 11 / 2017 \\
09-48: 16\end{array}$ & & Aceito \\
\hline $\begin{array}{l}\text { Projeto Detalhado / } \\
\text { Brochura } \\
\text { Investigador }\end{array}$ & projeto_pesquisa.pdf & $\begin{array}{c}02 / 11 / 2017 \\
08: 02: 15\end{array}$ & $\begin{array}{l}\text { MATHEUS SOUZA } \\
\text { FERREIRA }\end{array}$ & Aceito \\
\hline Folha de Rosto & CEP_folha_rosto.pdf & $\begin{array}{c}02 / 11 / 2017 \\
07: 55: 19\end{array}$ & $\begin{array}{l}\text { MATHEUS SOUZA } \\
\text { FERREIRA }\end{array}$ & Aceito \\
\hline
\end{tabular}

Situação do Parecer:

Aprovado

Necessita Apreciação da CONEP:

Não

SAO PAULO, 22 de Dezembro de 2017

Assinado por:

Maria Regina Alves Cardoso

(Coordenador)

Endereço: Av. Doutor Amaldo, 715

Bairro: Cerqueira Cesar

Municipio: SAOPAULO

UF: SP
Telefone: (11)3081-7779

Fax: (11)3061-7778

CEP: $01.246-904$

E-mail: coep@isp.usp.br

Pagina 02 de 02 
8.2 Detalhamento do levantamento realizado - Anexo $B$ 


\begin{tabular}{|c|c|c|c|c|c|c|c|c|c|c|}
\hline ID Autor & Título & Ano Fonte & Critério de adeq. (do Process & Aspecto & Origem & PNS & Covariáveis da Análise & Tipo de Análise & Tamanho Amostra & Resultados \\
\hline $\begin{array}{l}1 \text { Saavedra, } \\
\text { et al. }\end{array}$ & $\begin{array}{l}\text { Uso de diferentes } \\
\text { critérios para avaliação } \\
\text { da inadequação do pré- } \\
\text { natal: um estudo de base } \\
\text { populacional no extremo } \\
\text { Sul do Brasil }\end{array}$ & $\begin{array}{l}2015 \text { primária (questionário } \\
\text { padrão até } 24 \text { horas após } \\
\text { o parto em todas as mães } \\
\text { nas } 2 \text { maternidades do } \\
\text { município de Rio Grande) }\end{array}$ & (múltiplos índices) & Utilização & $\begin{array}{l}\text { Diferentes índices } \\
\text { (Takeda, Coimbra } \\
\text { et al. e Silveira) }\end{array}$ & possível* & $\begin{array}{l}\text { Idade da mãe, Cor da pele, vive } \\
\text { com companheiro, Escolaridade, } \\
\text { Renda familiar, Exerceu } \\
\text { atividade remunerada durante } \\
\text { gravidez, } \\
\text { moradores por domicílio, índice } \\
\text { de bens em quartis, número de } \\
\text { filhos tidos, teve aborto, planejou } \\
\text { gravidez, tipo de médico que fez } \\
\text { pré-natal, intercorrências }\end{array}$ & $\begin{array}{l}\text { Descritivo e Analítico, qui- } \\
\text { quadrado para comparar } \\
\text { proporções e regressão de } \\
\text { Poisson para modelo } \\
\text { multivariado, Razão de } \\
\text { Prevalência }\end{array}$ & 2395 gestantes & $\begin{array}{l}\text { Encontrou associação } \\
\text { entre pré-natal } \\
\text { inadequado pelo índice } \\
\text { de Silveira } \\
\text { principalmente e } \\
\text { categorias das } \\
\text { covariáveis }\end{array}$ \\
\hline $\begin{array}{l}2 \text { Silva, et } \\
\text { al. }\end{array}$ & $\begin{array}{l}\text { Desenvolvimento e } \\
\text { aplicação de um novo } \\
\text { índice para avaliação do } \\
\text { pré-natal }\end{array}$ & $\begin{array}{l}2013 \text { primária (elaboração de } \\
\text { instrumento próprio, } \\
\text { entrevistas com gestantes } \\
\text { e profissionais da saúde e } \\
\text { consultas em Cartão da } \\
\text { Gestante e Caderneta da } \\
\text { Criança, aplicado em } 44 \\
\text { serviços de atenção } \\
\text { básica do Municíio de } \\
\text { João Pessoa) }\end{array}$ & $\begin{array}{l}\text { adequado superior }(100 \% \text { de } \\
\text { questões adequadas); } \\
\text { adequado ( }>75 \%) \text {; } \\
\text { intermediário ( } 51 \text { a } 74 \%) \text {; e } \\
\text { inadequado (<50\%); e } \\
\text { outros índices }\end{array}$ & $\begin{array}{l}\text { Qualidade e } \\
\text { Utilização }\end{array}$ & $\begin{array}{l}\text { índices de utilização } \\
\text { + novo índice (base } \\
\text { em diretrizes do } \\
\text { PHPN elementos } \\
\text { quanti-qualitativos } \\
\text { distribuídos segundo } \\
\text { tríade avaliativa } \\
\text { infra-estrutura, } \\
\text { processo de } \\
\text { trabalho e }\end{array}$ & Ausência de variáveis & $\begin{array}{l}\text { Novo índice proposto, Índice de } \\
\text { Kessner e Índice de Kotelchuck; } \\
\text { prematuridade, baixo peso ao } \\
\text { nascer, peso insuficiente ao } \\
\text { nascer, aleitamento materno } \\
\text { exclusivo }\end{array}$ & $\begin{array}{l}\text { Estudo transversal, } \\
\text { analítico-descritivo, OR }\end{array}$ & 238 gestantes & $\begin{array}{l}\text { categorias do índice } \\
\text { proposto mostraram-se } \\
\text { consistentes para } \\
\text { detectar as variáveis } \\
\text { prematuridade, peso } \\
\text { insuficiente } \\
\text { ao nascer e não } \\
\text { realização do } \\
\text { aleitamento materno } \\
\text { exclusivo }\end{array}$ \\
\hline $\begin{array}{l}3 \text { Santos } \\
\text { Neto, et } \\
\text { al. }\end{array}$ & $\begin{array}{l}\text { Acesso à assistência pré- } \\
\text { natal: avaliação da } \\
\text { adequação por diferentes } \\
\text { índices }\end{array}$ & $\begin{array}{l}2013 \text { primária (formulários de } \\
\text { pesquisa, cartões de } \\
\text { gestantes e prontuários } \\
\text { médicos de puérperas, } \\
\text { com parto em } \\
\text { maternidades da Região } \\
\text { Metropolitana da Grande } \\
\text { Vitória ES) }\end{array}$ & (múltiplos índices) & $\begin{array}{l}\text { Utilização (o } \\
\text { índice } \\
\text { baseado no } \\
\text { PHPN não } \\
\text { apresentou } \\
\text { procedimento } \\
\text { s mínimos na } \\
\text { construção) }\end{array}$ & $\begin{array}{l}\text { Diferentes índices } \\
\text { (modificações de } \\
\text { Kessner e } \\
\text { Kotelchuck e índice } \\
\text { baseado no PHPN } \\
\text { sem considerar } \\
\text { procedimentos } \\
\text { mínimos) }\end{array}$ & $\begin{array}{l}\text { Ausência de variáveis } \\
\text { para alguns dos índices, } \\
\text { outros seriam } \\
\text { possiveis* }\end{array}$ & $\begin{array}{l}\text { Comparações entre os índices } \\
\text { de Ciari Jr. et al., Kessner, } \\
\text { Alexander \& Cornely, Rosen et } \\
\text { al., Kotelchuck, } \\
\text { Takeda, Brazil (PHPN), Villar et } \\
\text { al., Coutinho et al., Carvalho \& } \\
\text { Novaes. }\end{array}$ & $\begin{array}{l}\text { descritivo (apresentação } \\
\text { de proporções e intervalos } \\
\text { de confiança; Coeficiente } \\
\text { de Kappa para } \\
\text { concordância entre índices } \\
\text { segundo distribuições } \\
\text { segundo categorias entre } \\
\text { índices diferentes; } \\
\text { Também sensibilidade e } \\
\text { especificidade (com } \\
\text { avaliação por curva } \\
\text { ROCC), valores preditivos }\end{array}$ & 937 gestantes & $\begin{array}{l}\text { maior prevalência de } \\
\text { adequação foi } \\
\text { encontrada } \\
\text { pelo índice } \\
\text { Takeda;maior } \\
\text { concordância } \\
\text { ocorreu entre os índices } \\
\text { de Villar et al. e } \\
\text { Rosen et al. }\end{array}$ \\
\hline $\begin{array}{l}4 \text { Pereira, } \\
\text { et al. }\end{array}$ & $\begin{array}{l}\text { Avaliação da adequação } \\
\text { da assistência pré-natal } \\
\text { em uma unidade } \\
\text { tradicional da atenção } \\
\text { primária à saúde }\end{array}$ & $\begin{array}{l}2013 \text { primária (questionário } \\
\text { aplicado em mães com } \\
\text { mais de } 18 \text { anos com } \\
\text { filhos até } 6 \text { meses de } \\
\text { idade, em unidade de } \\
\text { saúde do município de } \\
\text { Divinópolis }\end{array}$ & $\begin{array}{l}\text { Adequado - mínimo } 6 \\
\text { consultas ( } 1 \text { no } 1^{\circ} \text { trimestre } \\
\text { gestacional, } 2 \text { no } 2^{\circ} \text { e } 3 \text { no } \\
3^{\circ} \text {; realização de } \\
\text { procedimentos básicos) }\end{array}$ & Qualidade & PHPN & Ausência de variáveis & $\begin{array}{l}\text { Profissional responsável pela } \\
\text { assistência pré-natal, tipo de } \\
\text { gestação, tipo de parto, }\end{array}$ & descritivo & 23 gestantes & $\begin{array}{l}\text { assistência pré-natal no } \\
\text { município apresentaram } \\
\text { inadequações segundo o } \\
\text { que é preconizado } \\
\text { pelo Ministério da Saúde }\end{array}$ \\
\hline
\end{tabular}




\begin{tabular}{|c|c|c|c|c|c|c|c|c|c|c|c|}
\hline ID Autor & Título & Ano & Fonte & Critério de adeq. (do Proces & s Aspecto & Origem & PNS & Covariáveis da Análise & Tipo de Análise & Tamanho Amostı & a Resultados \\
\hline $\begin{array}{l}5 \text { Vettore, } \\
\text { et al. }\end{array}$ & $\begin{array}{l}\text { Avaliacao do manejo da } \\
\text { infeccao urinaria no pre- } \\
\text { natal em gestantes do } \\
\text { Sistema Unico de Saude } \\
\text { no municipio do Rio de } \\
\text { Janeiro }\end{array}$ & 2013 & $\begin{array}{l}3 \text { primária (entrevistas com } \\
\text { as gestantes e } \\
\text { informações do cartão pré } \\
\text { natal) }\end{array}$ & $\begin{array}{l}\text { Inadequado Intermediário, } \\
\text { Adequado e Mais que } \\
\text { - adequado }\end{array}$ & Utilização & $\begin{array}{l}\text { Índice de } \\
\text { Kotelchuck }\end{array}$ & possível* & $\begin{array}{l}\text { Presença de infecção do trato } \\
\text { urinário, raça cor, peso da } \\
\text { gestante, tipo de gestação }\end{array}$ & $\begin{array}{l}\text { Estudo transversal, } \\
\text { analítico-descritvo, qui- } \\
\text { quadrado, regressão } \\
\text { logística, OR }\end{array}$ & 1091 gestantes & $\begin{array}{l}\text { Gestantes com qualidade } \\
\text { do pré-natal } \\
\text { parcialmente adequado } \\
\text { ou inadequado } \\
\text { apresentaram maior } \\
\text { chance de infecção do } \\
\text { trato urinário. }\end{array}$ \\
\hline $\begin{array}{l}6 \text { Vettore, } \\
\text { et al. }\end{array}$ & $\begin{array}{l}\text { Avaliação da qualidade } \\
\text { da atenção pré-natal } \\
\text { dentre gestantes com e } \\
\text { sem história de } \\
\text { prematuridade no } \\
\text { Sistema Único de Saúde } \\
\text { no Rio de Janeiro, Brasil }\end{array}$ & 2013 & $\begin{array}{l}3 \text { primária (entrevistas com } \\
\text { as gestantes e } \\
\text { informações do cartão pré } \\
\text { natal) }\end{array}$ & $\begin{array}{l}\text { Inadequado Intermediário, } \\
\text { Adequado e Mais que } \\
\text { - adequado }\end{array}$ & Utilização & $\begin{array}{l}\text { Índice de } \\
\text { Kotelchuck }\end{array}$ & possível* & prematuridade, história obstétrica & $\begin{array}{l}\text { Estudo transversal, } \\
\text { analítico-descritvo, qui- } \\
\text { quadrado, regressão } \\
\text { logística }\end{array}$ & 1239 gestantes & $\begin{array}{l}\text { História de } \\
\text { prematuridade não } \\
\text { influenciou para que } \\
\text { essas gestantes tivessem } \\
\text { um pré-natal de melhor } \\
\text { qualidade. Insatisfação } \\
\text { em relação ao modo de } \\
\text { funcionamento dos } \\
\text { serviços. }\end{array}$ \\
\hline 7 Becker & $\begin{array}{l}\text { Avaliação da qualidade } \\
\text { da assistência pré-natal } \\
\text { na atenção primária no } \\
\text { município de Rio Branco, } \\
\text { Acre }\end{array}$ & 2012 & $\begin{array}{l}2 \text { primária e secundária } \\
\text { (Bases SISPRENATAL e } \\
\text { SIAB) }\end{array}$ & $\begin{array}{l}\text { Adequado - mínimo } 6 \\
\text { consultas (1 no } 1^{\circ} \text { trimestre } \\
\text { gestacional, } 2 \text { no } 2^{\circ} \text { e } 3 \text { no } \\
3^{\circ} \text {; realização de } \\
\text { procedimentos básicos) }\end{array}$ & Qualidade & PHPN & Ausência de variáveis & $\begin{array}{l}\text { Renda, idade, sexo, raça/cor, } \\
\text { tipo de profissional que realizou } \\
\text { atendimento }\end{array}$ & $\begin{array}{l}\text { Descritivo, Matriz de } \\
\text { relevância, Matriz de } \\
\text { informação (conjunto de } \\
\text { indicadores para realizar } \\
\text { avaliação, pontuações) }\end{array}$ & 30 gestantes & $\begin{array}{l}\text { Apesar de a maioria ter } \\
\text { boa escolaridade, a } \\
\text { situação de pobreza em } \\
\text { que vive a maioria } \\
\text { dessas mulheres } \\
\text { (contexto externo) pode } \\
\text { ter influenciado a não } \\
\text { observancia de algumas } \\
\text { das importantes ações } \\
\text { da assistência pre-natal. }\end{array}$ \\
\hline $\begin{array}{l}8 \text { Rocha, et } \\
\text { al. }\end{array}$ & $\begin{array}{l}\text { Assistência pré-natal na } \\
\text { rede básica de Fortaleza- } \\
\text { CE: uma avaliação da } \\
\text { estrutura, do processo e } \\
\text { do resultado }\end{array}$ & 2012 & $\begin{array}{l}2 \text { primária - formulário } \\
\text { validado e dados } \\
\text { disponiblizados pela } \\
\text { Secretaria Municipal de } \\
\text { Saúde de Fortaleza }\end{array}$ & $\begin{array}{l}\% \text { de gestantes que } \\
\text { realizaram pelo menos } 6 \\
\text { consultas de pré-natal }\end{array}$ & $\begin{array}{l}\text { Cobertura } \\
\text { (nível } \\
\text { agregado) }\end{array}$ & - & possível* & $\begin{array}{l}\text { variáveis de estrutura (planta } \\
\text { física...), processo (\% gestantes } \\
\text { com } 7 \text { ou mais consultas...) e } \\
\text { resultado (\% de recém nascidos } \\
\text { diagnosticados com Sífilis } \\
\text { Congênita...), e indicadores de }\end{array}$ & $\begin{array}{l}\text { Descritivo, apresentação } \\
\text { de frequências absolutas e } \\
\text { relativas }\end{array}$ & $\begin{array}{l}30 \text { gestores } \\
\text { /profissionais de } \\
\text { saúde }\end{array}$ & $\begin{array}{l}\text { Estrutura foi bem } \\
\text { avaliada mas processo e } \\
\text { resultado não foram } \\
\text { apresentaram bons } \\
\text { resultados segundo a } \\
\text { avaliação. }\end{array}$ \\
\hline
\end{tabular}




\begin{tabular}{|c|c|c|c|c|c|c|c|c|c|c|c|c|}
\hline ID & Autor & Título & Ano & Fonte & Critério de adeq. (do Process & s Aspecto & Origem & PNS & Covariáveis da Análise & Tipo de Análise & Tamanho Amostra & Resultados \\
\hline & $\begin{array}{l}\text { Vilarinho, } \\
\text { et al. }\end{array}$ & $\begin{array}{l}\text { Avaliação da qualidade } \\
\text { da atenção à saúde de } \\
\text { adolescentes no pré-natal } \\
\text { e puerpério }\end{array}$ & 2012 & $\begin{array}{l}2 \text { primária (pesquisa em } \\
\text { prontuários e entrevistas } \\
\text { com adolescentes) }\end{array}$ & (múltiplos índices) & $\begin{array}{l}\text { Utilização e } \\
\text { Qualidade }\end{array}$ & $\begin{array}{l}\text { Índice de } \\
\text { Kotelchuck e } \\
\text { PHPN }\end{array}$ & $\begin{array}{l}\text { Ausência de variáveis } \\
\text { parcial }\end{array}$ & $\begin{array}{l}\text { variáveis de atenção puerperal } \\
\text { (visita domicilar, orientação } \\
\text { sobre anticoncepção, orientação } \\
\text { sobre amamentação...) }\end{array}$ & $\begin{array}{l}\text { Descritivo, apresentação } \\
\text { de frequências absolutas e } \\
\text { relativas }\end{array}$ & 44 gestantes & $\begin{array}{l}\text { Não adequação da } \\
\text { atenção no ciclo } \\
\text { gravídico-puerperal } \\
\text { refletida nos indicadores } \\
\text { considerados. }\end{array}$ \\
\hline 10 & $\begin{array}{l}\text { Domingu } \\
\text { es, et al. }\end{array}$ & $\begin{array}{l}\text { Avaliação da } \\
\text { implantação da } \\
\text { assistência pré-natal na } \\
\text { rede SUS do município } \\
\text { do Rio de Janeiro com } \\
\text { ênfase nas ações de } \\
\text { controle da síflilis e do } \\
\text { HIV }\end{array}$ & 2011 & $\begin{array}{l}1 \text { primária (entrevistas com } \\
\text { gestantes, profissionais e } \\
\text { consulta em cartão de pré- } \\
\text { natal) }\end{array}$ & $\begin{array}{l}\text { Adequado - mínimo } 6 \\
\text { consultas ( } 1 \text { no } 1^{\circ} \text { trimestre } \\
\text { gestacional, } 2 \text { no } 2^{\circ} \text { e } 3 \text { no } \\
3^{\circ} \text {; realização de } \\
\text { procedimentos básicos) + } \\
\text { realização de outros } \\
\text { procedimentos }\end{array}$ & Qualidade & $\begin{array}{l}\text { PHPN e PHPN } \\
\text { ampliado } \\
\text { (modificado) }\end{array}$ & Ausência de variáveis & $\begin{array}{l}\text { Indicadores do PHPN, Idade, } \\
\text { Cor, Escolaridade, Classe } \\
\text { Econômica, Tipo de gestação, } \\
\text { local de atendimento, Presença } \\
\text { de Síflis }\end{array}$ & $\begin{array}{l}\text { Estudo transversal, } \\
\text { analítico-descritivo, Razão } \\
\text { de prevalência, IC 95\%, }\end{array}$ & 1124 gestantes & $\begin{array}{l}\text { Identificação de } \\
\text { problemas no início } \\
\text { precoce da assistência } \\
\text { pré-natal, no número } \\
\text { adequado de consultas e } \\
\text { na realização dos } \\
\text { exames de rotina para o } \\
\text { conjunto das mulheres e } \\
\text { para aquelas que } \\
\text { apresentaram um caso } \\
\text { de sífilis congênita como } \\
\text { desfecho da gestação }\end{array}$ \\
\hline 11 & $\begin{array}{l}1 \text { Corrêa, et } \\
\text { al. }\end{array}$ & $\begin{array}{l}\text { Avaliação normativa do } \\
\text { pré-natal em uma } \\
\text { maternidade filantrópica } \\
\text { de São Paulo }\end{array}$ & 2011 & $\begin{array}{l}1 \text { primária (consulta } \\
\text { prontuários das gestantes) }\end{array}$ & $\begin{array}{l}\text { Adequado - mínimo } 6 \\
\text { consultas ( } 1 \text { no } 1^{\circ} \text { trimestre } \\
\text { gestacional, } 2 \text { no } 2^{\circ} \text { e } 3 \text { no } \\
3^{\circ} \text {; realização de } \\
\text { procedimentos básicos) }\end{array}$ & Qualidade & PHPN & Ausência de variáveis & $\begin{array}{l}\text { idade, escolaridade, presença de } \\
\text { companheiro estável, situação de } \\
\text { trabalho, acompanhamento para } \\
\text { as consultas, local de residência, } \\
\text { tipo de } \\
\text { gestação, paridade, número de } \\
\text { filhos }\end{array}$ & $\begin{array}{l}\text { Estudo transversal, Qui- } \\
\text { quadrado, apresentação de } \\
\text { frequências absolutas e } \\
\text { relativas }\end{array}$ & 301 gestantes & $\begin{array}{l}\text { O pré-natal adequado } \\
\text { apresentou diferença } \\
\text { estatísticamente } \\
\text { significante para maioria } \\
\text { das variáveis } \\
\text { dependentes } \\
\text { consideradas }\end{array}$ \\
\hline 12 & $\begin{array}{l}2 \text { Vettore, } \\
\text { et al. }\end{array}$ & $\begin{array}{l}\text { Cuidados pré-natais e } \\
\text { avaliação do manejo da } \\
\text { hipertensão arterial em } \\
\text { gestantes do SUS no } \\
\text { Município do Rio de } \\
\text { Janeiro, Brasil }\end{array}$ & 2011 & $\begin{array}{l}1 \text { primária (entrevistas com } \\
\text { gestantes e consulta de } \\
\text { cartão pré-natal) }\end{array}$ & $\begin{array}{l}\text { Inadequado Intermediário, } \\
\text { Adequado e Mais que } \\
\text { adequado (Início pré-natal } \\
\text { até } 4^{\circ} \text { mês e } 80 \% \text { ou mais } \\
\text { de consultas realizadas em } \\
\text { relação às esperadas para a }\end{array}$ & Utilização & $\begin{array}{l}\text { Índice de } \\
\text { Kotelchuck }\end{array}$ & possível* & $\begin{array}{l}\text { Hipertensão arterial, história } \\
\text { obstétrica, informações } \\
\text { demográficas e socioeconômicas }\end{array}$ & $\begin{array}{l}\text { Qui-quadrado e regressão } \\
\text { logística multivariada. }\end{array}$ & 1947 gestantes & $\begin{array}{l}\text { Não foram encontradas } \\
\text { diferenças de adequação } \\
\text { do pré-natal em relação } \\
\text { à hipertensão. }\end{array}$ \\
\hline
\end{tabular}




\begin{tabular}{|c|c|c|c|c|c|c|c|c|c|c|c|c|}
\hline ID & Autor & Título & Ano & Fonte & Critério de adeq. (do Process & Aspecto & Origem & PNS & Covariáveis da Análise & Tipo de Análise & Tamanho Amostra & Resultados \\
\hline & 3 Gregg & $\begin{array}{l}\text { Avaliação da adequação } \\
\text { da assistência pré-natal } \\
\text { em um Centro de Saúde } \\
\text { Escola em Manguinhos, }\end{array}$ & 2009 & 9 primária & $\begin{array}{l}\text { Kessner + realização de } \\
\text { procedimentos e presença } \\
\text { de prescrição de sulfato } \\
\text { ferroso e ácido fólico }\end{array}$ & Qualidade & $\begin{array}{l}\text { PHPN } \\
\text { (modificado) - } \\
\text { proposta de novo } \\
\text { índice inclui índice }\end{array}$ & Ausência de variáveis & & & & \\
\hline 14 & $\begin{array}{l}\text { Succi, et } \\
\text { al. }\end{array}$ & $\begin{array}{l}\text { Evaluation of prenatal } \\
\text { care at basic health units } \\
\text { in the city of Sao Paulo }\end{array}$ & 2008 & $\begin{array}{l}8 \text { primária (revisão de } \\
\text { prontuários de UBS) }\end{array}$ & $\begin{array}{l}\text { Adequado - Início no } \\
\text { primeiro trimestre, } \\
\text { realização de pelo menos } 6 \\
\text { consultas, realização de }\end{array}$ & qualidade & PHPN modificado & possível* & Ano, VDRL & $\begin{array}{l}\text { Estudo transversal } \\
\text { descritivo, apresentação } \\
\text { de frequências absolutas e } \\
\text { relativas, teste de Qui- }\end{array}$ & $\begin{array}{l}818 \text { gestantes em } \\
2000 \text { e } 1288 \text { em } \\
2004\end{array}$ & $\begin{array}{l}\text { Melhora do atendimento } \\
\text { no período mas } \\
\text { proporções baixas de } \\
\text { pré-natal de excelência }\end{array}$ \\
\hline 15 & 5 Nogueira & $\begin{array}{l}\text { Avaliação da assistência } \\
\text { pré-natal na XIX R. A. } \\
\text { do município do Rio de } \\
\text { Janeiro }\end{array}$ & 2008 & $\begin{array}{l}8 \text { primária (revisão de } \\
\text { prontuários e entrevista } \\
\text { com trabalhadores) }\end{array}$ & $\begin{array}{l}\% \text { de gestantes que } \\
\text { começaram no primeiro } \\
\text { trimestre, } \% \text { das que tiveram } \\
\text { minímo de consultas, \% das } \\
\text { que correspondiam a todos } \\
\text { itens do PHPN... }\end{array}$ & qualidade & PHPN & Ausência de variáveis & $\begin{array}{l}\text { Presença de consulta puerperal, } \\
\text { visita domicilar (acolhimento } \\
\text { mãe/bebê), peso ao nascer, } \\
\text { realização de procedimentos, } \\
\text { escolaridade da mãe }\end{array}$ & $\begin{array}{l}\text { Estudo transversal } \\
\text { descritivo, apresentação } \\
\text { de frequências absolutas e } \\
\text { relativas }\end{array}$ & 113 gestantes & $\begin{array}{l}\text { Verificou-se a } \\
\text { inadequação da } \\
\text { assistência, com a } \\
\text { utilização dos } \\
\text { indicadores de processo } \\
\text { do Ministério da Saúde, } \\
\text { tendo como fator } \\
\text { relevante à falta de } \\
\text { registros. }\end{array}$ \\
\hline 16 & $\begin{array}{l}6 \text { Gonçalve } \\
\text { s, et al. }\end{array}$ & $\begin{array}{l}\text { Avaliação da efetividade } \\
\text { da assistência pré-natal } \\
\text { de uma Unidade de } \\
\text { Saúde da Família em um } \\
\text { município da Grande São } \\
\text { Paulo }\end{array}$ & 2008 & $\begin{array}{l}8 \text { primária (análise de } \\
\text { prontuários e busca ativa } \\
\text { com ACSs) }\end{array}$ & $\begin{array}{l}\% \text { de gestantes que } \\
\text { começaram no primeiro } \\
\text { trimestre, } \% \text { das que tiveram } \\
\text { minímo de consultas }\end{array}$ & qualidade & PHPN parcial & possível* & $\begin{array}{l}\% \text { de abandono da assistência } \\
\text { pré-natal, \% de óbitos por } \\
\text { causas perinatais, \% de } \\
\text { criannças } \\
\text { com tétano neonatal, \% baixo } \\
\text { peso ao nascer, \% VDRL } \\
\text { positivos... }\end{array}$ & $\begin{array}{l}\text { Estudo descritivo, } \\
\text { apresentação de } \\
\text { frequências absolutas e } \\
\text { relativas }\end{array}$ & 50 gestantes & $\begin{array}{l}\text { Resultados positivos } \\
\text { evidenciam que PSE } \\
\text { propicia assistência pré- } \\
\text { natal de qualidade e } \\
\text { vínculo entre } \\
\text { profissionais com a } \\
\text { gestante é } \\
\text { imprescindível para }\end{array}$ \\
\hline
\end{tabular}




\begin{tabular}{|c|c|c|c|c|c|c|c|c|c|c|c|c|}
\hline ID & Autor & Título & Ano & Fonte & Critério de adeq. (do Process & s Aspecto & Origem & PNS & Covariáveis da Análise & Tipo de Análise & Tamanho Amo & Resultados \\
\hline & $\begin{array}{l}\text { Parada, } \\
\text { et al. }\end{array}$ & $\begin{array}{l}\text { Avaliação da assistência } \\
\text { pré-natal e puerperal } \\
\text { desenvolvidas em região } \\
\text { do interior do Estado de } \\
\text { São Paulo em } 2005\end{array}$ & 2008 & $\begin{array}{l}8 \text { primária (revisão de } \\
\text { prontuários e entrevista } \\
\text { com gestores) }\end{array}$ & $\begin{array}{l}\% \text { de gestantes que } \\
\text { começaram no primeiro } \\
\text { trimestre, } \% \text { das que tiveram } \\
\text { minímo de consultas, } \% \text { das } \\
\text { que correspondiam a todos }\end{array}$ & qualidade & PHPN & Ausência de variáveis & $\begin{array}{l}\text { Exames básicos, Imunização } \\
\text { antitetânica, pressão arterial; } \\
\text { também indicadores de estrutura }\end{array}$ & $\begin{array}{l}\text { Estudo descritivo, } \\
\text { apresentação de } \\
\text { frequências absolutas e } \\
\text { relativas }\end{array}$ & 385 gestantes & $\begin{array}{l}\text { Maioria das gestantes } \\
\text { não realiza o conjunto } \\
\text { das atividades propostas } \\
\text { pelo PHPN na DIR XI }\end{array}$ \\
\hline 18 & $\begin{array}{l}\text { Nagaham } \\
\text { a, et al. }\end{array}$ & $\begin{array}{l}\text { O cuidado pré-natal em } \\
\text { hospital universitário: } \\
\text { uma avaliacão de } \\
\text { processo }\end{array}$ & 2006 & $\begin{array}{l}6 \text { primária -Transcrição de } \\
\text { prontuários hospitalares de } \\
\text { gestantes de } 1998 \text { a } 2001 \text { - } \\
\text { Hospital Universitário de } \\
\text { Maringá }\end{array}$ & $\begin{array}{l}\text { PHPN: adequado - primeira } \\
\text { consulta de pré-natal até o } \\
\text { 4o mês da gestação e } \\
\text { mínimo de seis consultas }\end{array}$ & $\begin{array}{l}\text { Qualidade e } \\
\text { Utilização }\end{array}$ & $\begin{array}{l}\text { Kotelchuck + } \\
\text { PHPN }\end{array}$ & possível* & $\begin{array}{l}\text { Comparação das distribuições de } \\
\text { gestantes segundo PHPN e } \\
\text { Kotelchuck. }\end{array}$ & $\begin{array}{l}\text { Estudo descritivo, } \\
\text { apresentação de } \\
\text { frequências absolutas e } \\
\text { relativas }\end{array}$ & 213 gestantes & $\begin{array}{l}44,5 \% \text { das gestantes } \\
\text { iniciam tardiamente o } \\
\text { pré-natal; número médio } \\
\text { de } 9,8 \text { consultas por } \\
\text { gestante } \\
\text { superior aos parâmetros } \\
\text { nacionais } \\
\text { recomendados; } \\
\text { indicadores do PHPN } \\
\text { identificaram que }\end{array}$ \\
\hline 19 & $\begin{array}{l}\text { Koffman, } \\
\text { et al. }\end{array}$ & $\begin{array}{l}\text { Avaliação da atenção } \\
\text { pré-natal em uma } \\
\text { instituição filantrópica da } \\
\text { cidade de São Paulo }\end{array}$ & 2005 & $\begin{array}{l}5 \text { primária (revisão de } \\
\text { prontuários de instituição } \\
\text { filantrópica do MSP) }\end{array}$ & $\begin{array}{l}\text { Adequado - uma visita até a } \\
20^{\mathrm{a}} \text { semana, minímo de } 6 \\
\text { consultas e adição de } \\
\text { realização de procedimentos }\end{array}$ & $\begin{array}{l}\text { Utilização/Qu } \\
\text { alidade }\end{array}$ & $\begin{array}{l}\text { Kessner adaptado } \\
\text { (Takeda) + adição } \\
\text { de realização de } \\
\text { procedimentos }\end{array}$ & possível* & $\begin{array}{l}\text { Idade, escolaridade, ocupação } \\
\text { da gestante, história obstétrica }\end{array}$ & $\begin{array}{l}\text { Estudo descritivo, } \\
\text { apresentação de } \\
\text { frequências absolutas e } \\
\text { relativas }\end{array}$ & 635 gestantes & $\begin{array}{l}\text { O tipo de avaliação } \\
\text { proposto é factível e } \\
\text { permite realizações } \\
\text { periódicas com vista à } \\
\text { melhora da adequação } \\
\text { dos indicadores da } \\
\text { assistência oferecida } \\
\text { pelo serviço. }\end{array}$ \\
\hline & $\begin{array}{l}\text { Ribeiro } \\
\text { Filho }\end{array}$ & $\begin{array}{l}\text { Avaliação de qualidade } \\
\text { da atenção pré-natal em } \\
\text { quatro unidades do } \\
\text { Programa de Saúde da } \\
\text { Família do município de } \\
\text { Manuas - AM }\end{array}$ & 2004 & $\begin{array}{l}4 \text { primário - prontuários } \\
\text { gestantes de } 4 \text { USFs em } \\
2001\end{array}$ & $\begin{array}{l}\text { sete indicadores de } \\
\text { avaliação de processo } \\
\text { sugeridos pelo Ministério da } \\
\text { Saúde(2002) e três } \\
\text { indicadores usados por } \\
\text { Silveira et al (2001) - Dentre } \\
\text { eles Kessner }\end{array}$ & Utilização & Kessner, Silveira & possível ${ }^{*}$ & $\begin{array}{l}\text { Grau de instrução, Escolaridade, } \\
\text { Estado Civil, Faixa Etária }\end{array}$ & $\begin{array}{l}\text { Estudo descritivo, } \\
\text { apresentação de } \\
\text { frequências absolutas e } \\
\text { relativas }\end{array}$ & 111 gestantes & $\begin{array}{l}\text { Somente algumas } \\
\text { pacientes tiveram um } \\
\text { adequado pré-natal de } \\
\text { acordo com o índice de } \\
\text { Kessner, tendo } \\
\text { predominado o nível } \\
\text { intermediário. }\end{array}$ \\
\hline
\end{tabular}




\begin{tabular}{|c|c|c|c|c|c|c|c|c|c|c|c|c|}
\hline ID & Autor & Título & Ano & o Fonte & Critério de adeq. (do Proces & s Aspecto & Origem & PNS & Covariáveis da Análise & Tipo de Análise & Tamanho Amostra & Resultados \\
\hline & $\begin{array}{l}\text { Leal, et } \\
\text { al. }\end{array}$ & $\begin{array}{l}\text { Uso do índice de } \\
\text { Kotelchuck modificado } \\
\text { na avaliação da } \\
\text { assistência pré-natal e } \\
\text { sua relação com as } \\
\text { características maternas } \\
\text { e o peso do recém- } \\
\text { nascido no Município do } \\
\text { Rio de Janeiro }\end{array}$ & & $\begin{array}{l}4 \text { primária (entrevistas } \\
\text { realizadas com puerpéras } \\
\text { de hospitais de acordo } \\
\text { com processo de } \\
\text { amostragem prévio) }\end{array}$ & $\begin{array}{l}\text { Não fez pré-natal, } \\
\text { Inadequado Intermediário, } \\
\text { Adequado e Mais que } \\
\text { adequado }\end{array}$ & Utilização & $\begin{array}{l}\text { Kotelchuck } \\
\text { modificado }\end{array}$ & possível $^{*}$ & $\begin{array}{l}\text { nível de instrução, viver com pai } \\
\text { do RN, tentar abortar, diabetes, } \\
\text { satisfação com a gravidez, cor } \\
\text { da pele, paridade, idade, local de } \\
\text { residência }\end{array}$ & $\begin{array}{l}\text { Regressão logística ordinal } \\
\text { e linear, qui-quadrado }\end{array}$ & 9920 puerpéras & $\begin{array}{l}\text { Utilização adequada da } \\
\text { assistência pré-natal no } \\
\text { MRJ contribuiu na } \\
\text { prevenção do PN e as } \\
\text { mães que menos } \\
\text { utilizaram os serviços } \\
\text { pré-natais têm piores } \\
\text { condições } \\
\text { socioeducacionais, de } \\
\text { apoio familiar e de risco } \\
\text { obstétrico. }\end{array}$ \\
\hline & $\begin{array}{l}\text { Carvalho, } \\
\text { et al. }\end{array}$ & $\begin{array}{l}\text { Avaliação da } \\
\text { implantação de programa } \\
\text { de atenção pré-natal no } \\
\text { Município de Curitiba, } \\
\text { Paraná, Brasil: estudo } \\
\text { em coorte de primigestas }\end{array}$ & 2004 & $\begin{array}{l}4 \text { primária - duas } \\
\text { entrevistas domiciliares, } \\
\text { consulta no cartão da } \\
\text { gestante ou prontuário } \\
\text { ambulatorial, e no } \\
\text { prontuário hospitalar }\end{array}$ & $\begin{array}{l}\text { Adequado - mínimo } 6 \\
\text { consultas ( } 1 \text { no } 1^{\circ} \text { trimestre } \\
\text { gestacional, } 2 \text { no } 2^{\circ} \text { e } 3 \text { no } \\
3^{\circ} \text {; realização de } \\
\text { procedimentos básicos) }\end{array}$ & Qualidade & PHPN & Ausência de variáveis & $\begin{array}{l}\text { Realização de procedimentos e } \\
\text { orientações conforme PHPN }\end{array}$ & $\begin{array}{l}\text { Análise descritiva, } \\
\text { apresentação de } \\
\text { frequências absolutas e } \\
\text { relativas }\end{array}$ & 660 primigestas & $\begin{array}{l}\text { Apenas } 38,6 \% \text { das } \\
\text { mulheres } \\
\text { preencheram todos os } \\
\text { requisitos com a } \\
\text { classificação } \\
\text { empregada. }\end{array}$ \\
\hline & $\begin{array}{l}\text { Moura, et } \\
\text { al. }\end{array}$ & $\begin{array}{l}\text { Avaliação da assistência } \\
\text { pré-natal oferecida em } \\
\text { uma microrregião de } \\
\text { saúde do Ceará, Brasil }\end{array}$ & 2003 & $\begin{array}{l}3 \text { Dados secundários - } \\
\text { SIAB, SINASC e Revisão } \\
\text { de Prontuários }\end{array}$ & $\begin{array}{l}\% \text { gestantes com início do } \\
\text { pré-natal até } 3^{\circ} \text { mês e } \% \text { de } \\
\text { consultas realizadas } \\
(\text { nenhuma, } 1-3,4-6,7+)\end{array}$ & $\begin{array}{l}\text { Acesso (nível } \\
\text { agregado) }\end{array}$ & & possível & $\begin{array}{l}\text { Menores de } 20 \text { anos, } \\
\text { Acompanhada dos agentes de } \\
\text { saúde, Vacina em dia }\end{array}$ & $\begin{array}{l}\text { Análise descritiva, } \\
\text { apresentação de } \\
\text { frequências absolutas e } \\
\text { relativas }\end{array}$ & 1023 gestantes & $\begin{array}{l}\text { Excelente cobertura da } \\
\text { população por equipes } \\
\text { de PSF, mas mostra-se } \\
\text { necessário avaliar o } \\
\text { impacto dessas ações } \\
\text { para a real melhoria na } \\
\text { qualidade de vida dessas } \\
\text { mulheres }\end{array}$ \\
\hline & $\begin{array}{l}\text { Silveira, } \\
\text { et al. }\end{array}$ & $\begin{array}{l}\text { Atençäo pré-natal na } \\
\text { rede básica: uma } \\
\text { avaliaçäo da estrutura e } \\
\text { do processo }\end{array}$ & 2001 & $\begin{array}{l}1 \text { Primário -auditoria de } \\
\text { registros médicos, } \\
\text { registros do pré-natal, } \\
\text { Pelotas, Sul do Brasil }\end{array}$ & $\begin{array}{l}\text { Kessner + realização de } \\
\text { exames e procedimentos }\end{array}$ & $\begin{array}{l}\text { Utilização / } \\
\text { Qualidade }\end{array}$ & Kessner & possível* & Procedimentos de exame clínico & $\begin{array}{l}\text { Análise descritiva, } \\
\text { apresentação de } \\
\text { frequências absolutas e } \\
\text { relativas }\end{array}$ & 839 gestantes & $\begin{array}{l}\text { Qualidade do cuidado } \\
\text { pré-natal foi considerada } \\
\text { precária. Proposta de } \\
\text { que mecanismos que } \\
\text { aumentem a } \\
\text { aderência das equipes } \\
\text { de saúde aos } \\
\text { procedimentos e à lógica } \\
\text { do programa, necessitam } \\
\text { ser desenvolvidos. }\end{array}$ \\
\hline
\end{tabular}


8.3 Módulos R e S da PNS 2013 - Anexo C

Extraídos do "Questionário dos moradores do domicílio" da PNS 2013, disponível completo em:

http://www.ibge.gov.br/home/estatistica/populacao/pns/2013/default_microdados.shtm (acesso em novembro de 2017). 
Módulo R. Saúde da Mulher (mulheres de 18 anos e mais de idade)

Neste módulo, vamos fazer perguntas sobre a sua saúde, exames preventivos, história reprodutiva e planejamento familiar.

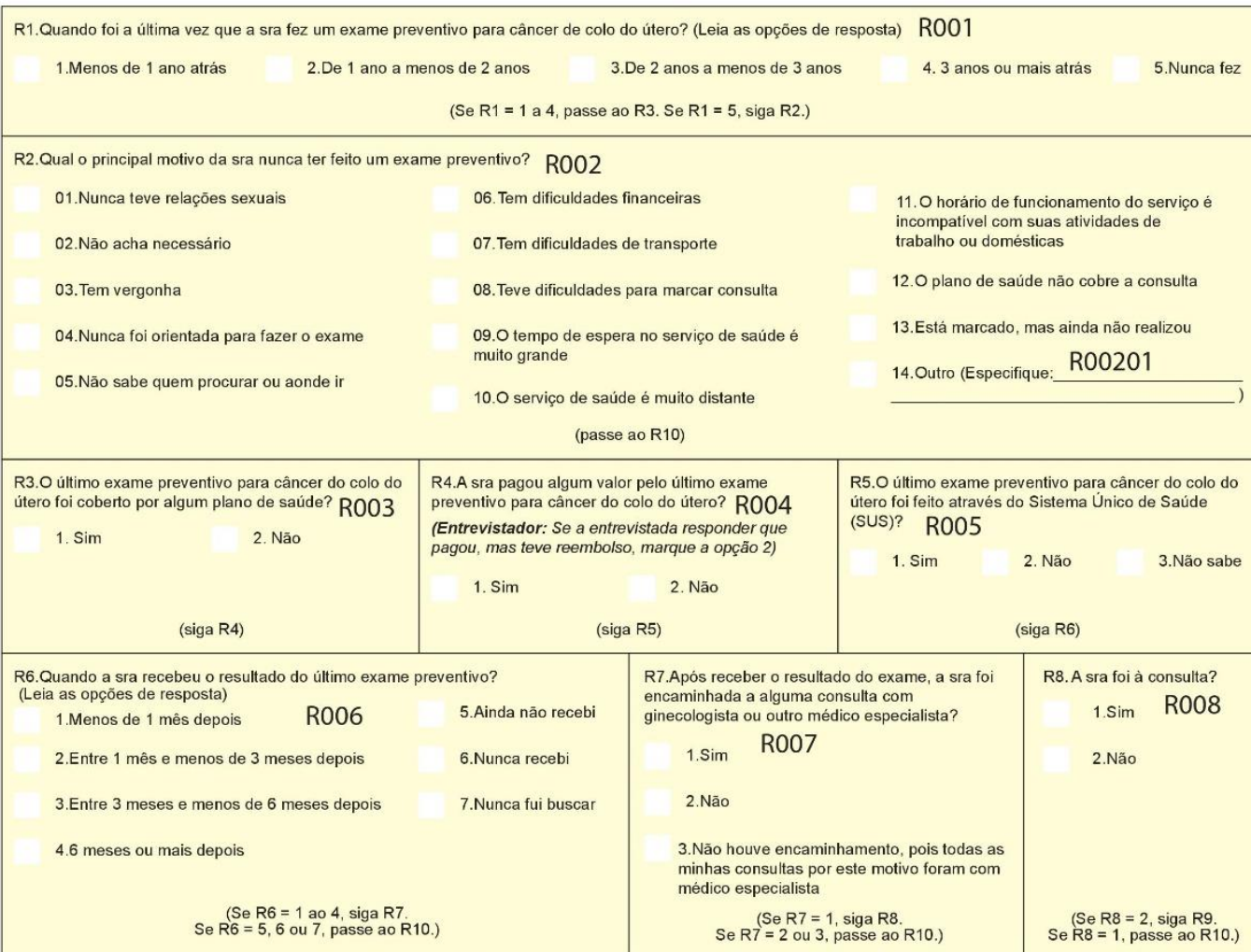

R9.Qual o principal motivo da sra não ter ido à consulta? R009

\begin{tabular}{|c|c|c|}
\hline 01. A consulta está marcada, mas ainda näo foi & 05 Teve dificuldades de transporte & 09 O servico de saúde era muito distante \\
\hline 02 Nāo achou necessário & 06 Nāo consequiu marcar & $\begin{array}{l}10.0 \text { horário de funcionamento do serviço de } \\
\text { saúde era incompativel com as atividades de }\end{array}$ \\
\hline 03Nã̀ sabia ouem nrocurar ou aอnde ir & $\begin{array}{l}07.0 \text { tempo de espera no serviço de saúde era } \\
\text { muito grande }\end{array}$ & $\begin{array}{l}\text { saude era incompativel com as atividades de } \\
\text { trabalho ou domésticas }\end{array}$ \\
\hline O4. Estava com dificuldades financeiras & 08 O plano de saúde não ccbria a consulta & \\
\hline
\end{tabular}
(siga R10)

\begin{tabular}{l|l} 
R10.A sra já foi submetida a & R11.Segundo o médico, qual o motivo da retirada do útero?(Leia as opçōes de resposta)
\end{tabular}

1.Mioma uterino R011 5 Complicações da gravidez ou parto

1. Sim R010

2.Não

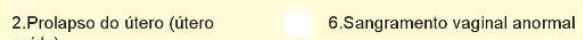

3.Endometriose

7.Outro (Especifique: R01101

4.Câncer ginecológico

(Se R10=1, siga R11.
Se R10=2, passe ao R13)

(siga R12)

(siga R13)

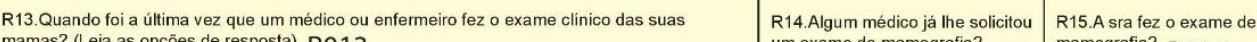
mamas? (Leia as opçöes de resposta) R013

1.Menos de 1 ano atrás

4.3 anos ou mais atrás

2.De 1 ano a menos de 2 anos atrás

5. Nunca fez

um exame de mamografia? mamografia? R015

R014

R12. Que idade a sra tinha

R012

3.De 2 anos a menos de 3 anos atrás 


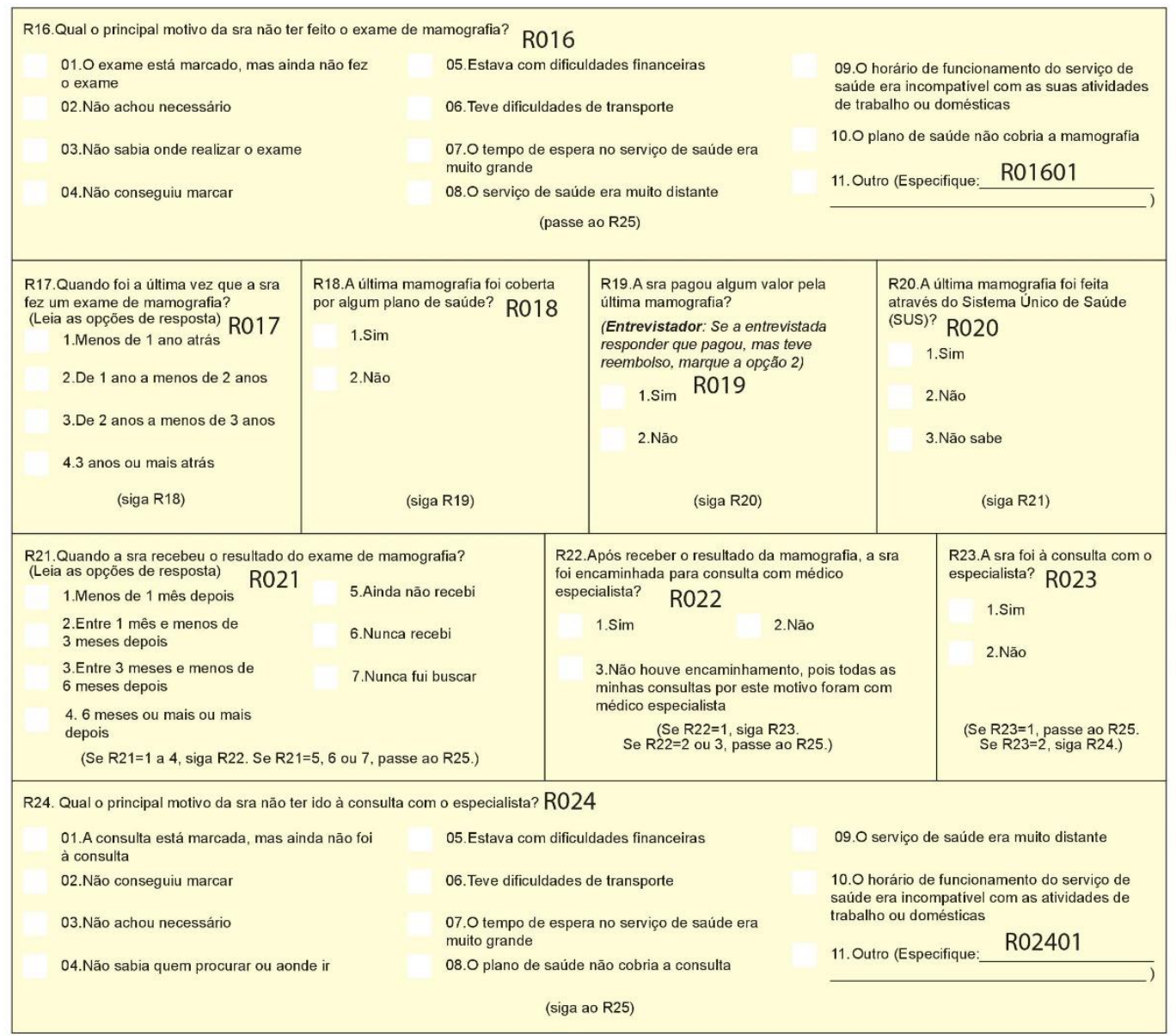

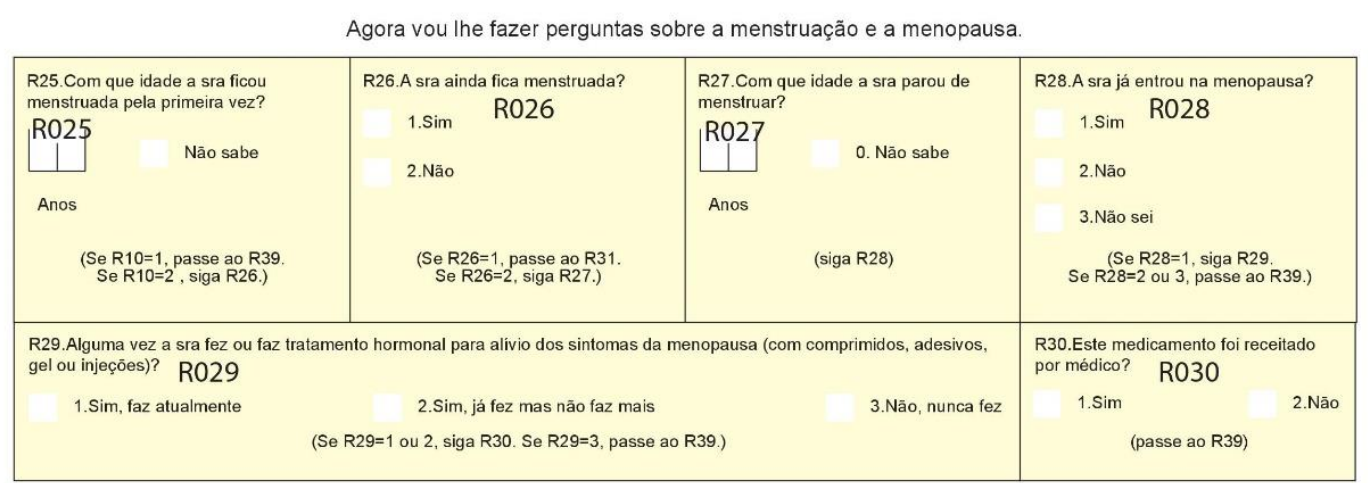

Agora vou the fazer perguntas sobre planejamento familiar e contracepção.

\begin{tabular}{|c|c|c|c|c|}
\hline $\begin{array}{l}\text { R31. Nos últimos } 12 \text { meses, a sra teve } \\
\text { relaçōes sexuais? R031 }\end{array}$ & $\begin{array}{l}\text { R32. Nos últimos } 12 \text { meses, a sra } \\
\text { participou de grupo de planejamento }\end{array}$ & $\begin{array}{l}\text { R33.E o seu parceiro pa } \\
\text { grupo de planejamento } f\end{array}$ & & $\begin{array}{l}\text { R34.A sra usa algum método para } \\
\text { evitar a gravidez atualmente? }\end{array}$ \\
\hline 2.Năo & $\begin{array}{l}\text { 1.Sim } \\
\text { 1.Sim? }\end{array}$ & 1. Sim R033 & 2. Não & 1.Sim R034 \\
\hline $\begin{array}{c}\text { (Se R31=1, siga } R 32 . \\
\text { Se R31=2, passe ao R39.) }\end{array}$ & $\begin{array}{l}\text { (Se R32=1, siga R33. } \\
\text { Se R32=2, passe ao R34.) }\end{array}$ & (siga R34 & & $\begin{array}{c}\text { (Se R34=2, siga R35. } \\
\text { Se R34=1, passe ao R36.) }\end{array}$ \\
\hline
\end{tabular}




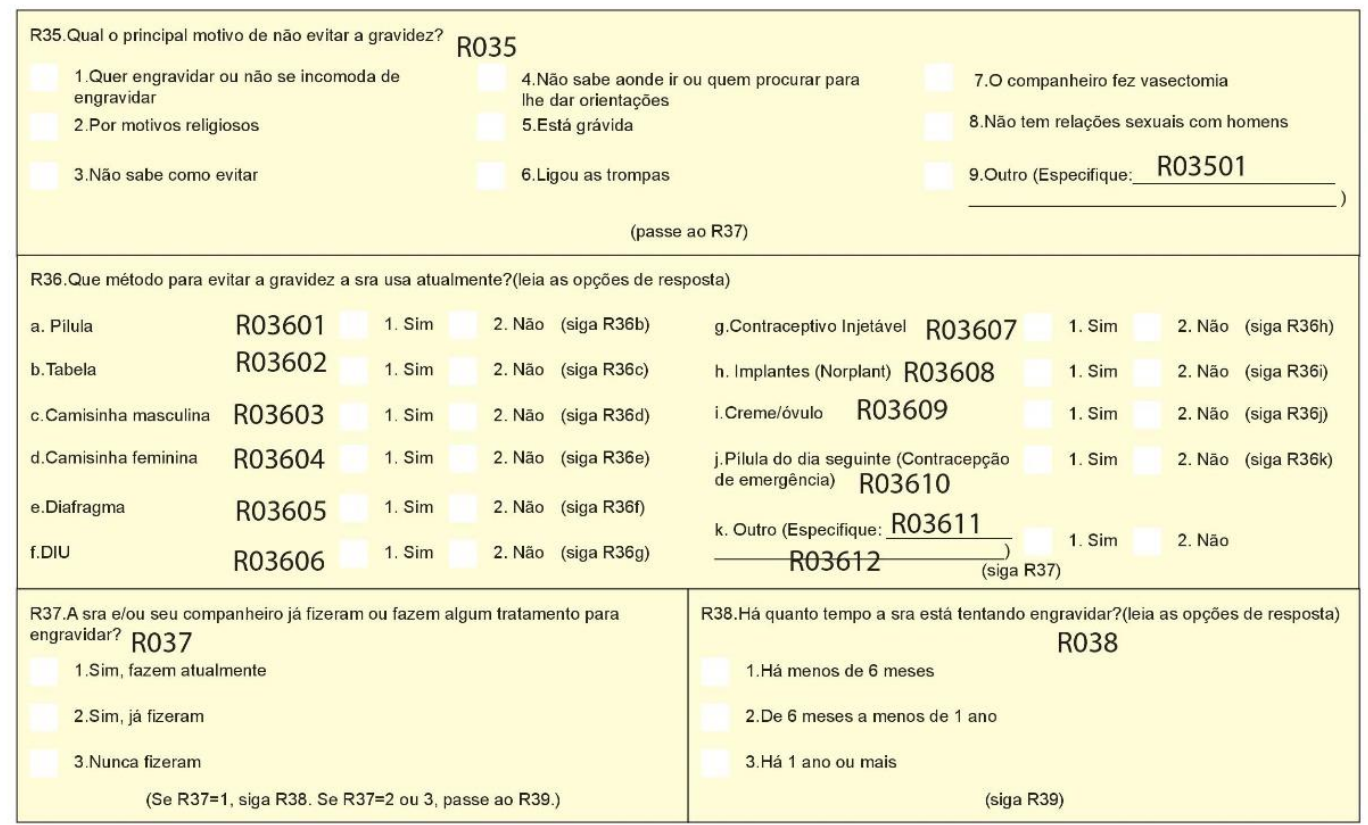

Agora vou the fazer perguntas sobre história reprodutiva

(Se mulher e $\mathrm{C} 8 \geq 50$ ou mais $\rightarrow$ passe ao Módulo $U$. Se mulher e $\mathrm{C} 8<50$, siga R39).

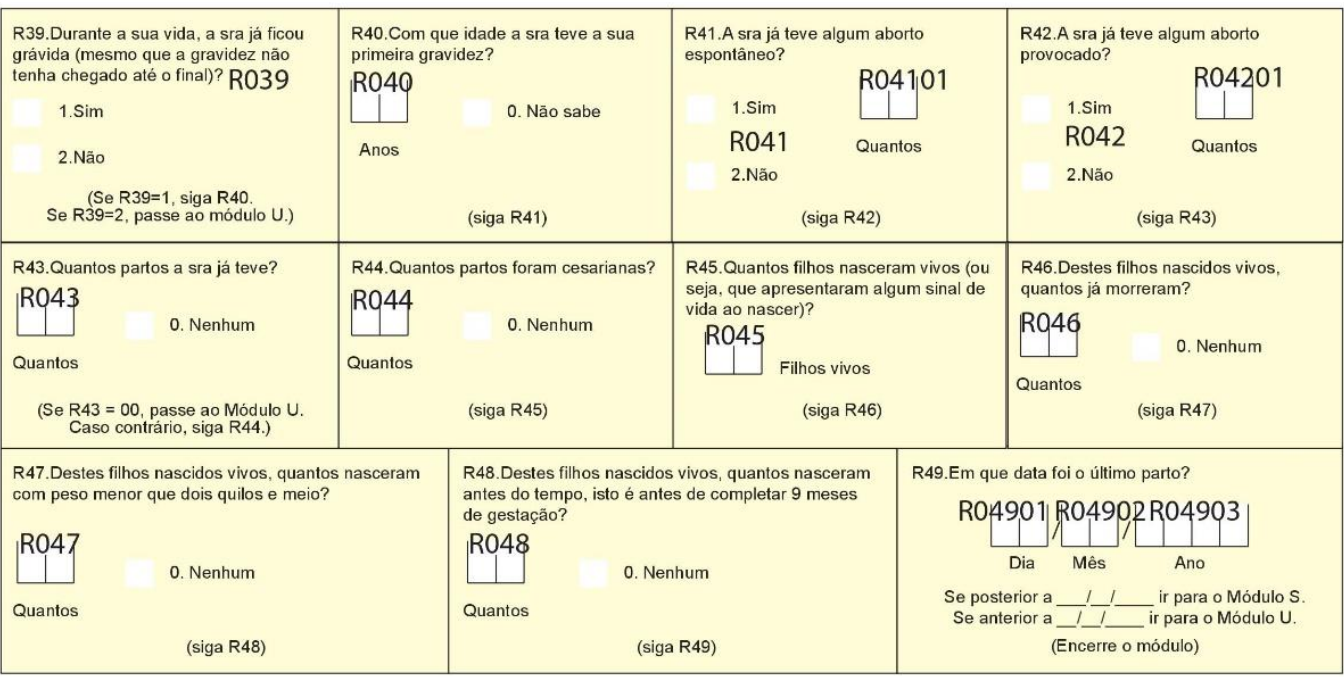

Módulo S. Atendimento Pré-natal

Agora vou Ihe fazer perguntas sobre o atendimento pré-natal

Entrevistador: As questões deste módulo são dirigidas às mulheres que tiveram algum parto no periodo de 28/07/2011 a 27/07/2013. Considerar o último parto.

\begin{tabular}{|c|c|c|c|}
\hline $\begin{array}{l}\text { S1. Na última vez que a sra esteve } \\
\text { grávida, a sra fez pré-natal? S001 } \\
\text { 1. Sim }\end{array}$ & $\begin{array}{l}\text { S2.Na última vez que a sra esteve } \\
\text { grávida a sra recebeu o cartāo de } \\
\text { pré-natal? S002 } \\
\text { 1.Sim }\end{array}$ & $\begin{array}{l}\text { S3.Com quantas semanas de gravidez } \\
\text { a sra iniciou o pré-natal? } \\
\begin{array}{lll}S 003 & \text { 88. Năo sabe }\end{array}\end{array}$ & $\begin{array}{l}\text { S4. Quantas consultas de pré-natal a } \\
\text { sra teve? } \\
\text { SO04 }\end{array}$ \\
\hline 2.Não & 2.Não & Semanas & Consultas \\
\hline ( $\mathrm{Se} S 1=2$, passe ao $\mathrm{S} 44$.) & (siga S3) & (siga S4) & (siga S5) \\
\hline
\end{tabular}




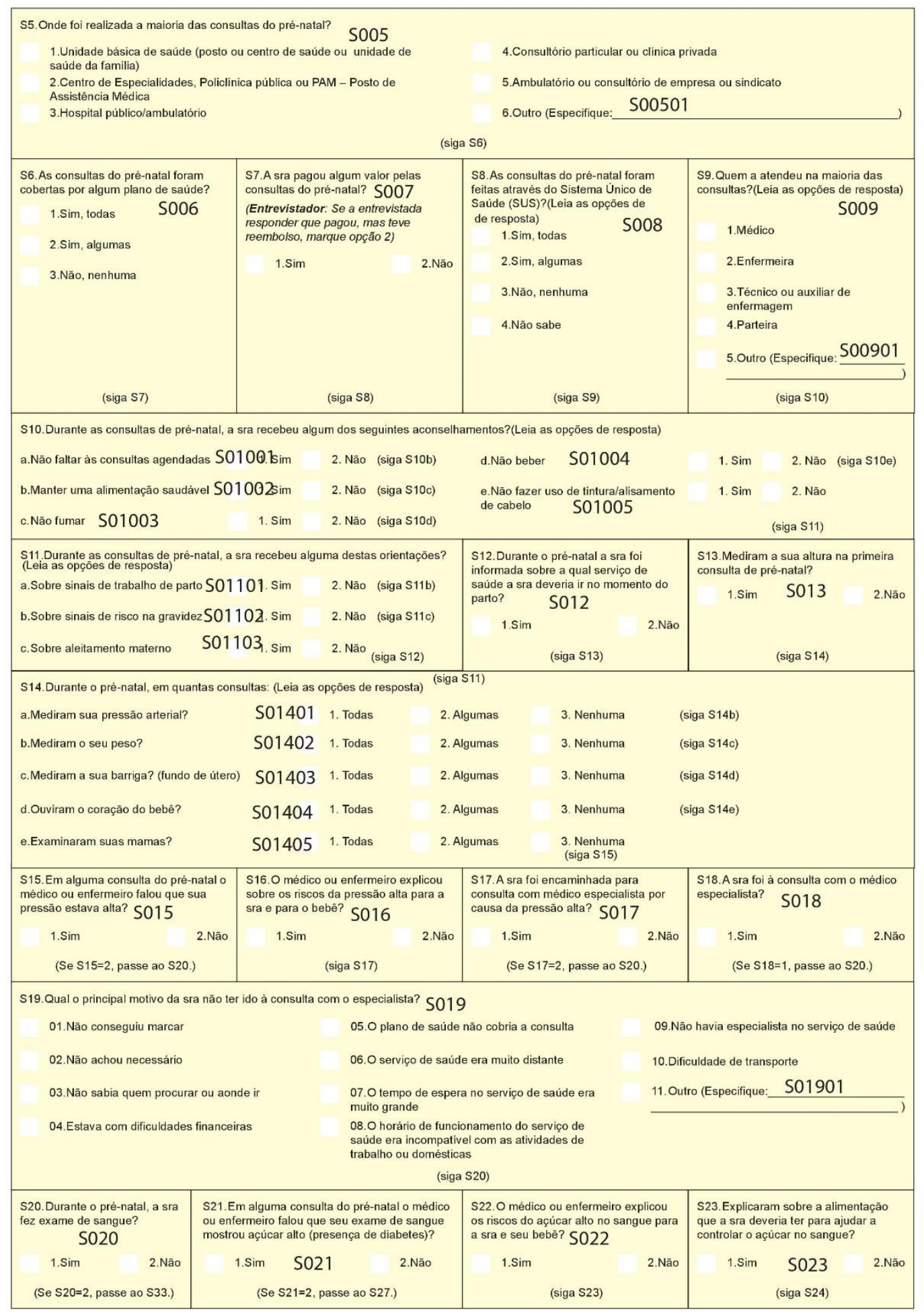




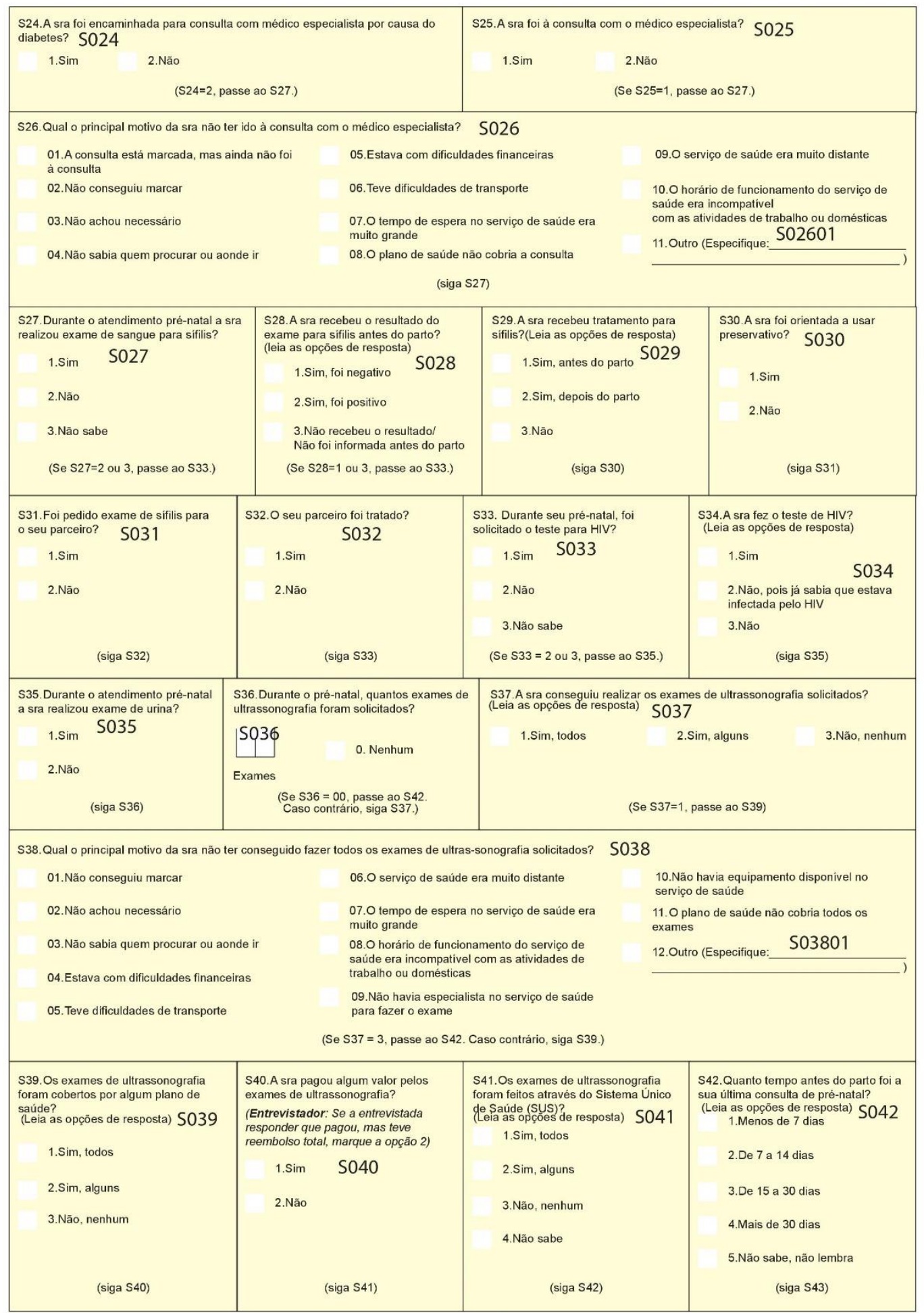

47 


\begin{tabular}{|c|c|c|c|}
\hline S43. Com quantas semanas de gravidez a sra estava & S44. Qual o seu peso antes de engravidar? & \multicolumn{2}{|c|}{ S45. Quantos quilos a sra engordou na gestaçāo? ) } \\
\hline S043 & S044 & S045 & 0. Não sabe \\
\hline 88. Năo sabe & 0. Não sabe & & 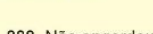 \\
\hline Semanas & Quilograma & Quilograma & \\
\hline (siga S44) & (siga S45) & & \\
\hline
\end{tabular}

Agora, vamos the fazer perguntas sobre a assistência ao último parto.

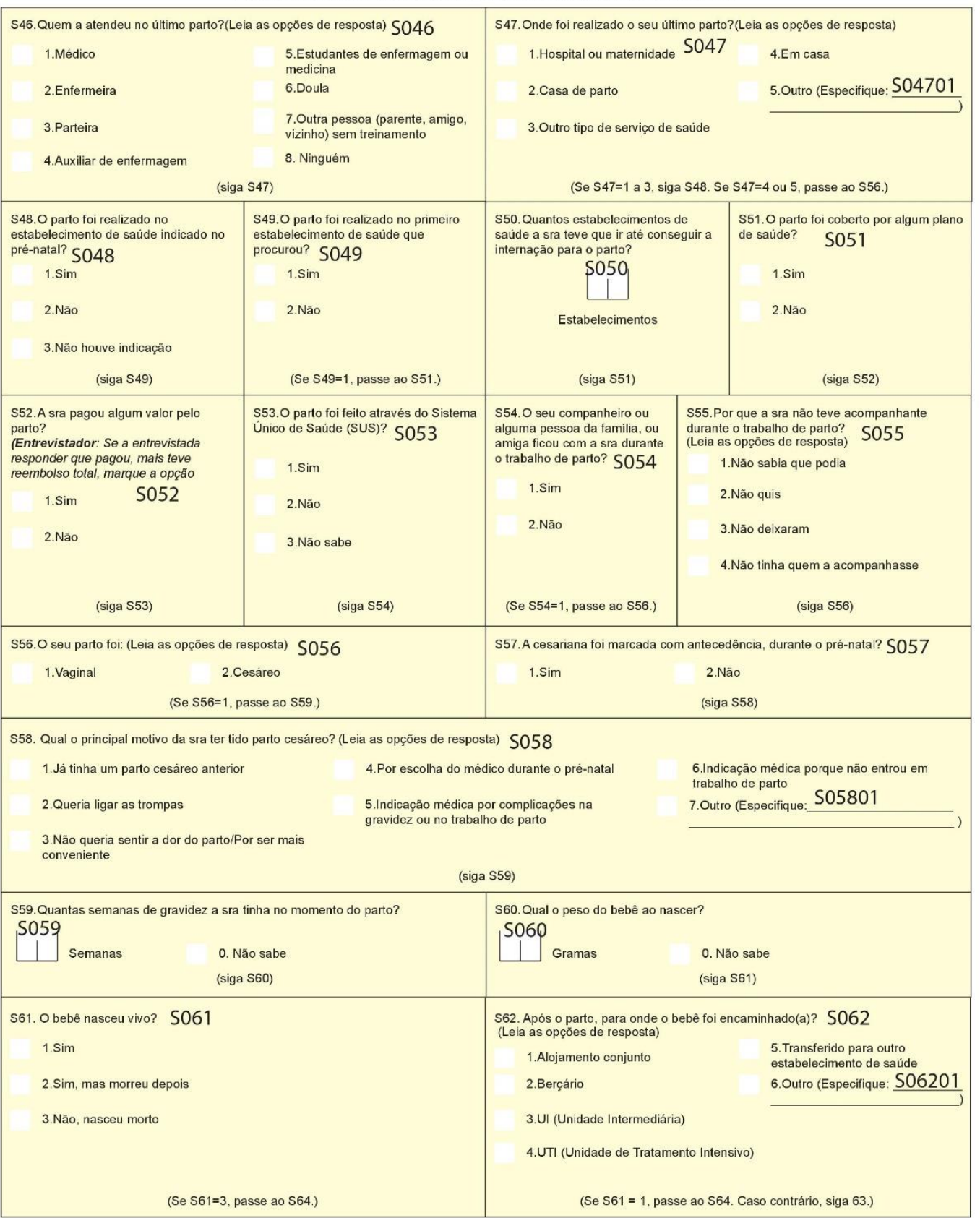

48 